Florida International University

FIU Digital Commons

FIU Electronic Theses and Dissertations

University Graduate School

3-19-2020

\title{
Understanding L2 Learners' Writing Needs and Attitudes in EAP Writing Contexts
}

Renata Pavanelli Pereira

Florida International University, rpava001@fiu.edu

Follow this and additional works at: https://digitalcommons.fiu.edu/etd

Part of the Curriculum and Instruction Commons

\section{Recommended Citation}

Pavanelli Pereira, Renata, "Understanding L2 Learners' Writing Needs and Attitudes in EAP Writing Contexts" (2020). FIU Electronic Theses and Dissertations. 4381.

https://digitalcommons.fiu.edu/etd/4381

This work is brought to you for free and open access by the University Graduate School at FIU Digital Commons. It has been accepted for inclusion in FIU Electronic Theses and Dissertations by an authorized administrator of FIU Digital Commons. For more information, please contact dcc@fiu.edu. 


\title{
FLORIDA INTERNATIONAL UNIVERSITY
}

Miami, Florida

\section{UNDERSTANDING L2 LEARNERS' WRITING NEEDS AND ATTITUDES IN EAP WRITING CONTEXTS}

\author{
A dissertation submitted in partial fulfillment of the \\ requirements for the degree of \\ DOCTOR OF PHILOSOPHY \\ in \\ CURRICULUM AND INSTRUCTION
}

by

Renata Pavanelli Pereira

2020 
To: Dean Michael R. Heithaus

College of Arts, Sciences and Education

This dissertation, written by Renata Pavanelli Pereira, and entitled Understanding L2 Learners' Writing Needs and Attitudes in EAP Writing Contexts, having been approved in respect to style and intellectual content, is referred to you for judgment.

We have read this dissertation and recommend that it be approved.

Melissa Baralt

Mido Chang

Thomas Reio

Eric Dwyer, Major Professor

Date of Defense: March 19, 2020

The dissertation of Renata Pavanelli Pereira is approved.

Dean Michael R. Heithaus

College of Arts, Sciences and Education

Andrés G. Gil

Vice President for Research and Economic Development and Dean of the University Graduate School

Florida International University, 2020 
(C) Copyright 2020 by Renata Pavanelli Pereira

All rights reserved. 


\section{DEDICATION}

To my husband, Adam, whose patience, encouragement, and support throughout the process kept me moving forward in my doctoral study. Words cannot express how grateful I am that you were with me on this journey. 


\section{ACKNOWLEDGMENTS}

This dissertation would not have been possible without the guidance and support of my committee members. First, I would like to express my gratitude to my major professor, Dr. Eric Dwyer. His patience and willingness to provide me with guidance and detailed feedback helped me develop, conduct, and finally write this research study. He continuously challenged me to perform at my best and tirelessly acted as my advocate.

I am deeply grateful to Dr. Mido Chang, who has been with me from my first days at FIU. She has always supported me and given me the freedom to call upon her advice and expertise. Her kindness and positivity have helped me find my joy in quantitative research. I am thankful for the guidance and support of Dr. Melissa Baralt, who enlightened me to begin a study in needs analysis. She has been of great help in developing the research instruments of this study by offering prompt feedback and very useful suggestions.

I would also like to acknowledge the assistance of Dr. Thomas Reio. He inspired me to recognize the importance of including a conceptual framework in my research study. Finally, I would like to thank Dr. Kyle Perkins who guided me during my first year in the doctoral program. His kindness and compassion inspired me to continue my studies. To conclude, I cannot forget to thank my family and friends for their unconditional support in these very intense academic years. This dissertation would not have been possible without their assistance and support. 


\title{
ABSTRACT OF THE DISSERTATION \\ UNDERSTANDING L2 LEARNERS' WRITING NEEDS AND ATTITUDES IN EAP WRITING CONTEXTS
}

\author{
by \\ Renata Pavanelli Pereira \\ Florida International University, 2020 \\ Miami, Florida \\ Professor Eric Dwyer, Major Professor
}

The purpose of this study was to conduct a needs analysis in order to identify the real-world writing tasks that diverse English for Academic Purposes (EAP) learners are required to perform in academic contexts. The study initially uncovered the culturally and linguistically diverse backgrounds of EAP learners across three Southeastern state colleges. The study then identified the writing tasks that were being completed in an advanced EAP composition course. Furthermore, the study explored the writing needs of EAP learners with a focus on the participants' experiences and attitudes about the writing tasks they performed in the composition course. Finally, an analysis was conducted of the real content-level writing tasks that are required of EAP learners across different majors, so a comparison of these tasks could reveal whether the writing tasks completed in the advanced EAP composition course were aligned with those completed across disciplines. Via diverse sources and methods, this study employed semi-structured interviews, short online learner surveys, and written documents. A sample of seven EAP faculty members, three current EAP learners, and three former EAP learners were selected to be part of the semi-structured interview process. The short online learner surveys were distributed to 
169 EAP learners who were currently enrolled in the advanced EAP composition course. Regarding the document analysis, 18 faculty members from the EAP programs and 203 from different disciplines shared their course materials for analysis. Results indicated that EAP learners came from culturally and linguistically diverse backgrounds. Furthermore, findings revealed that EAP learners shared positive attitudes about the writing tasks they completed in their advanced EAP composition courses. Finally, findings showed that the writing tasks most often expected of EAP learners in the advanced EAP composition course were personal essays with basic elements of writing. However, very few course documents across disciplines showed that students were assigned essay writings; they were instead assigned complex assignment tasks that included critical-thinking and problem-solving skills. Therefore, the findings of this study ultimately indicated that the writing tasks required of EAP learners in the advanced EAP composition course differed from those they were expected to complete across disciplines. 


\section{TABLE OF CONTENTS}

CHAPTER

PAGE

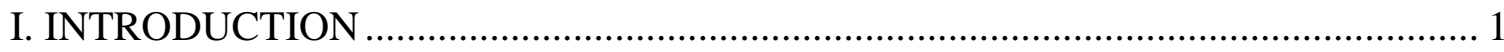

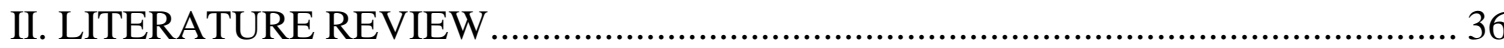

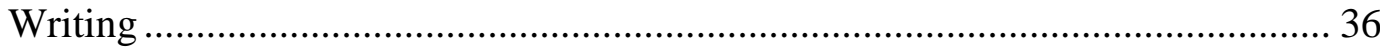

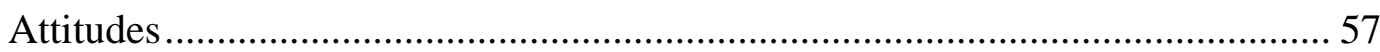

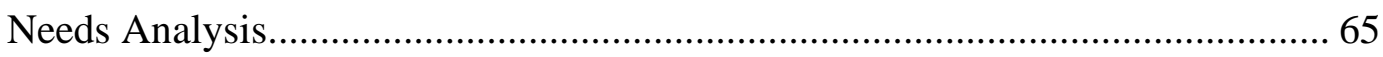

Attitudes and Writing Needs in L2 Context .................................................... 79

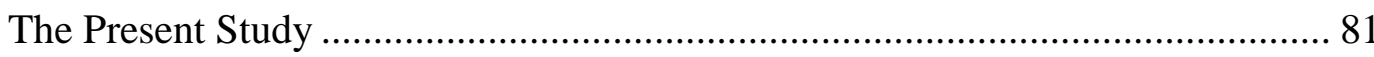

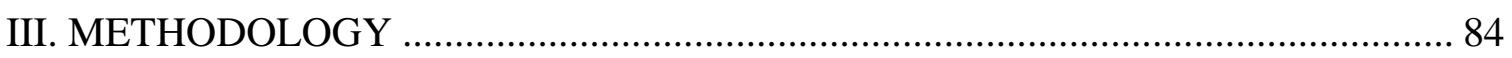

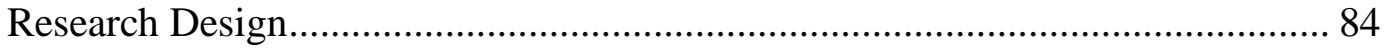

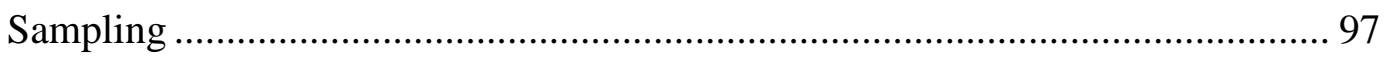

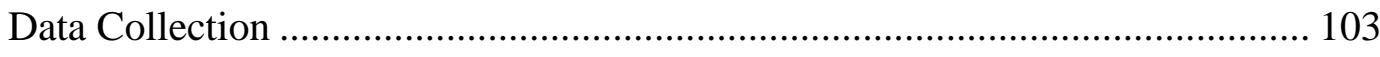

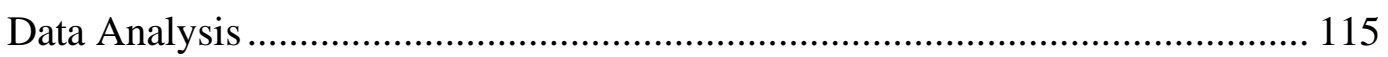

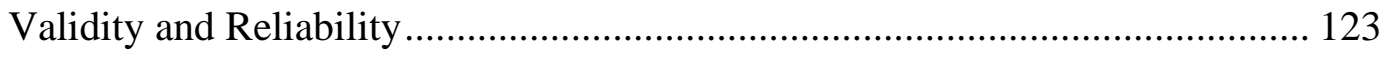

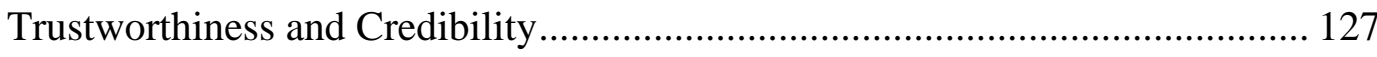

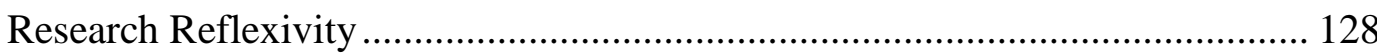

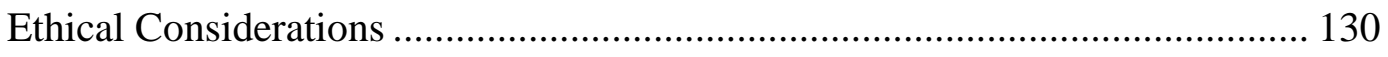

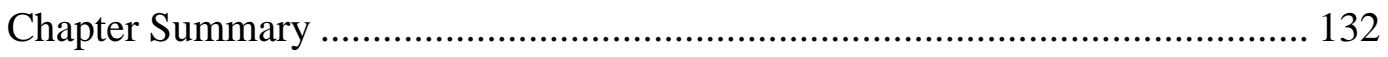

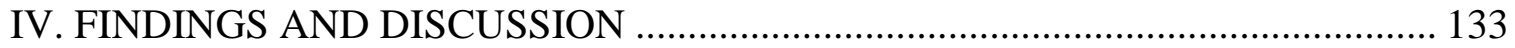

Findings of the Interview Responses .......................................................... 134

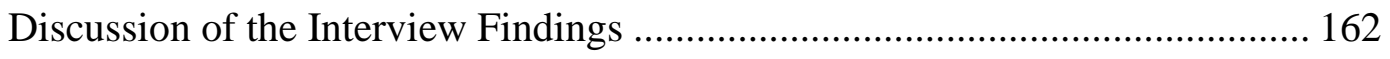

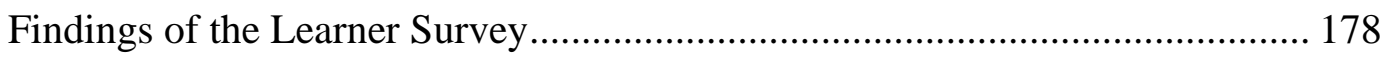

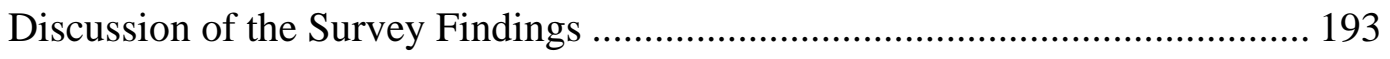

Findings and Discussion of the Written Documents............................................ 197 
V. CONCLUSIONS, IMPLICATIONS, LIMITATIONS, AND FURTHER

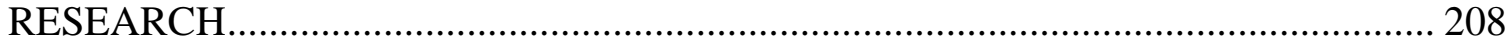

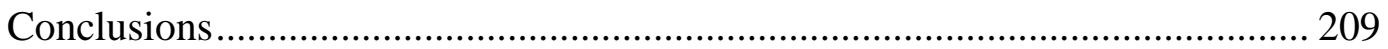

Implications of the Study ............................................................................ 218

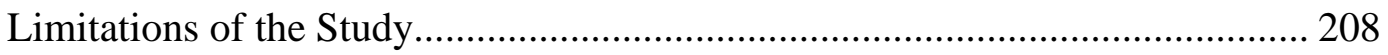

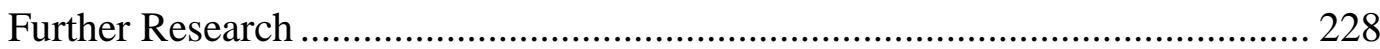

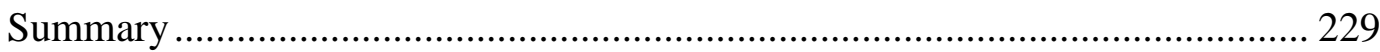

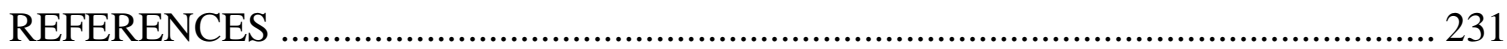

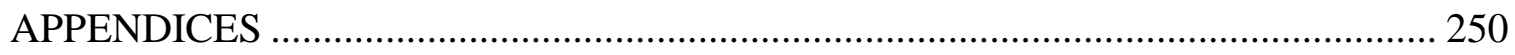

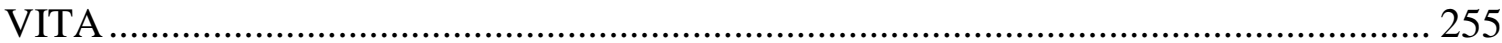




\section{LIST OF TABLES}

TABLE

PAGE

1. Summary of the Definition of Needs Analysis ...................................................... 71

2. Overview of the EAP Writing Competencies ................................................... 90

3. Description of EAP Faculty Members ….......................................................... 100

4. Description of Current EAP Learners ................................................................. 101

5. Description of Former EAP Learners ............................................................... 101

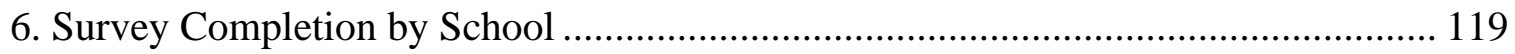

7. Code book for Content Analysis ..................................................................... 120

8. Revised Code Book for Content Analysis ....................................................... 121

9. Colored Schema for Each Participant .............................................................. 136

10. Analysis of Basic Composition - Understanding the Essay .................................. 164

11. Analysis of Basic Composition - Developing the Essay ...................................... 166

12. Strategy for Performance Improvement........................................................ 167

13. Peer Strategy for Performance Improvement .................................................. 169

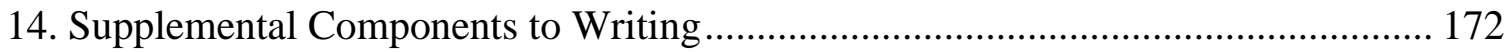

15. Introduction to Advanced Writing ............................................................... 174

16. Descriptive Statistics for Demographic Factors by School ................................. 181

17. Descriptive Statistics for Demographic Factors by School ................................. 183

18. Frequencies for Basic Composition by Schools ............................................. 186

19. Frequencies for Writing Process by Schools ................................................ 186

20. Frequencies for Rhetorical Modes and Supplemental Components by Schools ...... 187

21. Frequencies for Research Paper and Others by Schools.................................... 188 
22. Units of Analysis by Quality for Attitudes about the Composition Course

23. Attitudes about the Composition Course

24. Units of Analysis by Relevence for Attitudes about Learning Writing....

25. Attitudes about Learning Writing

26. Writing Tasks Aligned with Course Objectives

27. Writing Tasks Completed across Disciplines by Academic Areas of Study

204 


\section{LIST OF FIGURES}

FIGURE

PAGE

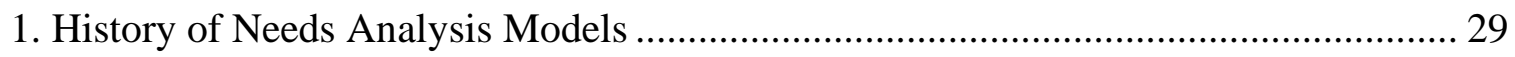

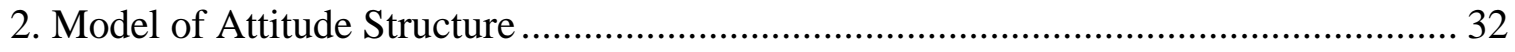

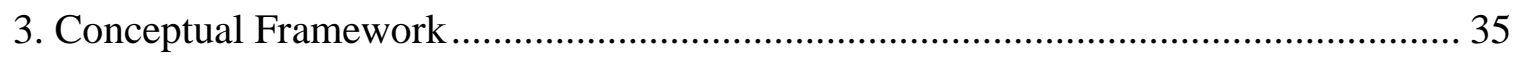

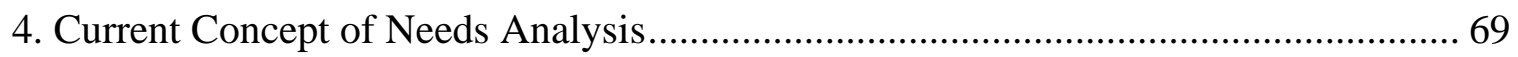

5. Research Questions Aligned with the Conceptual Framework ................................ 83

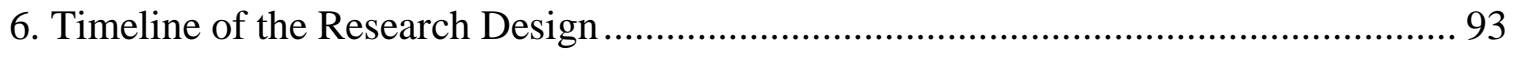

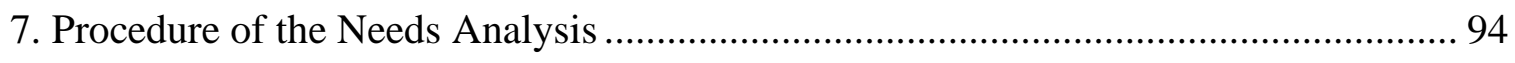

8. Relative Structure of Interview Questions ....................................................... 105

9. Applied Methods Aligned with the Research Questions ....................................... 134

10. Organizational Schema of the Interview Findings........................................... 137

11. Concurrences and Discrepancies of the Writing Tasks ..................................... 177

12. Organizational Schema of the Survey Results .............................................. 184

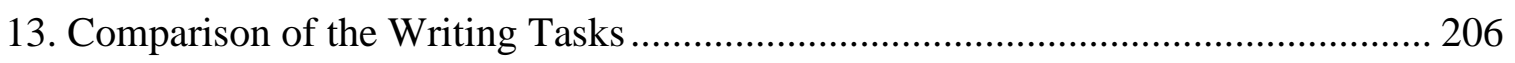

14. The Conceptual Framework Along with the Concept of Needs Analysis ............... 218 


\section{ABBREVIATIONS AND ACRONYMS}

\begin{tabular}{|c|c|}
\hline AHCD & Arts, Humanities, Communication, and Design \\
\hline EAP & English for Academic Purposes \\
\hline ESL & English as a Second Language \\
\hline EOP & English for Occupational Purposes \\
\hline L1 & Frist Language \\
\hline L2 & Second Language \\
\hline LSA & Learning Situation Analysis \\
\hline MA & Means Analysis \\
\hline NA & Needs Analysis \\
\hline PSA & Present Situation Analysis \\
\hline SBSHS & Social, Behavioral Sciences, and Human Services \\
\hline SCT & Sociocultural Theory \\
\hline STEM & Science, Technology, Engineering, and Mathematics \\
\hline TBLT & Task-based Language Teaching \\
\hline TESL & Teaching English as a Second Language \\
\hline TSA & Target Situation Analysis \\
\hline ZPD & Zone of Proximal Development \\
\hline
\end{tabular}




\section{CHAPTER I}

\section{INTRODUCTION}

English Language Teaching (ELT) consists of general and specific English language teaching. General English refers to teaching second language (L2) learners to survive in their community on a daily basis (Dudley-Evans \& St. John, 1998). The focus of general English is the development of speaking, listening, reading, and writing skills in the areas of grammar and vocabulary as well as understanding the culture of Englishspeaking countries. In contrast, English for Specific Purposes (ESP) is defined as determining the specific needs of a group of L2 learners, with the primary focus on the training of appropriate language in terms of grammar, vocabulary, register, and genre (Dudley-Evans \& St. John, 1998). ESP is further divided into two groups: English for Occupational Purposes (EOP) and English for Academic Purposes (EAP). The term EOP refers to training individuals to perform in specific professional situations. The subfields of EOP are professional English, business English, and vocational English. On the other hand, EAP prepares L2 learners to use appropriate language in specific academic contexts so they can succeed in a chosen post-secondary degree program.

EAP courses are recognized as an important component of success in the Englishspeaking academic context because they help L2 learners raise their level of general English, improve their academic language skills, and develop the academic-level proficiency that will prepare them to succeed in their academic coursework in postsecondary academic programs in the United States. Jordan (1997) stated that the purpose of EAP courses is for $\mathrm{L} 2$ learners to complete tasks in a formal and academic setting while focusing on proficiency in language use, such as effective listening comprehension 
and note-taking, writing in the appropriate academic register, reading effectively, and conducting library research.

Prior to registering for college-level content courses, the State Board of Education (SBOE) requires that students with limited English proficiency take a placement test and be placed in designated EAP courses. EAP programs in Florida state colleges consist of six levels of instruction in four skill areas, such as grammar, listening/speaking, reading, and writing (The Florida College System, 2018). The course series provides institutional credits for levels 1-4 and college credits for levels 5 and 6 (The Florida College System, 2018). L2 learners placed into institutional credit EAP courses are then required to continue to college-level EAP courses, including the advanced EAP composition course (Level 6). L2 learners enrolled in the advanced EAP composition course learn and develop necessary academic reading, writing and research skills to succeed in academic coursework and workplace (The Florida College System, 2018). The successful completion of the advanced EAP composition course can prepare L2 learners for collegelevel writing assignments not only in the advanced EAP composition course, but also in post-secondary academic programs.

\section{Diverse L2 learners in EAP Writing Contexts}

To achieve academic success and compete in the marketplace, learners need to possess skills to think critically and creatively, solve problems, collaborate, and communicate. Skills in composing and expressing ideas well in writing can contribute to success in all academic tasks. However, writing remains challenging for some learners. Data from Partnership for $21^{\text {st }}$ Century Learning (P21) reported that only $27 \%$ of learners in college-level content courses performed well in writing (2018). Wu and Rubin (2000) 
reported that learners had inadequate literacy skills, had poor knowledge of grammar rules, and lacked a substantive concept of critical thinking and problem solving. In fact, the writing proficiency of L2 learners from diverse backgrounds may even be more affected. U.S. classrooms have experienced a large trend of L2 learners with culturally and linguistically diverse backgrounds, and many may not be benefitting from the opportunity for an outstanding writing instruction. Data from the Institute of International Education (IIE) indicated that 5\% of the undergraduate population were L2 learners from 60 different countries (2017). Therefore, it is important to understand that diversity occurs among L2 learners in terms of language, age, gender, social class, cultural background, prior education, and learning styles, which can influence language acquisition and language conventions (Ball, 2006; Clark, 2012; Leki \& Carson, 1997; Matsuda, 1997; Raimes, 1998). L2 learners from diverse backgrounds can differ in their approaches to learning and their levels of proficiency, so they should be perceived as individual learners with specific language needs.

In addition, writing is a challenging mental process for $\mathrm{L} 2$ learners because it involves the knowledge of composing sentences, the process of generating ideas, drafting and revising, and the attention in acquiring academic language skills, such as grammar (Matsuda, 2003a) and vocabulary (Kim, 2012). Gass and Selinker (2009) stated that little knowledge of the second language and limited vocabulary affect language performance, indicating that "The lexicon may be the most important language component for learners" (Gass \& Selinker, 2009, p. 449). The act of composing in academic contexts can also create problems for L2 learners. Formulating, developing, and analyzing new ideas as well as acquiring language proficiency can be difficult for $\mathrm{L} 2$ learners because of their 
various cultural, social and educational backgrounds (Raimes, 1991), and the influence of rhetorical preferences in organizing information (Cai, 1999; Connor, 1996; Leki, 1992).

The lack of ability in grammatical and vocabulary competence in L2 learners, as well as lack of ability in composing an academic writing, can pose a unique set of challenges to writing teachers as they try to address the needs of L2 learners with diverse backgrounds (Miller-Cochran, 2012). For this reason, writing teachers may misinterpret their L2 learners and be unaware of the differences between linguistic difficulties and composing difficulties, consequently encouraging them to judge content and language more critically (Grabe \& Kaplan, 1996). However, teaching L2 learners involves perceiving their individual characteristics and differences, as well as addressing their unique needs and carefully planning pedagogical solutions determined by their educational, cultural, and socioeconomic differences (Matsuda, 1997, 2003a). Belcher and Connor (2001) pointed out that L2 learners should "be seen not as belonging to separate, identifiable cultural groups but as individuals in groups that are undergoing continuous change" (p. 76). Furthermore, it is important for L2 educators to refer to theoretical frameworks and writing pedagogies of L2 writing so they design and implement appropriate tools for effective instruction, make instructional decisions to best serve their L2 learners in their educational contexts (Atkinson, 2010; Matsuda, 2003a), and understand that the writing discourse strategies among L2 learners differ across cultural, linguistic, and educational contexts (Ball, 2006).

Leki (1992) stated that "Hidden behind the texts that ESL students produce is once again the great diversity of the ESL student population" (p. 86). However, challenges that L2 learners with diverse backgrounds face in L2 composition courses, and 
how to help them improve their writing skills, have been ignored in disciplinary practices (Matsuda, 2003a). Therefore, understanding the language learning of L2 learners with culturally and linguistically diverse backgrounds should be acknowledged.

\section{Differences in L1 and L2 writing}

Conventions and practices of writing vary in L1 and L2. There is evidence to suggest that both "L1 and L2 writers employ recursive composing process, involving planning, writing, and revising, to develop their ideas and find the appropriate rhetorical and linguistic means to express them" (Silva, 1993, p. 657). However, the teaching of L2 differs from L1 because of L2 learners' cultural differences in rhetoric, approach to learning, and levels of proficiency.

Silva (1993) conducted a meta-analysis of 72 empirical studies to explore the fundamental differences between L1 and L2 writing. He found that although the composing process was somehow similar in L1 and L2 writing, the L2 composing process was more problematic and less effective, which differed mainly in the subprocess of planning, writing, and revising. Results indicated that L2 learners' planning strategies were less effective as a result of the amount of time they spent figuring out the topic, generating and organizing ideas, and transferring these ideas into written text. In addition, the writing process was more laborious and less fluent and effective. L2 learners spent more time referring to the prompt and outline and consulting a dictionary as a consequence of their lack of adequate vocabulary knowledge. Finally, L2 learners employed less revising than L1 learners. They hardly reflected on their written texts and focused substantially on grammar and less on mechanics. 
Silva (1993) also examined the differences of L1 and L2 written texts in terms of fluency, accuracy, and structure. He reported that L2 texts were shorter than L1 texts. Furthermore, L2 learners had more overall errors on morphosyntactic and lexicosemantic features. Regarding morphosyntactic features, L2 learners used more superlatives, coordination, and pronouns, and fewer subordinations and modifiers than L2 learners. With regard to lexicosemantic features, L2 learners used fewer synonyms and collocations and less variety in the use of lexical cohesion. In terms of structure, Silva (1993) showed that L1 learners preferred to use deductive rhetorical patterns while L2 learners tended to use inductive rhetorical patterns. Moreover, L2 learners used less sequential structure (introduction, discussion, and conclusion) and did not fully state and support their position. They also committed more errors in the use of conjunctive elements.

Besides the analysis on composing process and the aspects of written texts, other studies showed that language and culture also influence L1 and L2 writing. Silva, Leki, and Carson (1997) noted that cultural background influences language conventions, as well as rhetorical and organizational patterns. Kaplan (1966) argued that language and culture have unique rhetorical conventions and that rhetorical patterns of writing from L2 learners' primary language interfere with their L2 writing performance. Therefore, L2 learners' primary language and their knowledge of the rhetorical patterns of their native language influence L2 writing pedagogy and their preferences in organizing information and structuring arguments (Leki, 1992; Matsuda, 2003a). Wu and Rubin (2000) discovered that values of individualism (interest of the individual) and collectivism (effects of their actions on others) also reflected on the rhetorical features of 
college students' writing. The authors investigated how culture and language influenced some writing features in individualist and collectivist societies. They found that U.S. students were more direct and provided more personal responses, while Asian students often used more collective responses. Therefore, indirectness was associated with collectivism, whereas personal experiences and directness reflected U.S. values of individualism.

Drawing attention to the cultural distinctions between L1 composition studies and L2 writing instructions, Silva, Leki, and Carson (1997) synthesized a set of differences for L2 learners. The first difference was the epistemological issue. In L2 writing instruction, cultural context and belief systems are significant determinants of a writer's purpose; however, it can be re-casted "as an issue of social context when viewed from the larger cross-cultural perspective" (p. 349). The second issue was the function of writing. Writing moves away from "a conventional focus on the message or text toward an investigation of the writer or encoder, highlighting writer's composing processes" (p. 349), which emphasizes the importance of writing as knowledge storage and mental development. However, this concept of knowledge storage and personal experience creates complexities for many L2 learners in multicultural societies, because writing is considered to be for practical and communicative purposes and not an instrument for life changing experiences as perceived by L1 learners. The final issue was the textual issue, which relates to cross-cultural discourse patterns and contrastive rhetoric. According to Silva, Leki, and Carson (1997), "Rhetorical form is a product of a culture's world view and social conventions, and that the degree to which texts are logical, well-formed, and successful depends on their sociocultural context" (p. 357). Thus, "text cannot be defined 
from a monocultural perspective and the influence of culturally-preferred text structures must be considered as one of the factors that affect writers' composing processes" (p. 352).

Aligned to the studies on cultural and linguistic differences, L2 learners also face challenges in practices and literacy acquisition (McCarthey \& Garcia, 2005) caused by writing styles from different cultural beliefs and language conventions. These differences in cultural norms and rhetorical styles may contribute to learners' low performance and resistance in completing writing tasks (McCarthey \& Garcia, 2005). Therefore, writing needs of L2 learners and their perceptions about writing may play an essential role in their development as a writer. Since "L2 writers are sufficiently different in nature, teachers need to be appropriately prepared to teach them effectively and fairly" (Matsuda \& Silva, 2001, p. 46), considering writing as culturally transmitted and not naturally acquired.

\section{Challenges in EAP Writing Courses}

\section{Challenges of $\mathrm{L} 2$ learners}

One of the principles of academic writing is the ability of learners to gather different ideas and opinions so they can develop their own voice. Fundamental academic writing elements include forming, developing, and organizing ideas, as well as composing a thesis statement, writing convincing supporting sentences, and editing written text. Other academic writing conventions include outlining, summarizing, and paraphrasing. Regarding the logical sequence of a written text, learners also need to be aware of grammatical concepts and mechanics for convention, clarity, and unity. Therefore, the importance of academic writing is not only to master the English language 
but also to be successful in other disciplinary courses in which English is the medium of instruction (Chou, 2011).

However, academic writing remains a prominent concern because of the large and diverse student population who have English as a second language and who are studying in U.S. colleges. L2 learners face writing challenges because their academic needs vary according to their linguistic, educational, cultural, and socioeconomic backgrounds (Giridharan, 2012; Kim, 2012). Therefore, teaching L2 learners with non-Englishspeaking backgrounds involves perceiving their individual characteristics and differences, as well as carefully addressing their needs in terms of their ethnicities, demographics, and socioeconomic status.

Coming from diverse backgrounds, L2 learners use non-English-like patterns that may not be appropriate and natural to a native English-speaking audience. They demonstrate an inability to compose written text because they employ rhetoric and a sequence of thoughts that violate standard English conventions. As an integral part of any formal communication, English writers use a linear sequence that begins with the thesis statement and then a series of supporting sentences, reinforced with facts and examples so they can develop a central idea (McCarthey \& Garcia, 2005). In contrast, L2 learners write in a non-linear sequence which can cause them to have difficulties writing in a second language, thus affecting their overall academic performance (Chou, 2011).

L2 learners also lack comprehension strategies when directly or implicitly interacting with the text, and their writings reflect their personal experiences or general knowledge. They struggle to generate, organize, and communicate ideas, or think in a creative manner. They also struggle to identify main ideas and key points of a text, as 
well as locating pertinent information and rephrasing it in their own words. Shafie, Maesin, Osman, Nayan, and Mansor (2010) concluded that L2 learners in EAP writing courses could not express concepts and ideas nor produce effective writing assignments in the target language because of the lack of language proficiency. In a study conducted by Carroll and Dunkelblau (2011), L2 learners in EAP writing courses revealed that they had difficulty outlining, paraphrasing, and summarizing authors' ideas and the key points of a text. Finally, L2 learners had difficulty perceiving their own errors. After receiving feedback on their writing, they struggled to revise and edit it (Leki \& Carson, 1994). In a study of how L2 learners revised their work, Silva (1993) observed that L2 learners revised at a superficial level, focusing primarily on grammatical correction and transferring their L1 writing ability to L2. Giridharan (2012) also reported that revision was a challenge for L2 learners. On the basis of L2 learners' essay drafts and reflections recorded in their diaries, she stated that learners could draft essays and brainstorm ideas with their peers, but she indicated that most respondents were unable to self-edit their own work and agreed that their self-evaluation did not match the evaluation by their instructor.

From a study on how former L2 learners in EAP contexts perceived their writing instructions and how these instructions assisted in their disciplinary courses, Leki and Carson (1994) reported that EAP instruction did not assist L2 learners in their disciplinary courses because they were not exposed to different types of academic discourse. Thus, the authors argued that EAP learners needed to incorporate more task management strategies, such as managing text (brainstorming, planning, outlining, drafting, revising, proof-reading), managing sources (summarizing, synthesizing, using 
quotes), and managing research (library skills, research skills) that could prepare them for the types of writing they could encounter once they entered a full academic program. Similarly, Leki and Carson (1997) conducted another comprehensive study comparing the types of assignments former L2 learners in EAP contexts received in their disciplinary courses. Results indicated the writing tasks required in academic collegelevel content courses did not correspond to the types of assignments required in EAP writing courses. Therefore, EAP writing teachers needed to provide more content-based assignments, such as summary, annotated bibliography, report, and research projects rather than drafts and personal essays.

Carroll and Dunkelblau (2011) conducted a related study with 23 faculty members teaching introductory English courses, introductory content-based courses, and ESL composition courses. They described the writing tasks that L2 learners encountered in introductory academic courses and determined whether or not the ESL writing curriculum reflected the writing requirements of introductory academic courses. Results indicated that the writing tasks L2 learners received once they entered their full academic programs were essays, summaries, and research papers. However, L2 learners were assigned more essays per semester, rather than summaries and research papers. The authors concluded that there was a difference in the complexity of the assignments given by content-area and ESL teachers. Writing across disciplines required extensive critical thinking skills, such as analysis, synthesis, and evaluation.

For L2 learners, acquiring critical thinking skills must be challenging since they are also in the process of achieving linguistic accuracy and academic vocabulary acquisition. Therefore, EAP writing teachers should introduce challenging assignments 
that require L2 learners to interact with the text and be able to "critically reflect on the ideas within that text" (Carroll \& Dunkelblau, 2011, p. 278). The primary needs of L2 learners do not consist of writing conventions only; they also entail direct practice in language process and discourse development such as audience, rhetorical structure, coherence, cohesion, and clarity. As a consequence of L2 learners' cultural differences in rhetoric and language conventions for L2 learners, they face challenges in their writing courses. Identifying these challenges and understanding the primary needs of L2 learners can help them improve their writing skills and succeed in both EAP writing courses and disciplinary courses.

\section{Challenges of EAP Writing Teachers}

Writing can also be a challenge for many EAP writing teachers, primarily because of the large and diverse student population in the EAP program. As a result of the increased number of diverse learners in the EAP program, the quality of teaching is crucial for L2 learners' education, employment, and general survival needs (Long, 2015). In addition, EAP teachers need to be aware of changes in developing best practices in English language programs, particularly in academic writing. Yet, EAP teachers face challenges in adapting to the increasingly diverse student body, especially in academic writing.

Low language proficiency is a challenging factor that EAP writing teachers encounter among L2 learners. When trying to address the needs of L2 learners, EAP writing teachers face challenges caused by L2 learners' lack of ability in academic writing, their inadequacy of ideas, and their limited vocabulary and knowledge (Gass \& Selinker, 2009; Kim, 2012; Miller-Cochran, 2012). Furthermore, EAP writing teachers 
have difficulties developing comprehensive linguistic, rhetorical, and cultural knowledge as well as metalinguistic abilities in the writing of L2 learners with diverse backgrounds (Kim, 2012). Therefore, EAP writing teachers spend their preparation time developing syllabi with writing assignments that focus on students understanding of the basic elements of writing, such as organization, coherence, and sentence structure, with the aim of preparing L2 learners for the writing assignments that they will be required to complete once in their college-level content courses (Carroll \& Dunkelblau, 2011). However, teachers may provide a rhetorical pattern without knowledge of its usefulness and application in academic disciplines, isolating themselves in the world of their own classroom and department curriculum. Carroll and Dunkelblau (2011) also stated that the writing assignments given in EAP courses do not require students to interact with the text in order to adequately prepare them for the types of writing assignments encountered in disciplinary courses.

Other major problems that EAP writing teachers face when teaching writing are the topics that students should write about, whether personal or academic writing, as well as the teaching method that should be used to deliver the outcome. Raimes (1991) stated that the writer-dominated approach, known as the process approach, does not train students for academic writing, using non-assigned topics based only on their own personal experiences. In addition, the form-dominated approach, called the product approach, is mainly based on assigned topics in which students practice grammatical, syntactic, and rhetorical forms. A balance of both approaches should be implemented to help students improve their language skills for better communicating their ideas through writing (Raimes, 1991). In the teaching of writing structure to L2 learners, EAP writing 
teachers need to be aware of these challenges in order to help L2 learners improve their writing skills and strategies to develop academic writing in the discipline (Raimes, 1991). Additionally, the progress and attainment of writing proficiency in disciplinary courses depend on the mastery of academic writing (Leki \& Carson, 1994). Therefore, the diverse needs of L2 learners should be addressed in academic writing courses.

\section{Needs Analysis in EAP Writing}

The goal of the advanced EAP composition course is to prepare L2 learners to succeed in academic settings, but the challenges they face while enrolled in this course may diminish their ability to improve their academic writing assignments and succeed in college-level content courses. Needs analysis, also called needs assessments, is a flexible approach that can refine this situation since it pays attention to the diversity of L2 learners (Long, 2015). Needs analysis is defined as a systematic collection that involves gathering information for the development of a defensible curriculum so the learning needs of a particular group of students can be met (Brown, 1995, 2009). The main purpose of needs analysis is to identify learners' current and future language needs from multiple perspectives in order to improve and define the curriculum of language programs. The rationale for conducting a needs analysis is to also create effective course design, to hold programs accountable, and to assess its effectiveness in the language teaching field (Long, 2005). In addition, needs analysis is an important initial component that improves teaching materials, enhances learning activities, improves assessment strategies, and develops an appropriate and specialized language curriculum.

Needs analysis is an important procedure to be conducted in EAP contexts

(Hutchinson \& Waters, 1987; Dudley-Evans \& St. John, 1998; Shing \& Sim, 2011). The 
content of an EAP curriculum should rely on the L2 learners' language needs in a particular academic learning context. Needs analysis is also a crucial part of academic writing courses. Designing academic writing courses according to L2 learners' writing needs is an important tool for finding out the writing tasks these learners need to complete, as well as the writing skills and strategies they need in order to perform these specific writing tasks. By understanding L2 learners' writing needs, they gain a better control of their writing and overcome challenges in academic writing in a second language environment.

The writing needs of L2 learners should be addressed to better understand how to help them achieve academic writing success and improve their academic language skills, not only in grammar, vocabulary, and mechanics, but also in other aspects of writing such as styles and genres of academic discourse. In addition, they need to achieve linguistic accuracy and academic vocabulary acquisition while solving problems and developing critical thinking skills.

\section{Attitude in EAP Writing}

L2 learners enrolled in the advanced EAP composition course come from different ethnicities, demographics, and socioeconomic status. Differences in their diverse backgrounds may affect how L2 learners perceive their beliefs about themselves, about their reading and writing skills, and about knowledge itself. Their attitudes toward learning academic writing may also be influenced by their skills, knowledge, and sociocultural context into their academic writing courses.

The three components of the tripartite model proposed by Rosenberg and Hovland (1960) are the focus of this current study: cognition, affect, and behavior. The cognitive 
component impacts how learners perceive their beliefs and knowledge, organize and retain information, and understand the language learning process. It contains four steps: activating prior knowledge, creating new knowledge, examining new knowledge, and applying past knowledge to new situations. The affective component, on the other hand, outlines feelings and emotional responses about an object. The behavioral component deals with how learners behave in different situations.

The cognitive, affective, and behavioral aspects of attitude are important factors that influence not only language learning but also language performance, especially writing performance. Positive attitudes toward learning writing can encourage positive behavior and enthusiasm to develop writing skills, to articulate ideas, to solve problems, to think critically, and to promote the ability to write (Gau, Hermanson, Logar, \& Smerek, 2003). In addition, L2 learners with positive attitudes generate high motivation and perceive value in written communication (Gau et al., 2003).

It is reasonable to speculate that attitudes toward learning writing are related to learners' success. When enrolled in college-level content courses, learners, especially L2 learners, are expected to perform well in a variety of writing tasks and develop new skills and strategies in their disciplinary courses. Although a few studies have revealed that learners with positive attitudes about writing put more effort into their writing tasks, studies on attitudes toward academic writing have received little attention in the literature (Graham, Berninger, \& Fan, 2007). In addition, studies on writing and attitudes with L2 learners in EAP contexts are non-existence. 


\section{Statement of the Problem}

Academic writing is widely recognized as a key skill that influences the ability of L2 learners to succeed in post-secondary education. The ability to write well academically in post-secondary education is, therefore, an expectation of all college students. For many L2 learners, learning to write in academic English is a challenging process. L2 learners need to gain proficiency in grammar, mechanics, and vocabulary in English writing, as well as in rhetorical styles and writing genres. According to Nunan (1999), "it is an enormous challenge to produce a coherent, fluent, extended piece of writing in L2" (p. 217). Furthermore, the ability of L2 learners to successfully complete academic writing tasks and develop academic writing skills and strategies may be influenced by culturally and linguistically diverse factors.

A plethora of studies have addressed a variety of issues related to $\mathrm{L} 2$ learners. Some studies (for example, Carroll \& Dunkelblau, 2011; Grabe, 2001; Leki \& Carson, 1997) have indicated that practices in EAP writing courses do not match the writing demands that L2 learners need to address in disciplinary courses. As stated by Grabe (2001), "L2 writers have less practice in the skills they need, they often are not challenged sufficiently, and they often engage in writing that is not valued in many later courses" (p. 44). L2 learners produce personal essays rather than content-based assignments (Leki \& Carson, 1997) and struggle interacting implicitly with the text (Carroll \& Dunkelblau, 2011). Other studies have examined differences between the composing process of L1 and L2 writing (Silva, 1993), the influence of L2 culture in rhetorical conventions and organizational patterns (Kaplan, 1966; Kim, 2012; Leki, 1992; Silva, Leki, \& Carson, 1997), and the interference of the L2 learners' primary language in 
L2 writing performance (Kaplan, 1966; Leki, 1992). Previous studies have also found that L2 learners encounter difficulties in writing when learning new words (Gass \& Selinker, 2009; Kim, 2012; Miller-Cochran, 2012), expressing concepts or producing effective writing assignments (Shafie et al., 2010), outlining, paraphrasing, and summarizing (Carroll \& Dunkelblau, 2011), perceiving their own errors (Leki \& Carson, 1994), and revising and editing their work (Giridharan, 2012; Leki \& Carson, 1994; Silva, 1993). Although many studies have identified the challenges L2 learners face in writing courses, they have been conducted primarily at four-year institutions, where most of the ESL population consisted of international students. There is little research that has investigated writing issues at two-year institutions, where the population is a heterogenous mix of L2 learners.

Other studies have also discussed the needs of L2 learners. Previous research has found that identifying L2 learners' needs could help researchers and educators develop appropriate teaching materials, learning activities, and language curricula that meet the needs of culturally and linguistically diverse L2 learners. Although the issues of L2 learners' writing needs in EAP contexts have been considered, needs analysis has been the focus of communicative needs rather than writing needs (Brown, 2009; Long, 2015; Nunan, 1999). Therefore, more studies are needed to identify L2 learners' academic writing needs in order to help them develop as writers and succeed in the advanced EAP composition course and college-level content courses. In addition, compared to studies that have been carried out on the writing of learners whose first language was English, relatively few studies have focused on the academic writing needs of L2 learners with diverse ethnicities, demographics, and socioeconomic status. 
Regarding attitude, some studies found that L2 learners' positive attitudes about their writing ability influenced the success of a writing task (Graham et al., 2007) and affected how well they performed (Clark, 2012; Nelson, 2007). Although some studies have examined the relationship between attitude and writing (Graham et al., 2007; Knudson, 1991, 1992, 1993a, 1993b; Kotula, Tivnan, \& Aguilar, 2014; McCarthey \& Garcia, 2005), they were mainly conducted in elementary, middle, and high schools rather than in higher education and did not consider the perceived attitudes toward writing needs of diverse L2 learners enrolled in an advanced EAP composition course.

Undoubtedly, studies on L2 learners' writing needs and their attitudes toward writing have been investigated; however, the two topics have been conducted separately, with no focus on how L2 learners with diverse backgrounds perceive their writing needs. Moreover, some of these studies were not empirical studies nor did they incorporate triangulation of data as the main means of understanding L2 writing difficulties. It is argued that "one or more of the pragmatisms can provide a philosophy that supports paradigm integration and helps mixed research to peacefully coexist with the philosophies of quantitative and qualitative research" (Johnson, Onwuegbuzie, \& Turner, 2007, p. 125). Long (2005) advocates for the triangulation of data to increase the validity and credibility of the results. Via diverse methods and sources, a needs analysis was conducted to identify the real-world writing tasks that EAP learners would need to complete in academic contexts. Deeply understanding their writing needs could contribute to a better design, implementation, and teaching of the advanced EAP composition course, as well as their accomplishments in post-secondary education. 


\section{Purpose of the Study}

The purpose of the present study was to conduct a needs analysis in order to answer four research questions pertaining to the writing needs of diverse EAP learners from three Southeastern state colleges. The study initially uncovered the diverse population among EAP learners, prioritizing EAP learners' culturally and linguistically diverse backgrounds. The study then identified the real-world writing tasks that EAP learners have been required to complete in the advanced EAP composition course. Furthermore, it explored how EAP faculty members and EAP learners have perceived the writing tasks required of EAP learners in the advanced EAP composition course, prioritizing their experiences and attitudes. Finally, an analysis of real content-level writing tasks that EAP learners would be required to complete across different majors were conducted. A comparison of these tasks revealed whether the writing tasks learned in the advanced EAP composition course were aligned with those completed across disciplines.

The findings identified the potential best writing perceived as important writing components to successfully complete academic writing assignments. In addition, findings were expected to enhance writing instruction in EAP contexts, prepare EAP learners for college-level content courses, and help EAP practitioners develop appropriate curriculum and materials for EAP writing courses. Therefore, results from the needs analysis could help construct and deliver effective writing programs. 


\section{Research Questions}

Via diverse methods and sources, this study addressed four research questions:

1. How diverse are EAP learners across three Southeastern state colleges?

2. What are the real-world writing tasks currently being taught in the advanced EAP composition course?

3. How do both EAP learners and EAP faculty members perceive the real-world writing tasks currently taught in the advanced EAP composition course?

4. What are the real-world writing tasks that EAP learners need to complete across disciplines, and are they aligned with those taught in the advanced EAP composition course?

Research question one (RQ1) uncovered the diverse population among EAP learners across three Southeastern state colleges. Research question two (RQ2) was designed to identify the real-world writing tasks currently being taught in the EAP composition course. Regarding research question three (RQ3), attitudes about the writing tasks performed by EAP learners in the composition course were also the focus of this study. Finally, research question four (RQ4) investigated the writing tasks performed across diverse disciplinary courses and whether the writing tasks currently taught in the advanced EAP composition course were aligned with those completed across disciplines.

\section{Assumptions}

There are obstacles that L2 learners face in academic writing courses in postsecondary academic programs. For EAP learners to succeed in the advanced EAP composition course and disciplinary courses, it was important to conduct a needs analysis to explore the real-world writing tasks that EAP learners were required to perform in 
academic contexts. The first assumption entailed that EAP learners' writing needs could differ based on their culturally and linguistically diverse backgrounds. The second assumption was that identifying the writing tasks in EAP could help design better courses, develop appropriate curriculum, and improve teaching materials, learning activities and assessment strategies. The third assumption was that examining the perceptions of EAP faculty members and EAP learners about the writing tasks taught in the advanced EAP composition course could provide the opportunity for participants to share their specific insights about their personal experiences and attitudes. When their voices are included, learning can be enhanced and better understood. It is implied that EAP learners' experiences and attitudes can influence how they perceive academic writing, and consequently their academic writing needs. When the writing needs of EAP learners are identified, EAP learners can improve their academic writing skills and succeed in their academic writing assignments while in the advanced EAP composition course and college-level content courses.

\section{Significance of the Study}

Learning to write is one of the most complex skills, especially for second language learners. For some L2 learners, the primary concept of a well-written production is mastering the rules of grammar (Hinkel, 2011). However, ignoring other aspects of writing like drafting, revising, and editing can generate poor performance in writing, which may result in L2 learners lacking the ability to organize information for a well-structured piece of writing (Nunan, 1999). Therefore, writing performance has become a national concern since L2 learners may not have the level of writing proficiency needed to succeed in schools or the workplace. Given the poor performance 
of L2 learners in writing, researchers need to conduct studies to understand how to create effective writing tasks and identify effective methods for teaching writing skills and strategies. Moreover, it is important to provide L2 learners with adequate time to compose their writing, focusing on the content rather than on writing conventions. By focusing on the development of language proficiency as well as social, academic, and emotional challenges, this study fills the lacuna in the field of language and literacy.

The results of the current study also impact both instructors and program directors. The rationale for conducting this study is to understand the writing needs of EAP learners, so these needs can be addressed to help instructors and program directors better understand how to help EAP learners achieve academic writing success and improve their academic language skills. Therefore, EAP learners can gain better control of their writing and overcome challenges in academic writing in a second language environment and across disciplines. Instructors across disciplines can then receive EAP learners who are properly trained to complete the expected writing assignments in their discipline and consequently succeed in college.

By providing insights into EAP learners' diverse backgrounds and writing needs in postsecondary education, this study aims to strengthen the impact of EAP courses so that EAP learners can be better prepared for post-secondary education. The present study has implications for L2 researchers, educators, and curriculum designers because it tackles important issues in the language teaching field, helps to understand the needs of L2 learners, and helps to develop language learning programs. The outcome of this study bears significant implications for L2 writing instruction and can help improve the EAP course design to better serve the community in South Florida. 


\section{Conceptual Framework}

In the 1980s, the teaching of writing shifted from the oral proponents that were popular in the 1960s and early 1970s to the value of the written work. During that time, the theoretical constructs of L1 composition pedagogy informed the literature. As a result of the upsurge of the L1 pedagogical stance, most research and pedagogy of L2 writing evolved from the study of L1 composition. Therefore, the influence of L1 composition has been of great importance to $\mathrm{L} 2$ writing, indicating that $\mathrm{L} 2$ writers use similar patterns of rhetoric as L1 writers (Silva, 1993; Atkinson \& Ramanathan, 1995). Silva (1993) stated that "L1 and L2 writers employ a recursive composing process, involving planning, writing, and revising, to generate and develop their ideas and to find appropriate rhetorical and linguistic means to express them" (p. 37). Following this rationale, some researchers believe that major approaches to $\mathrm{L} 1$ composition research could be significant to $\mathrm{L} 2$ writing stances and practices.

One of the first theories used to explain writing is the cognitive approach to composition that emphasizes the importance of the cognitive process. The focus of the cognitive process view of writing is not on the product of composition, but on the process of arriving at the final product. Writers cycle through distinct steps of the writing process by producing multiple drafts before creating the final product. Furthermore, the process approach follows the cognitivist view that perceives writing as problem solving in which teachers facilitate writing activities that are designed to promote fluency, encourage selfdiscovery, and increase self-awareness of the process.

The cognitive process theory of Flower and Hayes (1980, 1981), for example, reflects the growth of a written product that is organized by stages in a linear sequence 
during the composing process. Writing consists of three components of cognitive processes: planning, translating, and reviewing. In the planning phase, writers are required to generate and organize ideas and identify the rhetorical problem. They then continue with the writing process by translating their thoughts and ideas into words and sentences. After the translating phase, they read and review their work by revising and editing their text. This model supports the cognitive idea that good writers understand their audience, the purpose of their text, and their own goals for writing (Hodges, 2017).

Although Flower and Hayes's model of the cognitive process of writing has been extensively discussed in the research literature, it has been mainly investigated in L1 composition (Raimes, 1987) rather than in L2 writing (Silva, 1993; Matsumoto, 1995). Experts in the field of L2 writing have criticized the process approach because of the L1 and L2 composing differences, suggesting that adapting L1 theories and practices could generate issues in L2 writing. (Silva \& Matsuda, 2001). This approach has also been criticized because of the lack of consideration for the social dimensions of writing (Leki, Cumming, \& Silva, 2008). Although the study of L2 writing has expanded, its nature and issues cannot be fully explained when relying only on the cognitive approach since not all components of the process approach seem appropriate in L2 context. The process approach prioritizes the use of personal experiences and personal voices but does not emphasize the teaching of grammar and lexis, nor does it conceptualize teacher authority, which could create problems for L2 writers who are not used to personalized learning but rather traditional methods of learning. Moreover, the focus of the process approach is on cognitive activities that emphasize the learner and the text, disregarding social context in L2 learning as well as cultural differences among L2 learners with culturally and 
linguistically diverse backgrounds. Therefore, the development of cognition results from using cultural tools in social interactions (Schunk, 2012), making the exploration of cognitive processes through a sociocultural perspective necessary.

In the 1980s and 1990s, L2 education adopted the sociocultural approach to theorize the L2 learning processes. Sociocultural theory posits that learning is not independent from social interaction and cultural practice. Learning is a mediated activity in which active learners use different linguistic and cultural tools to interact with others or the environment. According to Gass and Selinker (2009), "Language is not an isolated phenomenon that can be understood out of its social context" (p. 280). It is connected to social practices and adaptive to an emergent set of resources represented in social interaction, rather than situated in an individual's cognition (Gass \& Selinker, 2009).

As researchers recognized the importance of social and cultural contexts in L2 learning, sociocultural perspective became prominent in the field of L2 writing because of the central role of social interaction and cultural context in the development of cognition (Lantolf \& Thorne, 2006; Perry, 2012). Sociocultural perspective views writing as a social activity mediated by social context and cultural tools and situated in a specific community. Clark (2012) stated that "individuals perceive the world according to the shared beliefs and perceptions of the community or communities to which they belong" (p. 17). Learning to compose is not an isolated writing task but a social and cultural experience (Matsuda, 2015). Writing systems and practices are socially constructed and culturally contextualized, increasing communication and knowledge (Grabe \& Kaplan, 1996). Therefore, the development of complex cognitive activities in L2 writing can be facilitated by social interactions and cultural contexts. 
However, developing writing proficiency is a challenging form of social activity due to linguistic and cultural differences between L1 and L2 (Silva, 1993). It is not surprising that L2 learners tend to use patterns of organization and stylistic rhetorical conventions learned in their primary languages and cultures, which are transferred to their writing. As Leki (1992) stated, "Cultures evolve writing styles appropriate to their own histories and the needs of their societies" (p. 90). Thus, how a point is made, how ideas and strategies are presented, and how the same ideas are explained and defended vary across cultures. Since an individual's consciousness is shaped by culture through language and thoughts, understanding L2 learners' cultural backgrounds is important because they can have influential factors in language learning (Clark, 2012; Silva, Leki, $\&$ Carson, 1997). Since writing differs among cultures (Ball, 2006), it is also imperative to address that culture is an important factor that influences the writing of diverse L2 learners because they bring their own life experiences, languages, and expectations to their writing classes. According to Grabe and Kaplan (1996), "Writing abilities are not naturally acquired; they must be culturally (rather than biologically) transmitted in every generation, whether in schools or in other assisting environments" (p. 6). Therefore, it is critical to include diversity in the study of L2 writing because diverse learners struggle to adjust their college experiences with their own cultural and linguistic backgrounds (Matsuda, 2003a). Although there is a challenge to find ways to support the learning of culturally and linguistically diverse L2 learners, promoting equity in opportunity and accessibility to learners across cultures can help improve educational practices and writing instruction. In addition, understanding how these diverse L2 learners use their composing strategies can help them improve their writing skills. 
To meet the needs of these diverse L2 learners, needs analysis is a concept that can construct effective writing programs that pay attention to diversity. Needs analysis is a practical rather than theoretical framework which has been defined by Dudley-Evans and St. John (1998) as a means of establishing the "what and how of a course" (p. 126). Long (2015) stated that needs analysis identifies the communicative goals and language needs of a particular group of students, so an appropriate program can be designed and delivered. He also argued that approaches to language teaching needs should be relevant to learners' language needs. There have been varied models and approaches to needs analysis in second language learning. Munby's (1978) Sociolinguistic Model is one of the most influential models used to identify learners' needs in language programs. This model relies on the concept that learning needs should be the basis of syllabus design and that needs analysis should focus on identifying language functions and situations for language use (Dudley-Evans \& St. John, 1998; Hutchinson \& Waters, 1987; Long, 2005). The shortcomings of this model are not taking into consideration learners' voices and their needs as learner variables (West, 1994). To make up the deficiencies of Munby's model, other approaches have been discussed. Richterich and Chancerel (1977) propose a systematic approach that meets the present situation and emergent needs of L2 learners. Although this approach considers the nature of learner needs, it does not consider learners' real-life needs and their perceptions of their needs (West, 1994). For this reason, Hutchinson and Waters (1987) offer a learning-centered approach, which consists of target needs and learning needs. Target needs involve "necessities" (necessary needs of learners to succeed in the target situation), "lack" (gap between "necessities" and the current proficiency of learners), and "wants" (learners' view of their needs). Learning 
needs, on the other hand, include factors linked to the process of learning. Brindley (1989) also proposes an approach to needs analysis, namely learner-centered approach. This approach is divided into perceived needs vs. felt needs, product-oriented interpretation vs. process-oriented interpretation, and objective needs vs. subjective needs. Perceived needs include perceptions from experts while felt needs are from the perspective of the learners. Product-oriented means language that learners need in the target situation whereas the process-oriented focuses on how learners respond to their learning situation. Finally, objective needs are explored prior to a course with the intention of collecting factual information about the learners while subjective needs are addressed during the course and derived from affective and cognitive factors in order to guide the learning process. Figure 1 represents the history of the theoretical approaches to needs analysis.

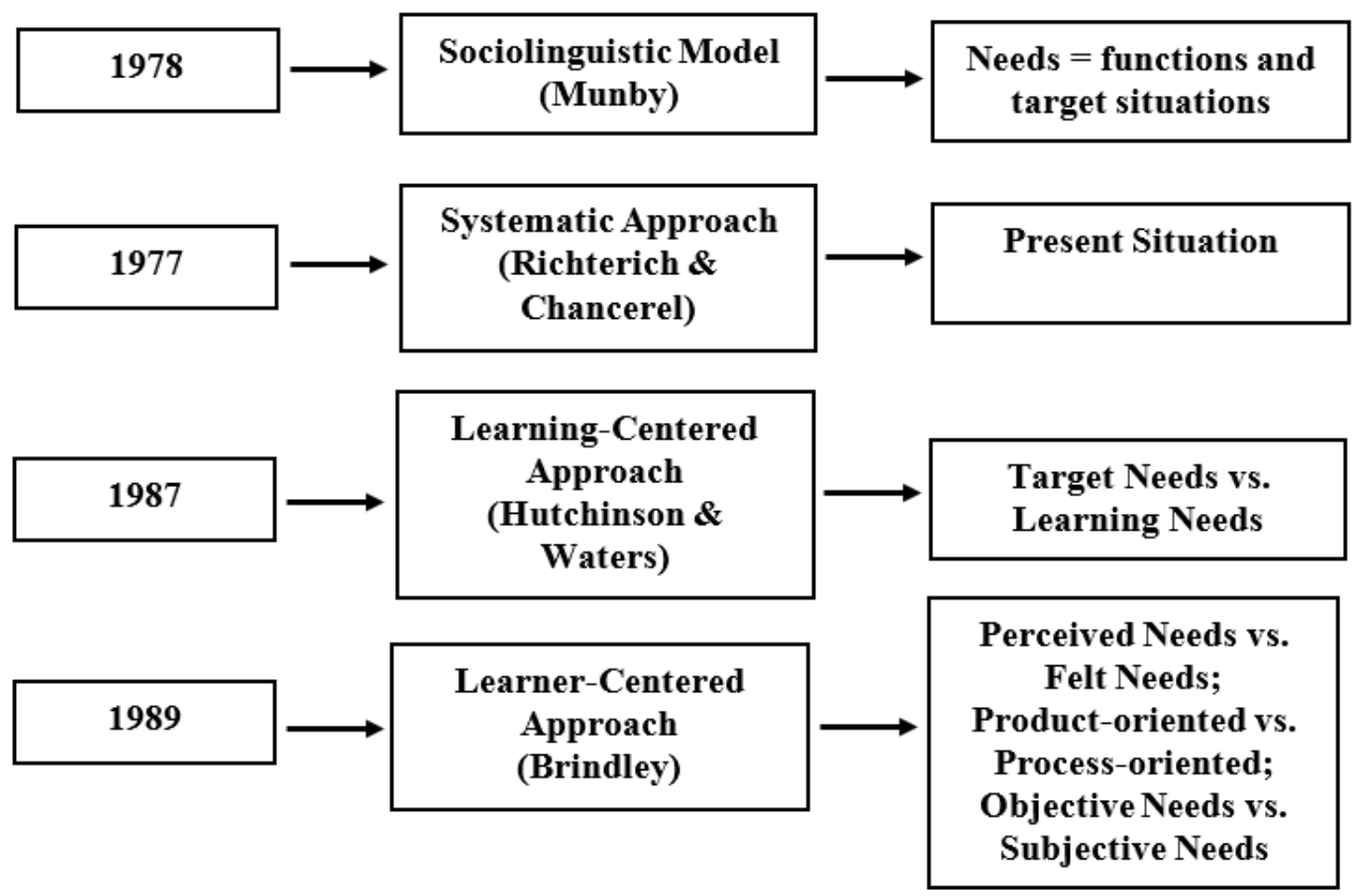

Figure 1. History of Needs Analysis Models 
The traditional needs analysis framework such as the ones mentioned above adopts tasks as a unit of analysis that need to be performed by students (Lambert, 2010). Long (2016) argued that tasks mean "the real-world communicative uses to which learners will put the L2 beyond the classroom; the things they will do in and through the L2" (p. 6). According to Serafini, Torres, and Long (2015), tasks are "meaningful classroom activities that are connected the real-world and that necessitate the use of language (p. 449). Long (2005) explained that tasks as a unit of analysis have three levels of task analysis. The target tasks, known as the communicative acts achieved through language in the outside world, are organized into task types. Task types are the basis for course design that meets the needs of groups of learners. Finally, pedagogic tasks are materials and activities that students complete in the classrooms. Robinson (2001) noted: adopting tasks as the unit of analysis helps to ensure a high degree of real-world relevance, since they are based on a needs analysis of target performance objectives, thereby most likely increasing student interest and motivation in classroom pedagogic activities, and the possibility of direct transfer of the abilities developed in classrooms to similar situational contexts. (p. 292)

For learners to be prepared as agents of social changes, tasks should be adapted to individual needs and proficiency levels. The construct of tasks is compatible with both psycholinguistic and sociocultural theories for adult second language acquisition. Therefore, a task-based needs analysis is the first stage to identify the real-world communicative tasks of L2 learners from culturally and linguistically diverse backgrounds (Long, 2016). Identifying L2 learners' writing needs using an approach to needs analysis that includes all the appropriate constructs can be important because 
diverse groups of L2 learners may have different writing abilities and needs that may be influenced by their cultural values. Grabe and Kaplan (1996) argued that thinking and writing are culturally embedded, and that writing is determined by social perspectives and approaches to L2 writing. Therefore, highlighting individual differences and needs, as well as their sociocultural backgrounds and experiences, can have a significant role in the mastery of L2 writing. Needs analysis is a form to essentialize writing as a social activity that takes place in different cultural contexts and captures L2 learners' diverse writing needs based on their cultural and linguistic backgrounds. Therefore, the learning of writing depends not only on L2 learners' self-identity, social context, and cultural background, but also on their perceived need to use writing. Understanding L2 learners' needs based on their diverse backgrounds may also help them participate in real-world writing tasks. The concept of identifying L2 learners' needs is useful because it helps develop curriculum content, appropriate program design, and teaching materials and methods that can lead to learner success.

Since research has suggested that attitude has also impacted how learners perceived their writing needs (Bruning \& Horn, 2000; Graham et al., 2007), another important concept to consider is EAP learners' attitudes toward their writing. Learners' writing attitudes refer to the positive or negative cognitive, affective, and behavioral attitudinal aspects of learning writing. The components of attitude are affect, cognition, and behavior. Affect refers to an emotional reaction that acts as an evaluative element. Cognition encompasses perceptual responses, knowledge, and beliefs that individuals form as a result of their attitudes. Behavior includes overt actions, indicating what individuals do as a result of their attitudes. Smith (1971) interpreted that the first step in 
the process of the tripartite model is cognition. Learners develop a concept of language and then they develop certain feelings about this concept. The next step is evaluative. Learners receiving a failing grade may evaluate language as difficult and boring while learners receiving a passing grade may see language as interesting and exciting. Learners then behave in accordance with these evaluations. They participate actively or not; they do their homework or not; they continue their language study or not (p. 84).

The tripartite model has been extensively tested and widely accepted. To confirm the attitudinal aspects of the tripartite model, Breckler (1984) evaluated its validity and concluded that affect, behavior, and cognition are distinct components of attitudes. He also confirmed discriminant validity for the three components distinction with moderated correlations among the components. Therefore, the components have been considered an accurate representation of attitude in lieu of directly measuring learners' attitudes towards learning writing. Figure 2 is a representation of Breckler's model of the attitude structure.

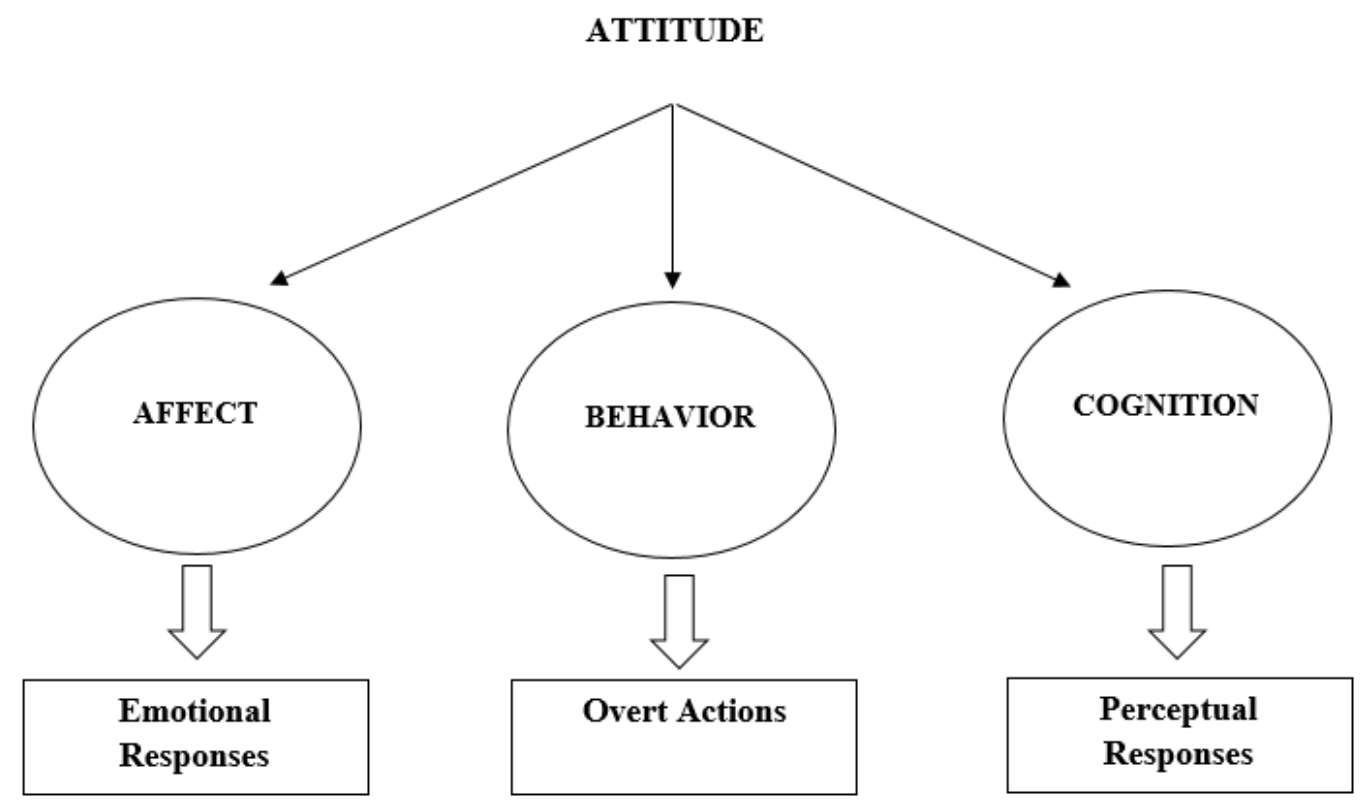

Figure 2. Model of Attitude Structure 
Since writing is shaped by the social context in which it occurs and influenced by learners' cultural, historical and political backgrounds (Graham et al., 2007; Schultz \& Fecho, 2000), the tripartite model neglects the sociocultural aspect of acquiring and expressing attitudes. Learners' attitudes toward writing are the result of not only individual factors but also sociocultural factors. With cultural and social support, L2 learners can become proficient in their ability to write in the target language. Negative attitudes toward writing, for example, are the result of social and individual factors; thus, it is important to establish writing activities that aim not only at cognitive changes but also at sociocultural changes.

The components identified in the literature led to the development of a conceptual framework which allowed the use of diverse methods and sources to explore EAP learners' writing needs using their experiences and attitudes, as well as their culturally and linguistically diverse backgrounds. Therefore, the present study aimed to touch upon aspects related to EAP learners' writing needs, attitudes, and diversity. The rationale for this model is derived from the concept that writing is influenced by social contexts and cultural differences. Identifying EAP learners' writing needs that are influenced by sociocultural perspectives can help improve writing instruction and curriculum. It can also help EAP learners overcome challenges and succeed in college. Additionally, positive attitude affects writing skills and leads to better writing performance. Therefore, combining the three elements can benefit EAP learners in the advanced EAP composition course because their needs depend on their cultural and social perspectives, on their attitudes about writing, and on their social and cultural perceptions. 
This theoretical framework seems adaptable to the needs of EAP learners since it considers the social nature of writing, is sensitive to individual needs, is suitable to EAP learners from culturally and linguistically diverse backgrounds, and emphasizes attitude as influential components of writing, which could potentially be modulated by curriculum that is informed by their real-life needs. Because of the lack of studies on writing needs, attitude, diversity, and sociocultural aspects of learning writing, it seemed important to undertake the present study in order to analyze how sociocultural aspects of learning writing affect EAP learners' writing needs in academic writing. Figure 3 refers to the conceptual framework of this study, which intends to capture the writing attitudes and complex needs of EAP diverse learners in order to create a cultural learning environment in the advanced EAP composition course.

\section{Organization of the Dissertation}

This dissertation is organized into five chapters. After Chapter I, which provides an introduction to the study and its conceptual framework, Chapter II contains the literature review, which begins with an overview of writing, attitudes, and needs analysis. The section concludes with an overview of the present study. Chapter III details the methods used to conduct this study. The methods chapter explains the research design, data collection, data analysis followed by validity and reliability, trustworthiness and credibility, research reflexivity, and ethical considerations. Chapter IV presents the findings and proceeds with discussions of these findings. Finally, Chapter V provides conclusions, implications along with recommendations, limitations, and suggestions for further research. 


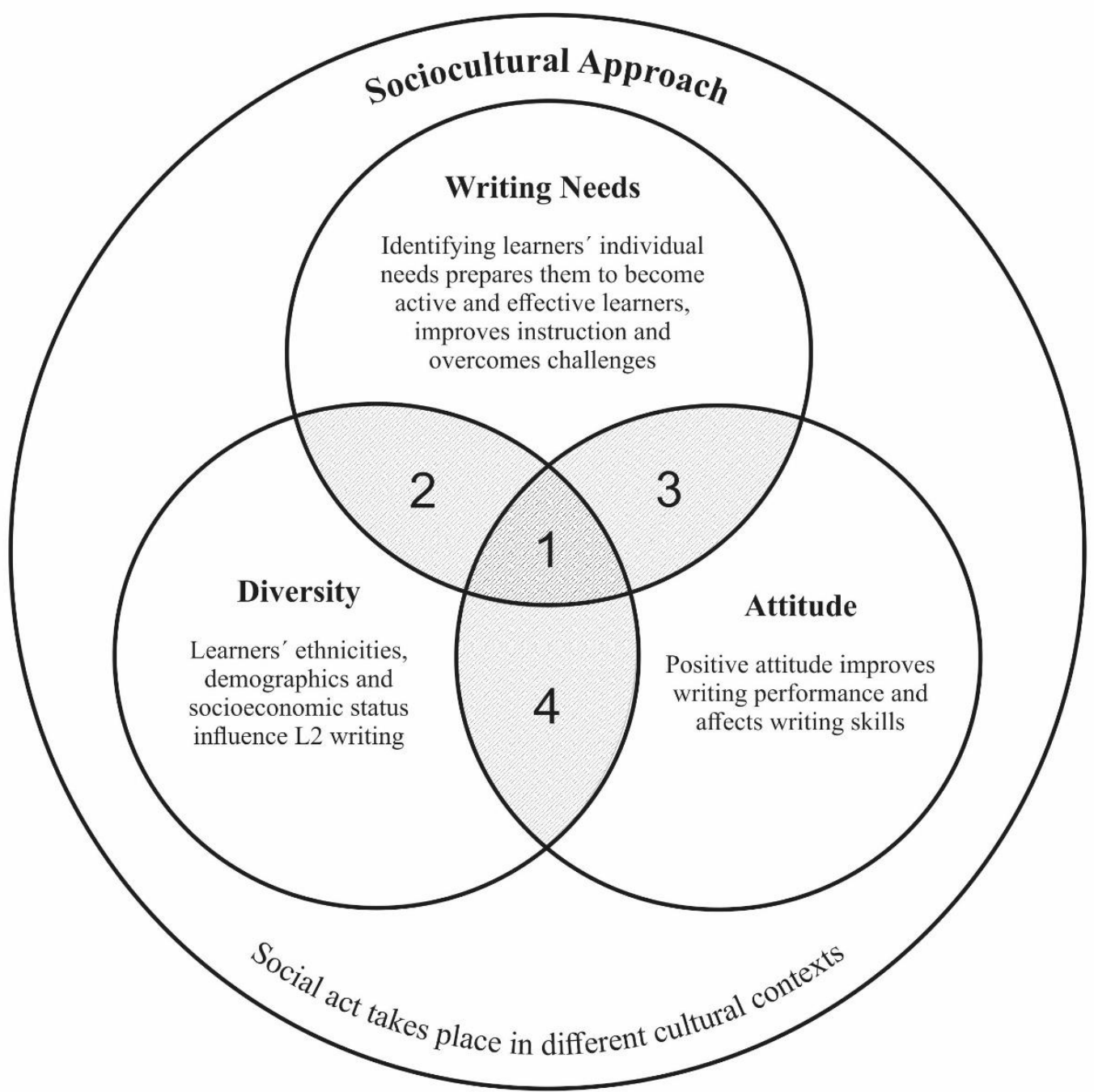

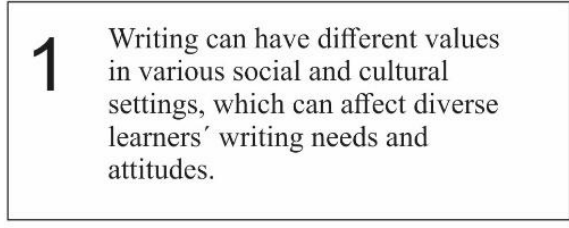

3 Attitude influences how learners perceive their writing needs since they positively engage in writing practices due to their attitudes.
2 Learners' writing needs differ according to learners' diverse backgrounds.

\section{Learners' diverse backgrounds influence their attitudes toward writing.}

Figure 3. Conceptual Framework 


\section{CHAPTER II}

\section{LITERATURE REVIEW}

The purpose of this chapter is to provide a review and synthesis of literature related to the theoretical framework and the problems employed in L2 writing, considering L2 learners' attitudes and writing needs in L2 writing courses. This chapter begins with a brief history of L2 writing, followed by an intense review of the complex cognitive procedures in the teaching of writing, including the principles and differences between the product-oriented approach and the process-oriented approach. Furthermore, the sociocultural context of L2 writing practices is briefly reviewed, followed by studies on writing rhetorical conventions and practices, with a focus on language and writing as cultural phenomena. L2 writers' attitudes toward language learning and writing are also covered followed by attitudinal aspects of cognition, behavior and affect, with primary focus on the affective component of attitude: self-efficacy. Finally, needs analysis is covered. This section discusses needs analysis and its approaches as well as L2 learners' writing needs. Finally, writing needs and attitudes toward writing are addressed.

\section{Writing}

Writing is an essential tool for communication and learning. Writing represents units of language that are symbolized by systems with "an attempt to communicate with the reader" (Grabe \& Kaplan, 1996, p. 209) and "increases human control of communication and knowledge" (Birch, 2007, p. 15). According to Giridharan (2012), "Writing involves composing, developing and analyzing ideas, implying the ability to rephrase information in the form of narrative, or transforming information into new texts as in argumentative writing (p. 578). Ferris and Hedgcook's (2014) more recent 
definition of writing is "a type of system that combines semiotic, communicative, cognitive, and creative functions" (p. 5).

Writing triggers thinking and allows learners to organize their ideas so they can increase their ability to summarize, analyze, and criticize. To achieve academic success and succeed in the workplace, students need to possess good writing skills, think critically and creatively, be able to solve problems, collaborate, and communicate properly. However, the ability of writing well is not a skill that is naturally acquired (Grabe \& Kaplan, 1996). Writing is a complex process that involves cognitive skills that are learned, practiced through experience, and culturally transmitted (Polio \& Williams, 2011). Writing is embedded in cultural context and social nature of learning; hence, learning the social patterns and cognitive functions can help decode and produce written texts.

\section{History of L2 writing}

In the 1960s behaviorism was the theoretical framework employed in writing instruction. The behaviorist learning theory was founded by the concept that learning resulted from a change in behavior and a system of reinforcement, through the use of extensive drills and practices that led to habit formation (Schunk, 2012). From the thinking of behavioral principles rose the audiolingual method, which reinforced oral patterns of language being learned to test the accurate use of grammatical rules. The audiolingual approach also posited that learning was a process of habit formation completed by oral practices as the primary means to language learning. Because the audiolingual method viewed spoken language as the primary source of learning, writing was perceived as secondary and used as reinforcement for oral habits. If writing was 
included in a lesson plan, it was used to reinforce the transcription of speech and not to create or express ideas, to synthesize information, or to explore thoughts (Leki, 1992). Phonetics, for example, was the basis of theoretical and practical studies of language, making orthography a representation of language (Matsuda, 2003b). Spoken form took precedent over written form because writing was "defined as an orthographic representation of speech" (Matsuda, 2003b, p. 16). Therefore, writing was neglected in the early years because of the emphasis on the teaching of spoken language during the dominance of the audiolingual approach.

Although there was a mix of oral and written work in early twentieth century, post-secondary education began to drop the emphasis on oral work and consequently to value the written work due to the creation of new universities (Brereton, 1995). Composition studies was then created as a specialization within English studies with attention to grammar, spelling, and punctuation and was handled through classical method of teaching and through work in Latin and Greek. Shortly after, teachers began to question the classical concept of composition as work of art. Consequently, a composition research community emerged in the 1970s with focus on conceptualizations of writing and the effectiveness of writing instruction. Finally, composition studies constituted a genuine discipline (Matsuda, 2003b).

As a consequence of an increasing number of non-native speakers of English in college composition courses, the teaching of English composition was expanded to prepare non-native English learners to function in post-secondary education by writing extensively for academic purposes. Although teachers of composition initially created remedial sections of English composition courses, they were unprepared to work with 
L2 learners due to their lack of foundation in L2 writing pedagogy and methods (Matsuda, 2003b). L2 learners needed to be taught by ESL trained specialists with analytical knowledge of English and deep insights into how native language interferes with the learning of the target language. Consequently, writing issues concerning L2 learners in English composition courses began to shift from English composition studies to L2 writing studies (Connor, 1996). Although L2 writing was influenced by the methodologies of English composition studies (Leki, 1992; Matsuda \& Silva, 2001), L2 writing was linguistically and rhetorically different (Silva, 1993). Recent studies suggested that L2 learners required more designated and specific instruction to develop rhetorical skills, text development strategies, and linguistic awareness (Leki, 1992).

L2 writing was removed from English composition studies and a new organization called TESOL was founded in 1966 to serve the needs and interests of these specialists (Ferris \& Hedgcock, 2014; Matsuda, 2003b). L2 writing then emerged as a sub-discipline of Teaching English as a Second Language (TESL) with several pedagogical approaches that represented different concepts of L2 writing (Ferris \& Hedgcock, 1998; Matsuda, 2003b). Researchers began to study aspects of writing, such as the features of academic genre and academic writing needs and tasks (Raimes, 1985). With the shift from English composition studies, L2 writing theory and practice claimed "its status as a discipline in its own right" (Ferris \& Hedgcock, 2014, p. 75).

Matsuda (2003b) explained that understanding the historical context of writing "is important both for researchers and teachers because our theoretical and pedagogical practices are always historically situated" (p. 15), thereby making it possible for teachers to apply appropriate theories and pedagogical strategies to other contexts. In addition, 
teachers began to investigate pedagogical approaches to writing, which played an important role in exploring the writing process of L2 contexts.

\section{Product-Oriented Approach and Process-Oriented Approach}

There are several approaches to teaching writing in the classroom. In the 1950s and 1960s, writing was influenced by a structuralist view of language that used a conventional approach to instruction as the primary means of composition-rhetoric instruction. The study of rhetoric and composition was mainly concerned with the analysis of literature. Principles and assumptions of writing instruction reflected "an educational philosophy that focused chiefly on the careful reading and analysis of canonical literature" (Ferris \& Hedgcock, 2014, p. 63). Writing was used in literacy work to address rhetorical structure and to introduce grammar rules for producing good writing (Ferris \& Hedgcock, 2014).

Following structuralism, the product approach reflects a traditional approach to teaching writing. In a sequence of teaching, learners are provided with an introduction and definition of a rhetorical form, and then they analyze a work of literature using contemporary and classic literacy sources in order to develop a writing task using the literacy sample, by imitating the previous rhetorical pattern (Kroll, 2011; Raimes, 1991). Ferris and Hedgcock (2014) also stated:

despite the near-absence of explicit rhetorical instruction, students are expected to produce and master a range of school-based models of rhetorical arrangements such as description, narration, exposition, comparison and contrast, process analysis, argumentation, and the like. (p. 63) 
Furthermore, the rhetorical convention includes controlled composition tasks with the development of sentence combining (Clark, 2012; Leki, 1992; Raimes, 1991). Learners combine sentence patterns to form paragraphs, and then the combine paragraphs to form essays. Leki (1992) stated that a "paragraph consists of a topic sentence, three supporting sentences, and a concluding sentence; an essay consists of an introductory paragraph with a thesis statement at the end of it, followed by three paragraphs of development, following by a concluding paragraph" (p. 6). By learning the basic patterns, it is believed that learners can transfer these skills to writing and compose effective academic writing. Modeling from samples is the focus of this approach (Nunan, 1999), and the final written production is supposed to be coherent with no grammatical errors.

Moreover, this teaching method primarily uses an appropriate written discourse and linguistic accuracy, focusing especially on grammatical and syntactic forms in which instructors use this approach to focus on the product of writing and the use of contemporary and classic literacy sources rather than on planning, drafting, revision, and editing of written texts (Clark, 2012; Grabe \& Kaplan, 1996; Hinkel, 2011; Kroll, 2011; Matsuda, 2003a). Essays are focused on the form of writing and are adhered to rhetorical conventions, including introductions, theses, paragraph structures, and conclusions.

Finally, this approach is not grounded in theory for learning and cognitive development due to its lack of focus on cognitive strategies. Its focus is on the form of writing, which yields unsatisfactory results (Ferris \& Hedgcock, 2014; Williams, 2003). Ferris and Hedgcock (2014) explained that the product-oriented approach contains static representation of learners' content knowledge and produces little effort devoted to strategies and cognitive operations. 
Despite this criticism, the product approach has also been discussed in L2 writing instruction. Traditionally, the teaching of L2 writing is language focused and reinforced by the spoken form of language. As in English composition studies, L2 writing focuses on the acquisition of spoken proficiency, positing that $\mathrm{L} 2$ learners can write after mastering the spoken language and orthographic conventions. In addition, L2 writing is mainly focused on discourse form and formal accuracy. Regarding the discourse form, an example of a product approach to L2 writing is the development of a five-paragraph expository essay with emphasis on the thesis statement at the end of the introduction, three body paragraphs with supporting details, and a conclusion. The product approach to L2 writing also focuses on the formal accuracy of the language, using language samples for repetition and memorization. According to Nunan (1991), L2 learners "engage in imitating, copying and transferring models of correct language" (p. 87). Finally, there is a heavy emphasis on the final product of the learning process. Teachers use controlled activities to achieve the end (Nunan, 1991).

Studies have shown that the product approach ignores fluency and does not provide L2 learners with the opportunity to express their ideas. Using modeling from samples in L2 writing courses leads to lack of attention to invention (Raimes, 1991) and prevents creativity since its focus is on reading and analyzing a text rather than writing a piece of work (Murray, 1980). Although L2 learners can become aware of different aspects of writing, such as grammar, vocabulary, organization and structure, the product approach encourages learners to apply the same writing structure in different rhetorical modes, inhibiting L2 learners rather than liberating them (Murray, 1980; Nunan, 1999). By implementing the product approach in L2 writing instruction, L2 learners are still not 
able to produce effective texts. Therefore, the teaching of rhetoric and writing began to drift away from the product of composing.

In the late 1970s, rhetoric-composition instruction began to shift away from the structuralist view of language and grammar-based methods, favoring approaches that focused on communication as the main goal of language learning. The rhetoriccomposition theory then changed from the product-oriented approach to the processoriented approach. The process approach arose "in reaction to the dominance of [the] product-centered pedagogy [in which] students learned modes of discourse and applied them to write their five-paragraph themes on topics assigned by the teacher, which were then graded without the opportunity to receive feedback or to revise" (Matsuda, 2003a, p. 67). According to Clark (2012), the "process approach to writing and the teaching of writing mean devoting increased attention to writers and the activities in which writers engage when they create and produce a text, as opposed to analyzing and attempting to reproduce model texts" (p. 7). Therefore, learners engage in writing activities in which they "discover their own composing process" (Clark, 2012, p. 6) by creating or producing a text rather than analyzing or attempting to reproduce a sample text, with the support of teachers who create "a facilitative learning environment to enable students to do so" (Clark, 2012, p. 6) rather than focus on direct instruction, grading and correcting grammar.

Moving away from the structuralist view, the process approach emphasizes two views: expressionism and cognitivism. The expressionist view promotes self-discovery and values learners' fluency and personal voice using personalized writing instruction. This view emphasizes writers as creators of their original ideas, in which they explore 
themselves, convey their thoughts, and claim their individual voice (Ferris \& Hedgcock, 2014). Contrary to the product approach, the expressionist view of the process approach does not focus on the production of syntactic and discourse structures or on isolated textual parts and grammatical features, but involves discovering novel ideas, expressing them in writing, and revising emergent texts (Ferris \& Hedgcock, 2014; Matsuda, 2003a; Raimes, 1991). Therefore, learners write less formally to a broader audience rather than to the instructor only, and they can express their feelings, ideas and opinions in which written texts convey meaning.

Cognitivism, on the other hand, promotes higher-order thinking and problem solving where writers engage in nonlinear mental strategies as planning, formulating and revision. The concept of cognitivism relies on "understanding how individuals learn to write" (Clark, 2012, p. 5) by emphasizing the process of developing organization and discovering meanings and ideas in multiple drafts as well as promoting proficiency in rhetorical functions and pedagogical genres.

The new institutional approach is centered on discovering personal meaning where teachers expect students to create ideas and to discover the purpose of composing. The process of creating writing is based on the quality of prewriting, writing and revision where teachers facilitate the composing process and students develop their own voice. The advocates of the process approach emphasize the importance of discovering their own voice, choosing their own topic, providing feedback, encouraging revision, and using peer collaboration. Finally, the notion of process underlines communicative, taskbased, and collaborative instruction and curriculum development (Nunan, 1989; Raimes, 1991). 
As in composition studies, L2 writing also emerged from a product-oriented pedagogy: the audiolingual method (Leki, 1992; Matsuda, 2003c). Because of the dominance of the audiolingual approach, opponents of this method began to discuss the need for better L2 writing instruction. In the 1980s, process-oriented pedagogy was introduced to the ESL field, and L2 instructors and researchers explored the idea of incorporating it in the teaching of L2 writing due to its success and dominance in the teaching of writing (Matsuda, 2003c).

According to Clark (2012), "the goal for a writing course is to help students develop an effective writing process" (p. 1). Matsuda (2003c) stated:

The notion of writing as process was introduced to L2 studies by Vivian Zamel (1976), who argued that advanced L2 writers are similar to L1 writers and can benefit from instruction emphasizing the process of writing. Rather than the view of writing as a reproduction of previously learned syntactic or discourse structures, the process-based approach emphasized the view of writing as a process of developing organization as well as meaning. (p. 21)

As a result L2 learners' different knowledge of written genres and array of composing strategies, as well as their lack of writing experience in their primary language when planning and composing writing tasks and categorizing and sequencing information, L2 learners require assistance as they become fluent and accurate L2 writers. As a result, L2 teachers shifted their attention from a product approach to a model of L2 writing pedagogy that emphasizes the use of process writing and multi-drafting.

The focus of the process approach falls mainly on generating ideas, drafting, editing, and revising (Clark, 2012; Ferris \& Hedgcock, 2014; Matsuda, 2003c) rather than 
evaluating grammatical structures and content in general without an opportunity for revision or feedback (Matsuda, 2003c; Nunan 1999). Writing is a process of discovery where L2 grammar and lexis are not addressed (Hinkel, 2011). This approach allows students the opportunity to explore ideas before being introduced to the topic sentence and details, to select their own topics, to generate ideas, to write drafts and revisions, and to provide feedback, excluding grammatical rules from the writing process (Raimes, 1991). Therefore, it is important to mention that the process is only an effective and appropriate approach to L2 writing when L2 learners have the opportunity to receive feedback from the teacher or their peers, allowing students to reflect on their plans, ideas, and language (Myles, 2002). Finally, Matsuda (2003c) argued that the process approach allows learners to create their own voice and become more self-directed while developing their academic writing skills.

However, the process approach to writing has had limited success. Because of the process pedagogy, L2 learners in U.S. colleges struggle with grammar and lexis in their writing and are unable to use proper conventions of academic written discourse. L2 learners produce texts that are vague and confusing without an explicit thesis and that are "rhetorically unstructured and overly personal" (Hinkel, 2011, p. 52) with basic and generalized sentence features. Furthermore, L2 writing pedagogy was developed using English composition studies in which most ESL teachers were unfamiliar with L1 rhetorical patterns and unaware of non-traditional approaches to teaching writing. Therefore, they never completely embraced the notion of the process-oriented approach, but more likely continued to use the traditional methods with emphasis on grammatical patterns (Leki, 1992). In addition, the primary focus of the process approach was on 
personal experience and on finding and developing a personal voice in writing. Finally, this approach gives the impression that grammatical accuracy is unimportant. According to Hinkel (2011), the process approach does not "provide an opportunity for writers to transform and expand their knowledge" (p. 55).

Opponents indicated that the process approach provides little insights between writers and audience, does not address how social factors such as gender, race, class, and culture influence writer's goals, and focuses only on guidelines for composing (Raimes, 1998). Moreover, the process approach does not cover cultural, educational and sociopolitical contexts. Although the process approach was influential to writing instruction, the process model was challenged for pedagogical, educational and cultural reasons. The text construction is perceived as individualistic and decontextualized (Polio \& Williams, 2011; Atkinson, 2003), which constitutes the beginning of the post-process era and rejecting the dominance of the process pedagogy (Matsuda, 2003c).

In the 1990s there was a shift to the post-process pedagogy that aimed "to identify and explore the shortcoming of current process-oriented beliefs and practices" (Ferris \& Hedgcock, 2014, p. 72) and to highlight "the rich, multifocal nature of the field, and go beyond non-traditional views of L2 writing research and teaching" (Atkinson, 2003, p. 12). The post-process approach is also referred as the social view of writing, as an extension of the process pedagogy, meaning "a shift of emphasis from cognitive issues to larger social issues" (Matsuda, 2003c, p. 73). The post-process framework stresses that writing is a social process that involves the writer, reader, text and context and should be engaged with the writers' background knowledge, interests and needs so that they can shape their texts to meet expectations. Thus, "L2 writing courses should feature the 
specific subject matter that L2 learners must master in their studies and beyond" (Ferris \& Hedgcock, 2014, p. 77). Atkinson (2003) viewed "the notion of 'post-process' as an appropriate basis on which to investigate the complex activity of L2 writing in its full range of sociocognitive situatedness, dynamism, diversity, and implications" (p. 10).

Research in the early 1970s was concerned with the written product and then was replaced with the writing process during the late 1970s. As a result of the increase number of culturally and linguistically diverse learners in post-secondary academic programs in the 1980s, writing became an integral part of success in academic and workplace settings; thus, the concept of writing instruction shifted focus toward social context and how language and writing differed depending on subcultures (Ball, 2006). Cumming (2001) also stated that studies on writing instruction have focused on three fundamental concepts of L2 writing: the quality of text produced, the process of composing, and the specific sociocultural context in which learning occurs. Although researchers suggest that the product-oriented approach, the process-oriented approach, and the post-process approach have significantly influenced the history of English composition studies and L2 writing, the instruction of writing must take into account the sociocultural context of writing, which has led to "a deep appreciation for the social, and often political, context in which L2 writers must learn and live" (Polio \& William, 2011, p. 501).

\section{Sociocultural Context of L2 Writing}

Sociocultural theory (SCT), initially proposed by Vygotsky (1986), posits that social interaction and cultural settings play an important role in individual's cognitive development and higher mental functioning. The social environment influences cognitive 
change that results "from using cultural tools in social interactions and from internalization and mentally transforming these interactions" (Schunk, 2012, p. 242). SCT believes that the integration of social and cultural elements plays a central role in human cognitive development and that the process of developing higher mental functioning helps individuals internalize or regulate their learning from social activities through a mediational tool. Mediation is the construct that underlines the process of internalization. Individuals do not interact directly with the environment but develop different mediational tools to mediate their activities, concepts, and social relations with oneself, with others, and with cultural artifacts. The primary mediated tool is language, which allows individuals to connect to the environment and make sense of the new knowledge. According to Gee (1996), language is fully attached "to social relations, cultural models, power and politics, perspectives on experience, values and attitudes, as well as things and places in the world" (p. 7).

Another commonly important Vygotskian concept is the Zone of Proximal Development (ZPD). Language as a mediated tool occurs within ZPD. Language plays an important role as a symbolic tool which allows individuals to collaboratively mediate problem solution through social interaction (Swain, 2005). Lantolf (2000) defined the ZPD as "the collaborative construction of opportunities for individuals to develop their mental abilities" (p. 17). In other words, internalization of language is facilitated by social interactions for the process of cognitive development and communicative purposes. ZPD also refers to the level of skills that individuals reach by working independently and the level of potential skills that individuals reach with the assistance of a teacher. Vygotsky (1978) defined ZPD as "the distance between the actual 
developmental level as determined by independent problem solving and the level of potential development as determined through problem solving under adult guidance or in collaboration with more capable peers" (p. 86).

ZPD can also be applied to the teaching of writing since it "embodies the social nature of learning and underscores the importance of collaborative learning" (Gass \& Selinker, 2009, p. 285). Teachers implement strategies to help learners mediate between what they know and what they will learn by assisting them to develop writing through social interaction. Teachers also play an active role since they offer support, provide feedback, and model writing practices (Hodges, 2017). According to Simeon (2015), "by adopting the concept of ZPD, teachers provide the assistance necessary to bring the learner to a higher level through the zone and to a greater independent capacity" (p. 22). In addition, writing is a tool for a social and collaborative activity that supports novice writers that learn from more experienced writers (Lantolf \& Thorne, 2006). Therefore, interaction between more skilled writers can help novice writers internalize language and perform tasks independently. Drawing from the Vygotskyan perspective, studies found that ZPD can provide opportunity for L2 learning and cognitive development (Swain, 2005). L2 learners develop higher order mental processes through the use of cultural tools and social interaction with teachers, peers, and other mediators, consequently, contributing to L2 writing development (Swain, 2005). Through social interaction, L2 learners can negotiate meaning that allows them to comprehend the written text and gain additional practice in their L2 writing (Ellis, 2008; Swain, 2001, 2005). 
The notion of voice is also influenced by cultural and social context (Matsuda, 2001). Vygotsky $(1978,1986)$ defined voice as a writer's identity and reflection of culture that is constructed by the writer, readers, and other social factors (Silva \& Matsuda, 2001; Matsuda \& Tardy, 2007; Zhao, 2017). Therefore, "voice is essentially the result of a social and cultural mediated activity with the individual" (Sperling, Appleman, Gilyard, \& Freedman, 2011, p. 73). In addition, writers have multiple voices for different rhetorical situations that posit and solve writing problems within historical, cultural, and social contexts. However, the importance of studying voice began because of the increase of diverse learners with different cultural and linguistic backgrounds in post-secondary education.

Garfield and Brockman (2000) concluded that voice is an important concept to teach in L2 writing courses because it allows L2 learners to respond to cultural conflicts and develop positive attitude about becoming good writers. The concept of voice in L2 writing is not only mediated by a social and cultural construction, but also as an individual accomplishment (Sperling et al., 2011). In the individualistic view, voice means an individual's identity in writing. However, the ideology of individualism in the context of L2 writing classrooms can be challenging for L2 learners.

Voice perceived as expression of individuality focuses on personal topics. A topic selected by L2 learners reflects and influences their cultural background and social context. Wang (2012) stated that "the choice of writing topic is influenced by cultural background and social conditions" (p. 638). She stated that an example of cultural influence on selecting a writing topic is Chinese learners. They may, for example, discuss their personal beliefs as common public topics while English learners rarely do since they 
are personal and not suitable to be discussed publicly. An example of social interaction influencing topic selection is that English learners discuss issues from the perspective of law, whereas Chinese learners prefer moralization by discussing issues from the perspective of morals (Wang, 2012).

SCT prioritizes the interaction between learners rather than the final product. However, voice is "largely culturally constrained" and "relatively inaccessible to students who are not full participants in the culture within which they are asked to write" (Ramanathan \& Kaplan, 1996, p. 22). L1 writers claim their voice earlier and directly in their writing while Chinese, for example, express their voice indirectly and later in the assignment (Wang, 2012). Thus, Chinese writers experience difficulties using their own voice and personal experiences. Therefore, voice as a pedagogical skill may not be acceptable for L2 learners with collectively oriented cultural backgrounds (Silva \& Matsuda, 2001; Shen, 1989). It is important to understand that writing is not separated from culture. Therefore, experiences that L2 learners have and interaction with which they engage are crucial to the development of cognition. Understanding L2 learners' challenges can help them improve their writing skills by identifying their true voice and identity, and consequently be able to express their personal experience in writing.

\section{Differences in Culturally Rhetorical Writing}

Developing literacy in any language requires learning its orthography, its social and rhetorical conventions, and its cognitive functions in order to decode and produce written texts. The term rhetoric means the art of composing effective discourse with the ability to persuade an audience. Clark (2012) defined rhetoric as "the complex interaction between the writer, reader, and the context" (p. 9). Rhetorical preferences and 
conventions are not acquired naturally but learned in schools. Therefore, the teaching of rhetorical patterns reflects socioeconomic, political, and educational realities rather than natural mental process. Furthermore, research on rhetorical preferences and conventions emphasized the importance of social context and cultural models on writing practices and writing development (Ball, 2006).

Contrastive rhetoric, on the other hand, is an area of research that identifies problems in writing and explains the rhetorical strategies transferred from the L1 in order to improve pedagogy. "Contrastive rhetoric deals with organization patterns, stylistic preferences, and other conventional aspects of specific genres, viewed across cultures" (Silva, Leki, \& Carson, 1997, p. 322). Atkinson (2004) argued that contrastive rhetoric "uses the notion of culture to explain differences in written texts and writing practices" (p. 287) and that "a better conceptualization of contrastive rhetoric needs to include a better conceptualization of culture" (p. 277). Connor also stated (1996) that "language and writing are cultural phenomena. As a direct consequence, each language has rhetorical conventions unique to it, such that the linguistic and rhetorical conventions of the first language interfere with writing in the second language" (p. 5). Although there is a strong relationship between communication skills and the development of literacy in both L1 and L2, the purposes of writing as well as the conventions and practices of writing vary from the L1 to the L2. L2 writers differ from L1 writers due to their expectations and assumptions about rhetorical conventions, which are based on L2 learners' different cultural conventions. Therefore, difficulties in L2 writing can be attributed to the interference of the L1 cultural conventions of writing (Wu \& Rubin, 2000). It has also been posited that psychocognitive and sociocultural demands are higher 
in L2 learners due to their differences in background knowledge and rhetorical academic patterns (Ferris \& Hedgcook, 2014).

Observing the discrepancy between L2 learners' ability to produce proper sentence-level structure and their ability to attain logical organization, Kaplan (1966) argued that language and culture have unique rhetorical conventions and that L1 rhetorical patterns of writing interfere with their L2 writing performance. Kaplan (1966) has also argued that the issues in organizing information were beyond sentence structures and examined the linguistic structure in terms of paragraph structure. Kaplan examined 600 writing samples produced by ESL college students with a variety of distinct primary languages. He proposed different rhetorical patterns in L2 writers' primary languages and their expository writing in English. According to his contrastive rhetoric study, English-speaking writers engaged in a linear structure while Arabicspeaking writers produced an extensive use of coordinating conjunctions, which could be considered excessive by English-speaking readers. Kaplan also demonstrated that Chinese and Japanese writers exhibited an illogical and indirect structure, circling around a topic or argument rather than explicitly introducing an argument. Finally, writers whose language was from Romance origin and Russian used disunified structure, deviating from the main topic or argument, often introducing unnecessary and irrelevant information (Kaplan, 1966).

Opponents of Kaplan's traditional contrastive rhetoric framework argued that his work was as ethnocentric by privileging the writing of native speakers of English. He examined products rather than developmental process, dismissing "linguistic and cultural differences in writing among closely related languages" (Connor, 1996, p. 495), and 
considering transferability from L1 a negative influence in L2 writing. In addition, his work did not include social factors of L2 learners, such as "the contexts, and purpose of their learning to write, or their age, race, class, gender, education, and prior experience" (Raimes, 1998, p. 143).

Consequently, other studies analyzed the comparison of discourse features in written texts from major languages in contrast to English. In English text, the main point is stated at the beginning and ideas are hierarchically organized with paragraph divisions to reflect the separation of ideas. The use of textual features as ambiguous nouns, referential pronouns and adverbs supports the discourse purpose by suggesting multiple interpretations. Hinds (1990) also affirmed that English writers reveal the purpose of their writing early in their text, adhering to a deductive structure. German texts, on the other hand, possess distinct preferences for the organization of written discourse followed by the importance of syntactic structure and content. Moreover, German writers favor digression while English writers favor a linear development (Connor, 1996; Grabe \& Kaplan, 1996).

There have also been other studies on contrastive rhetoric. Spanish writers, for example, prefer an elaborated style of writing using longer sentences with a great number of run-ons and fragments. They also tend to use a lot of pronouns and causal conjunctions. In many Asian languages, the thesis statement is located at the end of the text, making it inductive rather than deductive. The goal of the discourse organization is "to convince the reader of the validity of the writer's stance, instead of employing overt persuasion" (Hinkel, 2002, p. 31). Also, the responsibility for text clarity and explication is placed on the reader rather than on the writer. In Chinese, for example, the use of 
classical Chinese rhetoric and philosophy influences the structure of discourse and text. The classical rhetoric is mainly applied so Chinese writers can convince their audience. They also use rhetorical questions, analogies, and anecdotes to reveal their intentions. Japanese writers, on the other hand, use quasi-inductive rhetorical patterns with four units (kishōtenketsu) while Korean writers favor indirect and nonlinear development. They delay the introduction of purpose, and the thesis statement is at the end of the text. Semitic languages also tend to focus on the nonlinear development of writing. For example, Arabic writers develop paragraphs with a series of parallel constructions and coordinating conjunctions. They use adjective and adverb clauses to attain parallel balance between the subject and predicate structures of the sentence. They also use nonhierarchical organization of ideas and repetition of lexical items for the purpose of rhetorical persuasion.

In the 1990s, there was a significant shift from Kaplan's concept of contrastive rhetoric to a new perception. Contrastive rhetoric moved from structural descriptions of analyzing only the effects of transfer from L1 to L2 writing to "cognitive and sociocultural variables of writing in addition to the linguistic variables" (Connor, 1996, p. 18). To conclude that all learners should be subjected to identical cultural and linguistic influences is to mistakenly rely on cultural essentialism. Factors such as educational level, socioeconomic status, and geographic isolation can affect how L2 learners perceive academic writing and the challenges that they face while composing writing tasks. Therefore, educators need to be sensitive to issues pertaining to cultural and linguistic differences among L2 learners as well as the concept of cultural interference in L2 writing instructions. 


\begin{abstract}
Attitudes
Attitude is a mental state that influences individuals' responses to objects and situations in certain ways and can be perceived as positive, negative, or neutral. Attitude is defined as "a psychological tendency that is expressed by evaluating a particular entity with some degree of favor or disfavor" (Eagly \& Chaiken, 2007, p. 598). Gardner (1985) defined attitude as "an evaluative reaction to some referent or attitude object, inferred on the basis of the individual's beliefs or opinions about the referent" (p. 9). Baker (1992) explained that attitude is an indicator of people's "thoughts and beliefs, preferences and desires" (p. 9). According to Fazio and Olson (2003), "attitude is an unobservable psychological construct which can manifest itself in relevant beliefs, feelings, and behavioral components" (p. 139).

Considering the contextual factors of learners, Baron and Byrne (1984) defined attitude as feelings, beliefs, and behavior tendencies toward specific individuals, groups, ideas, or objects in which these individuals structure their complex social environments. Attitude is an aspect of the cognitive development that is developed early and is the result of the attitudes of families and communities as well as learners' interaction with other individuals from diverse backgrounds. The study of attitude became important for its direct influence over individual social behaviors, especially in academic literacy. The term literacy entails not only text forms but also "the social practices of individuals and groups in the contexts where these texts express meaning and purpose" (Ferris \& Hedgcock, 2014, p. 77). Thus, it is argued that learning process has social aspects besides the cognitive approach (Kara, 2009). The ability to master a language is not only influenced by the mental competence but also by learners' attitudes and perceptions about
\end{abstract}


the target language (Gardner \& Lambert, 1972). Attitude can enhance not only the process of language learning but also influence learners' behaviors and beliefs toward that language, culture, and community.

\section{Aspects of Attitudes: Affect, Cognition, and Behavior}

Researchers (Baker, 1992; Breckler, 1984; Fazio \& Olson, 2003; Feng \& Chen, 2009; Graham et al., 2007) have discussed attitude from three dimensions that possess different features: cognition, affect, and behavior. The cognitive aspect of attitude involves the beliefs, thoughts, and perceptions of learners about objects and situations and how they understand the process of language learning (Fazio \& Olson, 2003). The affective aspect of attitude consists of feelings, emotions, and moods of learners' degree of preference for an object or behavior (Fazio \& Olson, 2003). Focusing on the process of language learning, Feng and Chen (2009) stated that the learning process is affected by different emotional factors and influenced by learners' perspectives and attitudes toward the target language. Finally, the behavioral aspect of attitude indicates how learners behave and react in a particular situation. Behavior is an important component of attitude because learners' actions are influenced by how they feel about learning a language (Fazio \& Olson, 2003). Kara (2009) stated that learners' beliefs and emotions influence their behaviors and, consequently, their performance. It is argued that learners with positive beliefs about language learning tend to have positive attitudes towards language learning. Consequently, positive attitude results in positive behavior which leads learners to be more enthusiastic in solving problems, acquiring what is useful for daily life, and engaging themselves emotionally (Kara, 2009). 
Baker (1992) described the learning process on the basis of the three domains of attitude. The first domain in the learning process is how learners acquire, process and use knowledge, and how they perceive the concept of language (cognitive). The affective domain then deals with learners' emotions and feelings about the concept of language. The final domain is behavioral. Learners behave in accordance with their feelings about learning that language. Graham, Berninger, and Fan (2007) also discussed the three aspects of attitude, but in writing. In the cognitive component of attitude, learners with positive beliefs about writing expend greater effort than learners with negative beliefs. Affective and behavioral components may also have an impact on learners' choices of writing strategies used when producing a text. Finally, a positive affect and behavior may trigger the use of more creative forms for completing writing tasks.

The aspects of attitude are important factors that impact language learning and performance. According to Petric (2002), "attitudes, as an affective response, are determined by beliefs, which are basically cognitive. An attitude towards a certain behavior is determined by the belief about the outcome of such behavior and the evaluation of that outcome" (p. 21). In addition, learners' attitudes are formed as a result of their experiences which also impact behavior (Brown, 2005). Therefore, attitude determines behavior which influences the learning process. In addition, positive attitudes enhance motivation, which affects writing skills and leads to better writing performance (Gau et al., 2003). It is reasonable to speculate that the needs of L2 learners depend on their attitudes about learning writing. Although a few studies have revealed that learners with positive attitudes about writing put more effort into their writing tasks, no one has 
ever explored needs analysis and writing tasks based on students' real needs as affecting attitudes (Graham, Berninger, \& Fan, 2007).

Self-Efficacy. Many facets of learners' attitudes have been studied, especially self-efficacy. Bandura (1977) introduced the term self-efficacy and defined it as "the conviction that one can successfully execute the behavior required to produce the outcomes." (p. 193). He also argued that self-efficacy plays the role of a mediator between knowledge and action and is a cognitive factor that affects individuals based on their abilities to accomplish certain goals and their beliefs about the outcome of their efforts (Bandera, 1986). Sanders-Reio, Alexander, Reio, and Newman (2014) defined self-efficacy as “one's confidence in one's ability to perform tasks required to cope with situations and achieve specific goals" (p. 1). According to Bandura (2000), efficacy beliefs influence (1) whether people think erratically or strategically, optimistically or pessimistically, (2) what courses of action they choose to pursue, (3) the goals they set for themselves and their commitment to them, (4) how much effort they put forth in given endeavors, (5) the outcomes they expect their efforts to produce, (6) how long they persevere in the face of obstacles, (7) their resilience to adversity, (8) how much stress and depression they experience in coping with taxing environmental demands, and (9) the accomplishments they realize.

Following this concept, Bandura (1986) dismissed the theories of behaviorism, claiming that individuals are not passively shaped by reactions but rather are active participants in which behavior and learning are attained. Social cognitive theory, on the other hand, establishes "the importance of beliefs in human learning and performance" (Sanders-Reio et. al., 2014). Individuals' beliefs of their ability to perform specific 
actions are influenced by the accomplishments of these actions. Individuals are proactive and self-regulating rather than reactive and controlled by biological and environmental factors (Bandera, 1986). Additionally, these individuals "possess self-beliefs that enable them to exercise a measure of control over their thoughts, feelings, and actions" (Pajares, 2003, p. 139). These beliefs that individuals have about their abilities are crucial elements of human behavior as well as a principal component of academic motivation.

Self-efficacy under the social cognitive theory can promote learning based on others' experiences, successes and/or failures. Measures of self-efficacy are positively based on the amount of effort that learners expend when performing a task, persisting a difficult task, and recruiting strategies to perform a task.

\section{Learner Attitudes toward Writing}

Research has indicated that attitude is also significant to the study of writing. Since attitude is a key factor in language learning, many studies have already been conducted to examine the relationship between attitude and writing. Knudson (1991, 1992, 1993a, 1993b) examined the relationship between attitudes and writing across studies in grades 1-3, 4-8, and 9-12. Results from her studies indicated that female students had more positive attitudes toward writing than male students. Knudson also found that age affected how positive students felt about writing as they got older, while ethnicity did not have a direct effect on the results.

Kotula, Tivnan and Aguilar (2014) conducted a study with fourth- and fifth-grade students to examine their attitudes about writing and their writing ability as well as the relationship between gender and writing attitude. Data was collected from 367 students at the beginning and end of the year using an 18-item survey that focused on self-efficacy, 
self-concept, and perceived value of writing. Results from principal component analysis indicated three components: perceived value of writing, self-rating as a writer, and writing behavior. In addition, a small but consistent relationship between each component from the attitude survey and writing performance was reported. Regarding gender, female students had more positive attitudes about writing than male students in all three components.

Following the concept that writing is a social practice, McCarthey and Garcia (2005) studied 11 elementary L2 students' writing practices and attitudes toward writing in both English and their native languages, considering their home backgrounds (parents' educational backgrounds and income levels) and classroom contexts (frequency and quality of writing, teachers' expectations when students completed a task, plans for staying in the United States, writing support at home, and cultural expectations). Results indicated that participants engaged in a variety of home and school writing practices. A variety of home factors, especially social class, education of parents and parental support, influenced students' attitudes about writing, while classroom contexts, like the opportunity to write in various classroom settings, affected both students' writing practices and attitudes toward writing. They concluded that more opportunities to write in English and in students' native languages should be encouraged in the classroom to develop practices in both languages and foster a more positive attitude.

Although the previous studies on attitudes toward writing reveal important findings, they have focused mainly on writing performance and achievement, as well as gender, age, and ethnicity for 1-12 graders, but not for adult L2 learners in EAP writing courses. These studies have indicated a connection between learners' attitudes toward 
writing and performance; however, more research is needed to examine attitudes of L2 adult learners in EAP contexts. Additionally, many of the studies reported relatively small samples, and those with large samples targeted a specific age and ethnic range, not providing an adequate perspective. Previous studies vary by grades and populations of students, but no studies to date have been conducted with adult L2 learners in academic writing in EAP contexts.

\section{Learner Affective Attitude: Self-efficacy and Writing}

Writing can be challenging for learners because of several factors including affective variables (Graham et al., 2007; Graham \& Perin, 2007). A major concern of writing educators is that learners have a generally negative attitude toward writing (Graham et al., 2007). Studies have indicated that a positive attitude toward writing can affect writing skills and performance (Bruning \& Horn, 2000; Graham et al., 2007). There are different elements of writing attitude that can bring positive or negative results. Academic self-efficacy belief is a strong predictor of attitude in writing. Learners with high self-efficacy are more likely to learn how to write than learners with low selfefficacy. In addition, learners with lack of confidence in their writing skills are less likely to engage in writing tasks and develop writing skills and strategies.

Research regarding self-efficacy and writing has been conducted. Pajares and Johnson (1996) examined the influence of writing self-efficacy, writing aptitude, and writing apprehension in high-school students' essay-writing performance by controlling for gender and ethnic differences. Results indicated that self-efficacy beliefs and writing aptitude had a significant effect on writing performance. Furthermore, self-efficacy had a strong effect on apprehension, which had a modest effect on performance. In terms of 
gender, analysis revealed that female and male students did not differ in aptitude and performance; however, female students reported lower level of self-efficacy. Regarding the ethnic results, Hispanic students presented the lowest aptitude and performance scores.

Similar findings were seen in another study. Pajares and Valiante (1997) investigated the relationship among self-efficacy, writing apprehension, usefulness of writing, and writing aptitude on essay-writing performance of 218 upper elementary students. Gender was also computed as a variance in performance. Students' writing samples were used to analyze their writing performance, considering the previous four variables. Results revealed that self-efficacy beliefs had a direct effect on writing performance and aptitude, as well as on writing apprehension and usefulness of writing. In regard to gender differences, male and female students did not differ in performance, but female students with higher levels of self-efficacy reported writing to be more useful and had lower writing apprehension.

Pajares, Miller, and Johnson (1999) reported similar results in their study about self-efficacy, self-concept, and writing ability with 363 third to fifth grade students. They compared the relationship between writing ability and three elements of attitude: selfefficacy, self-concept and usefulness of writing, using three different surveys as quantitative instruments. Female and male students were asked to compare their writing abilities. Results from a multiple regression analysis revealed that self-efficacy predicted writing performance; however, usefulness of writing did not have a direct effect on performance. The researchers found that female students had higher levels of self-concept and were better writers than male students but did not have higher writing self-efficacy. 
As seen in the previous studies, self-efficacy is a strong predictor of academic performance and an important motivational factor. Learners who hold a low sense of selfefficacy may perceive a task as difficult and avoid its completion; however, learners with high confidence in their skills may be resilient and passionate when accomplishing a task, setting higher goals for themselves and selecting a more difficult task to complete.

Researchers have also indicated the relationship between cognition and writing by investigating factors that influence performance. Like previous studies that examined the relationship between attitude and writing, research on self-efficacy and writing has also focused on L1 learners in secondary education rather than L2 learners in post-secondary academic programs. Self-efficacy, as an important component of attitude, also affects L2 learners' attitudes toward academic writing since it can affect L2 learners' perception of writing based on their culturally and linguistically diverse backgrounds.

\section{Needs Analysis}

The research on learner needs, known as needs analysis or needs assessment, was established in the 1970s during the time the communicative approach to language learning replaced the grammar-based approach (West, 1994). In the 1970s, needs analysis consisted of assessing the communicative needs of the learners and creating techniques for specific learning objectives. In addition, needs analysis was mainly concerned with register analysis where needs were perceived as linguistic: language forms such as grammar and vocabulary were considered needs (Dudley-Evans \& St. John, 1998). With the publication of Munby's model, the Communicative Syllabus Design, in 1978, the occupational or educational purpose of the learners was newly placed as the central position within the framework of needs analysis. In addition, in Munby's model for 
syllabus design, situations and functions were set within the frame of needs analysis.

Influenced by Munby's model of needs analysis, other approaches to needs analysis were introduced in order to meet the needs of the learners.

The dominant approach in needs analysis is Target Situation Analysis (TSA). This approach provides information about objective needs and product-oriented interpretations, so the skills and language that learners will need in the context of language learning can be identified and the tasks, and activities that learners will be using in the target situation can be defined (Dudley-Evans \& St. John, 1998). Another major approach to needs analysis is Learning Situation Analysis (LSA), which includes subjective needs and process-oriented interpretations. This approach includes strategies that learners use to learn another language, considering learners' perceptions of their own needs. In LSA, problem-solving is a concept applied to "encourage students to think for themselves and to draw on their knowledge of the subject and of the world in general" (Dudley-Evans \& St. John, 1998, p. 27).

Present Situation Analysis (PSA) has also been proposed as an approach to needs analysis. It identifies current issues and language use and "estimates strengths and weaknesses in language, skills, and learning experiences" (Dudley-Evans \& St. John, 1998, p. 125). Means Analysis (MA) is the last approach and includes "information about the environment in which the course will be run" (Dudley-Evans \& St. John, 1998, p. 125). MA contains information of the local situation to understand how a language course may be implemented while being sensitive to a particular cultural environment since cultural information may affect the way learners learn the L2. 
When studying the concept of needs analysis, other terms like Register Analysis, Discourse Analysis, and Genre Analysis are also described. Register analysis focuses on the grammar and vocabulary of texts (Dudley-Evans \& St. John, 1998). It refers to the idea that English of a specific subject differs from General English in terms of it lexicogrammar. Dudley-Evans and St. John (1998) explained that although "grammar of scientific and technical writing does not differ from that of General English, certain grammatical and lexical forms are used much more frequently" (p. 21). The flaw of register analysis, and in particular for academic writing, is that it operates entirely at word and sentence level, restricting the analysis of texts. Since register analysis only focuses on words and sentences, attention is shifted to a level above the sentence.

Discourse analysis is an approach that investigates the cohesive links between sentences, paragraphs, and structures of texts. This approach explains how sentences are combined into discourse in order to produce meaning, with focus on the text rather than on the sentence itself. Although this approach focusses on communicative values of discourse rather than on the lexical and grammatical properties of register, it fails to consider academic and scientific contexts. Thus, an approach called genre analysis has been developed to analyze the differences between one type of text from another, with emphasis on the linguistic analysis of the language. In the genre analysis, models and descriptions of academic and scientific texts are used to enhance the ability of L2 learners to understand and to produce these texts.

All the previous approaches to needs analysis are fundamental components for assessing language needs of learners, but not a single approach can be a reliable indicator of what is needed to improve learning. Dudley-Evans and St. John (1998) suggested a 
concept of needs analysis that encompasses aspects of all the approaches, which is demonstrated in Figure 4. Their current concept of needs analysis includes:

A. professional information about the learners: the tasks and activities learners are/will be using English for - target situation analysis and objectives needs

B. personal information about learners: factors which may affect the way they learn such as previous learning experiences, cultural information, reasons for attending the course and expectations of it, attitude to English - wants, means, subjective needs

C. English language information about learners: what their current skills and language use are - present situation analysis - which allows us to assess (D)

D. the learner's lacks: the gap between (C) and (A) - lacks

E. language learning information: effective ways of learning the skills and language in (D) - learning needs

F. professional communication information about (A): knowledge of how language and skills are used in the target situation - linguistic analysis, discourse analysis, genre analysis

G. what is wanted from the course

H. information about the environment in which the course will be run - means analysis. (Dudley-Evans \& St. John, 1998, p. 125) 


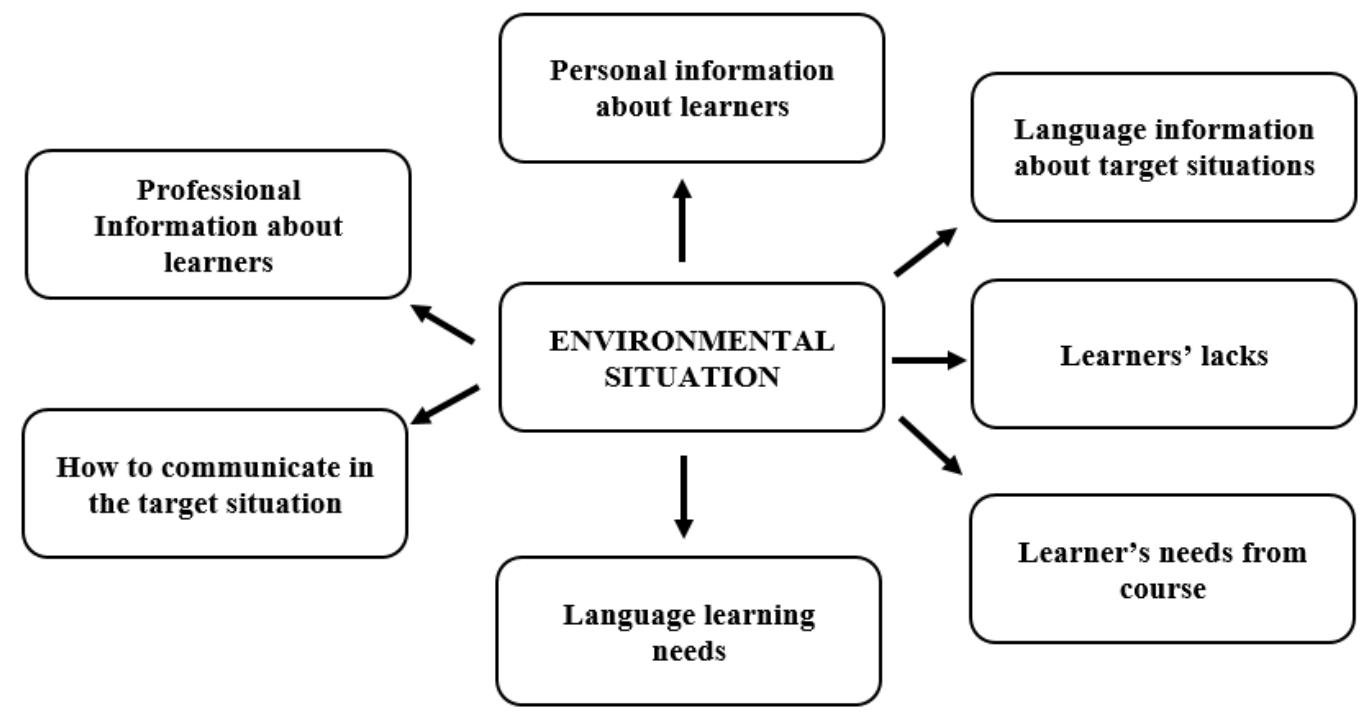

Figure 4. Current Concept of Needs Analysis (Adapted from Dudley-Evans and St. John, 1998, p. 125)

Up to now, the concept of needs analysis has included aspects of different approaches and has been defined from different perspectives by different scholars. Needs analysis has been defined as identifying learners' language needs so course design, materials development and curriculum development can be improved for specific groups of learners. Nunan (1988) stated that "techniques and procedures for collecting information to be used in syllabus design are referred to as needs analysis" (p. 13). Richards and Rodgers (1986) argued that "need analysis is concerned with identifying general and specific language needs that can be addressed in developing goals, objectives, and content in a language program" (p. 156). Brown (1995) referred to needs analysis as "the process of determining the needs for which a learner or group of learners acquire a language and arranging the needs according to priorities" (p. 35). IN a similar vein, Dudley-Evans and St. John (1998) explained that "needs analysis is the process of establishing the what and how of a course" (p. 126). For Iwai, Kondo, Lim, Ray, 
Shimizu, and Brown (1999), needs analysis refers to activities that involve the gathering of information in order to develop a systematic curriculum that meets the learning needs of a particular group of learners. Brown (2009) defined the concept of needs analysis as: the processes involved in gathering information about the needs of a particular client group in industry or education. Naturally, in educational programs, needs analyses focus on the learning needs of students, and then, once they are identified, needs are translated into learning objectives, which in turn serve as the basis for further development of teaching materials, learning activities, tests, program evaluation strategies, etc. Thus, needs analysis is the first step in curriculum development. (p. 269)

Long (2015) also stated that needs analysis "will identify which goals and communicative language needs are present in particular groups of students and thereby make the appropriate program design and delivery possible" (p. 89). He also stated that approaches to language teaching needs, relevance and accountability, and language programs as well as teaching materials and curriculum should be relevant to learners' language needs. Dudley-Evans and St. John (1998) explained:

First, needs analysis aims to know learners as people, as language users and as language learners. Second, needs analysis study also aims to know how language learning and skills learning can be maximized for a given learner group. Third, needs analysis study aims to know the target situations and learning environment so that data can appropriately be interpreted. (p. 126)

The definitions of needs analysis by the authors mentioned above are visually summarized in Table 1. 
Table 1

Summary of the Definition of Needs Analysis

\begin{tabular}{ll}
\hline Authors & NA Definition \\
\hline Nunan (1988) & To be used in syllabus design \\
Richard and Rodgers (1986) & $\begin{array}{l}\text { Identifying specific and general language } \\
\text { needs for language programs }\end{array}$ \\
Brown (1995) & $\begin{array}{l}\text { Determining the needs of a group of } \\
\text { learners according to their priorities }\end{array}$ \\
Iwai et al. (1999) & $\begin{array}{l}\text { Establishing the what and how of a course } \\
\text { Brown (2009) }\end{array}$ \\
$\begin{array}{l}\text { Gathering of information for a systematic } \\
\text { curriculum }\end{array}$ \\
$\begin{array}{l}\text { Focusing on learning needs and then } \\
\text { translated into learning objectives, } \\
\text { teaching materials, and curriculum } \\
\text { development }\end{array}$ \\
Long (2016) & $\begin{array}{l}\text { Identifying communicative language } \\
\text { needs for appropriate program design }\end{array}$ \\
\hline
\end{tabular}

Overall, needs analysis can be defined as a procedure that gathers information from learners, teachers, and language courses in order to identify learners' needs so a valid curriculum with reasonable instructional objectives can be designed, thus facilitating learning that involves tasks that meet learners' real-life needs in meaningful ways. The main purpose of needs analysis is to identify learners' current and future language needs from multiple perspectives in order to improve and define the curriculum of language programs. In addition, needs analysis allows researchers to set course objectives, determine an approach to teaching, and modify teaching techniques and materials. 
In needs analysis, it is also important to define the types of needs. While some scholars perceive needs as objective and product-oriented (Target needs - TSA), others hold the opinion that needs should include the learners' information, 'wants' and 'desires' about the target language (Learning needs - LSA). Hutchinson and Waters (1987) explained the concept of needs from both perspectives. Target needs refer to necessities, lacks, and wants of learners so they can function effectively in the target situation while learning needs refer to the learners' motivation and attitudes, expectations, reasons for learning, and learning style. They emphasized that both target needs and learning needs should be taken into consideration for suitable and efficient course design, material selection, and teaching evaluation.

Another way of distinguishing types of needs is to differentiate objective needs and subjective needs. According to Brown (1995), needs analysis allows a "systematic collection of and analysis of all subjective and objective information necessary to define and validate defensible curriculum purposes that satisfy the language learning requirements of students within the context of particular institutions that influence the learning and teaching situation" (p. 36).

Objective needs are the needs that identify the factual information of the learners through an analysis of their personal data without involving learners' personal background or viewpoint nor the use of the target language in real life. Nunan (1988) defined objective needs as "factual information which does not require the attitudes and views of the learners to be taken into account. Thus, biographical information on age, nationality, home language, etc. is said to be 'objective"' (p. 18). On the contrary, subjective needs refer to the language learning cognitive and affective needs of the 
learners. They reflect learners' perspectives of language learning and involve what and how learners like to learn another language (Dudley-Evans \& St. John, 1998). Subjective needs reflect "the perceptions, goals, and priorities of the learner. They will include, among other things, information on why the learner has undertaken to learn a second language, and the classroom tasks and activities which the learner prefers" (Nunan, 1988: 18). Nunan (1988) also explained that subjective needs also include "the preferred length and intensity of a course, the preferred learning arrangement (whether the learner wants to engage in classroom or non-classroom instruction), the preferred methodology (which will include the types of materials and activities preferred by the learner), [and] learning styles” (p. 42).

In sum, "objective needs refers to all factual information about learners, that is the biographical data such as age, sex, nationality, marital status, education background, previous language courses, current proficiency level whereas subjective needs refers to the cognitive and effective needs of learners in language learning, such as confidence, attitudes, and expectations" (Aimin \& Yan, 2012, p. 23, emphasis added). Both objective needs and subjective needs have an important role in language learning. Objective needs are the first step to begin the process of a needs analysis and form the broad parameters of a program; however, learners' language needs may be altered after learning begins, making subjective needs essential in collecting information about learners' views on priorities, preferences for learning strategies, and participation styles.

Some studies also show the importance of conducting a needs analysis in stages in order to create new data collection tools that obtain more refined and in-depth data. Data collection procedures used in needs analysis must be appropriate for the specific 
situation, be learner centered, be pragmatic, and be systematic. Brown (2009) described a model for conducting a needs analysis. He outlined three main phases: (a) getting ready to do needs analysis, (b) doing the needs analysis research, and (c) using the needs analysis results. In the first stage, Brown stated the importance of defining the purpose of the needs analysis, delimiting the student population, deciding upon approaches (direct, audiolingual, communicative, etc.) and syllabus (structural, situational, task-based, etc.), recognizing constraints, and selecting data collection procedures (questionnaires, interviews, observations, etc.). In the next stage, he showed the importance of collecting and analyzing data, as well as interpreting data. He mentioned that triangulation is a concept that can increase the credibility of the data and the interpretations of those data. The interpretation should also be seen as dependable, confirmable, credible, and transferable. In the last stage, he specified that determining learning objectives is a way of gathering the information learned in the needs analysis and including it in the actual instruction that will be delivered. Finally, evaluating and reporting on the needs analysis project are of crucial importance and need to include clear descriptions of the research methodology, participants, materials, procedures, and analyses.

It is important to point out that needs analysis is a rigorous study, in which various methodological approaches are used to collect data about the learning needs of learners. Different sources are employed, such as various expert informants (e.g., experts in a particular domain, language learners, applied linguists), while always using multiple methods (e.g., surveys, interviews) for the purpose of triangulation. This will allow the course designer, teacher and/or researcher to identify target tasks that will serve as course objectives and guide the creation of pedagogic tasks (Long, 2005, 2015). It has been 
argued by several scholars that the needs analysis plays a crucial role in the process of designing a language course as well as for the implementation, evaluation, and revision of the program. The rationale for needs analysis is that by identifying learners' language needs and using them as the basis of language instruction, instructors can provide learners with specific language needs so course content can be adjusted, and teaching activities, materials and evaluation strategies can be developed accordingly. Needs analysis provides credibility, validity, and relevancy for ESL programs (Johns, 1991).

Furthermore, a program that attempts to meet learners' language needs is more motivating and successful, helping learners with specific language needs succeed in their collegelevel content courses and future careers.

\section{Needs Analysis in L2 Writing}

Writing is an intellectual and complex activity that is not simply restricted to elements of grammar and punctuation. The ability to write well is an important component for academic achievement. However, developing skills to become an academic writer seems to be inadequate since instructional practices may not address the individual needs of the learners. Matsuda and Silva (1999) emphasized that there is a lack in providing an appropriate writing course for an increasingly diverse body of learners from linguistic, cultural and educational backgrounds at universities across the United States. Friedrich (2006) stated that "writing instruction must be customized" in order to "bring awareness to multifaceted college composition and to the potential for each student to become a competent writer" (p. 32). This is arguably an area of scholarship where needs analysis could serve academic writing; however, only a dearth of studies thus far has done so (Leki \& Carson, 1994, 1997). 
An effective way to acquire comprehensive knowledge regarding the needs of diverse learners is by carrying out a needs analysis so learners can be involved in every phase of the educational process. The advantages of conducting a needs analysis are to tailor a course according to the needs of the learners and to become aware of the challenges that these learners face in a learning environment. Recent interest in needs analysis has increased in the area of second language learning (L2). There is an urgent need for L2 courses to be relevant to the needs of specific and diverse groups of L2 learners (Long, 2015). By identifying elements of L2 learners' language needs and using them as the basis of L2 instruction, L2 learners are provided with specific language that they need to succeed in academic and workplace settings. Long (2015) argued that need analysis is important due to the increased number and diversity of L2 learners. What is needed in the learning of the L2 is a flexible approach that pays attention to the diversity of L2 learners. Therefore, the quality of the work that L2 educators need to do is crucial for the L2 learners' education, employment, and survival needs.

In English teaching and learning, needs analysis has become an important tool in developing courses and curriculum in the field of English for Specific Purposes (ESP), in which studies have shown the importance of conducting a needs analysis for curriculum development. In the subfield of English for Academic Purposes (EAP), needs analysis studies have focused on the needs of international students enrolled in English-medium institutions of higher education, with a few studies focusing on L2 learners' needs in EAP writing courses. Leki and Carson (1994) investigated students' perceptions of the relationship between ESL writing courses and writing tasks they completed in courses across disciplines. Thirty-three undergraduates enrolled either in an EAP writing course 
or in an intensive English program of first-year composition participated in their study. Results indicated that EAP writing courses were useful in dealing with other writing demands from other content courses. However, students enrolled in EAP writing courses composed personal essays rather than research or analytical style essays encountered in college-level content courses. Therefore, Leki and Carson (1994) concluded that EAP students needed to learn how to supply relevant materials, learn what to include from sources, and learn how to logically support their arguments.

From interview data collected from EAP students regarding their writing experiences, Leki and Carson (1997) stated that students enrolled in EAP writing courses did not directly interact with the text, and their compositions were based merely on their general knowledge or personal experiences. The students spent most of their time learning unnecessary lessons that were neither relevant to their academic courses, nor met their academic needs, limiting their personal and academic growth. Furthermore, writing tasks assigned to the students in the EAP writing courses did not correspond to the types of college-level writing assignments. They argued that EAP students needed to learn basic and academic writing elements that would prepare them for the types of writing they would encounter once entered in a full academic program.

Matsuda, Saenkhum, and Accardi (2013), on the contrary, analyzed teachers' perceptions of L2 students' writing needs. They investigated writing teachers' perceptions of the needs of L2 students by distributing an online perception survey to 74 teachers from a writing program at a large public university in the Southwestern United States. The findings revealed that some teachers recognized the writing needs of their L2 students, but others did not make any special provisions in their classroom to 
address the L2 students' unique needs. Their study also suggested different reasons for the writing teachers' inability to address the specific needs of L2 students. They specified that L2 students' needs were constrained by program policies, the need for more time and attention on the part of the teachers, the limitation of professional preparation, and the lack of instructional materials that are suitable for L2 writers (Matsuda et al., 2013). By understanding teachers' perceptions of L2 learners' writing needs, the impact of L2 writing research in instructional contexts can be assessed, and the professional development needs of writing teachers can be identified. It is important that teachers be aware of L2 learners' needs and be better prepared to address them by developing instructional practices that are sensitive to the linguistic and cultural needs of L2 learners.

It is not clear how successful researchers have been in determining current and future writing needs in L2 writing courses and how L2 learners use what is learned in L2 writing courses across the curriculum. Unfortunately, there have been few studies that examine faculty members' perceptions and viewpoints of L2 learners' writing needs. Attempts to conduct a needs analysis in L2 writing courses have come primarily from student surveys and from surveys of college and university faculty members with limited expertise in research methods with the learners as the primary respondents (Leki and Carson, 1997; Long, 2015). Since writing activities may have different values in various social, cultural, and educational settings, it is necessary to conduct a study with semistructured interviews from different respondents; thus, L2 teachers and researchers can understand ways to address the writing needs of L2 learners from culturally and linguistically diverse backgrounds. The knowledge about writing, how L2 learners are taught, and how they use writing can also help identify their writing needs and prepare 
them for language and social skills. In addition, writing instruction in L2 writing courses has the assumption that what is taught and learned in these courses would help L2 learners develop the necessary writing skills to complete academic writing assignments and succeed in academic college-level content courses.

\section{Attitudes and Writing Needs in L2 Context}

Attitudes are positive or negative feelings that learners have about language learning and acquisition. Having beliefs that support positive feelings about the target language can lead to learning success. In addition, the success in learning a second language is influenced by attitudes toward the community of speakers of that language. Studies on attitudes have postulated that learners with high sense of attitude tend to approach difficult tasks with confidence while learners with low sense of attitude tend to avoid these tasks. Attitude is also an important factor that leads to success in L2 writing. Negative attitude toward writing has been connected to L2 learners' poor performance. If L2 learners do not feel self-assured about their written production, the written product may be poor. However, L2 learners with positive feelings regarding writing may be more interested in completing a writing task. Positive attitude is crucial for the learning of L2 writing since it has a positive effect on L2 learners' writing process and increases their writing performance. Furthermore, L2 learners' attitudes toward writing can be influenced by their linguistic and sociocultural environments.

In order to help L2 learners succeed in their writing classes, researchers and educators need to understand not only their attitudes toward writing but also their writing needs. Needs analysis allows L2 learners to voice their needs and educators to understand the background of L2 learners' attitudes toward writing. However, "[the] findings from a 
needs analysis are not absolute but relative and there is no single, unique set of needs. The findings depend on who asks what questions and how the responses are interpreted. What we ask and how we interpret are dependent on a particular view of the world, on attitudes and values” (Dudley-Evans \& St. John, 1998, p. 26). Different studies have examined L2 learners' writing needs and their attitudes towards writing.

Cai (2013) investigated students' perspectives and attitudes towards academic writing in a new EAP program at a university in South China. The small-scaled needs analysis reported on a survey of 50 students and on a focus group interview with a smaller group. Results showed that most of the students had never taken an academic writing course before and that academic writing skills, such as reviewing and critiquing, were challenging. In addition, Cai (2013) concluded that students wished to be enrolled in a course that provided them with generic features and linguistic resources for properly writing academic papers. Giridharan (2012) also conducted a study on academic writing in order to explore critical gaps in academic writing among ESL students at university level. She employed four criteria for developing good academic writing skills, such as attitudes toward academic writing tasks, planning, writing paragraphs and essays, and evaluation of one's own writing. She examined ESL students' challenges in academic writing and identified grammatical, structural and syntactic errors made in writing tasks. Students showed positive attitudes toward the writing tasks. They enjoyed practicing the writing tasks, drafting essays, and working with peers, but they were unable to evaluate their own work.

Ismail, Hussin, and Darus (2012) also investigated L2 students' writing attitudes, learning problems, and learning needs faced in English writing courses. Participants were 
60 students enrolled in a writing course and four writing instructors. Students were given a needs analysis questionnaire while instructors were interviewed in order to explore useful elements to be considered in an online writing program. Results showed that students had negative attitudes toward writing and perceived writing as difficult due to the lack of practice time allocated in class, dull writing activities, and lack of emphasis in critical thinking. The authors then suggested that L2 students' writing needs be identified in order to improve writing courses and enhance students' writing interests. Xiao (2006), on the other hand, examined the learning needs and preferences of Chinese students in a composition course and found that students had positive attitudes toward academic writing. In addition, she analyzed their attitudes toward teaching approaches, the learning of culture, authority in class, language learning strategies, and problems encountered in composition courses. Results from a questionnaire survey revealed that students had favorable attitudes toward communicative activities in the classroom and learning the target culture. The aforementioned studies revealed some prominent problems affecting L2 learners' performance. L2 learners had language difficulties and possessed negative attitudes toward their writing. Additionally, it was determined that L2 learners were discouraged and did not participate actively in their writing practices because they were mainly superficial and did not represent their writing needs. Therefore, the way learners feel and react to their writing practices determine the quality of their writing composition (Chuo, 2007).

\section{The Present Study}

The emphasis on effective writing instruction for the development of writing competencies has increased in recent years. However, L2 writing research has 
concentrated on issues related to the teaching of writing and learning strategies in general rather than on L2 learners' real-world writing needs in higher education (Leki, 1995). The concept of needs expands to sociocultural factors that represent diverse L2 learners coming from culturally and linguistically diverse backgrounds. The present study addressed key gaps in the literature by focusing on the writing needs, attitudes, diversity, and sociocultural aspects of learning academic writing. By providing insights into EAP learners' diverse backgrounds and writing needs in postsecondary education, this study aimed to strengthen the impact of EAP courses so that EAP learners can be better prepared for post-secondary education. To fill this lacuna in the literature, this study aimed to answer the following research questions:

1. How diverse are EAP learners across three Southeastern state colleges?

2. What are the real-world writing tasks currently being taught in the advanced EAP composition course?

3. How do both EAP learners and EAP faculty members perceive the real-world writing tasks currently taught in the advanced EAP composition course?

4. What are the real-world writing tasks that EAP learners need to complete across disciplines, and are they aligned with those taught in the advanced EAP composition course?

The research questions were developed from the conceptual framework formulated by integrating the theoretical frameworks of the needs analysis models; the cognitive, affective and behavioral aspects of attitude, and diversity, taking into consideration the sociocultural aspects of learning writing. Figure 5 demonstrates the research questions aligned with the conceptual framework. 
How diverse are EAP learners across three Southeastern State Colleges?

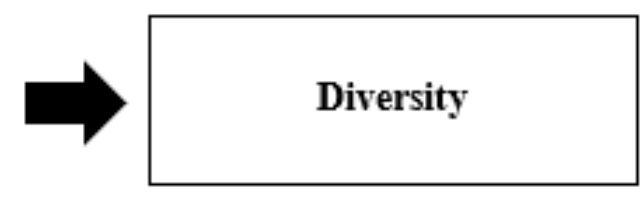

What are the real-world writing tasks currently being taught in the advanced EAP composition course?

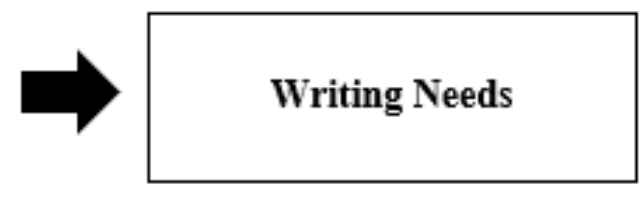

How do both EAP learners and EAP faculty members perceive the realworld writing tasks currently taught in the advanced EAP composition course?

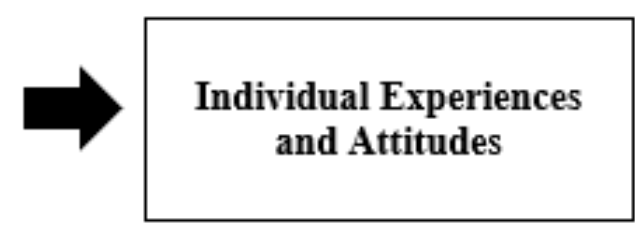

What are the real-world writing tasks that EAP learners need to complete across disciplines, and are they aligned with those taught in the advanced EAP composition course?

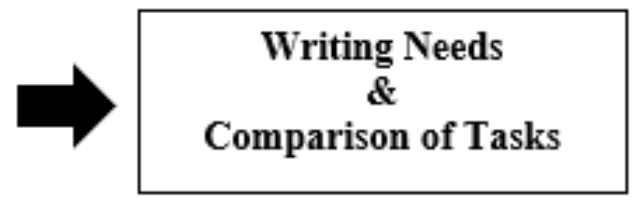

Figure 5. Research Questions Aligned with the Conceptual Framework 


\section{CHAPTER III \\ METHODOLOGY}

This chapter provides an overview of the methodology employed in this study and a framework that describes the research plan. The chapter begins with the rationale for the design of the study, followed by the settings and description of the advanced EAP composition course and the procedure used to conduct this needs analysis. The study proceeds to an explanation about the participants, methods of data collection, and data analysis in order address each research question. Advances to validity and reliability in relation to quantitative data collection methods are then discussed, as are the integrity procedures employed to enhance the trustworthiness and credibility of the study. The chapter concludes with a detailed description of the role of the researcher and a discussion on ethical considerations.

\section{Research Design}

The present study included a needs analysis that identified the real-world writing tasks that diverse EAP learners were required to complete in academic contexts, as well as EAP faculty members' and EAP learners' experiences and attitudes toward academic writing. Via diverse sources and methods, the study adopted qualitative and quantitative forms of analysis. The purpose of the qualitative approach is to inductively understand a social phenomenon and interpret how students perceive their lives and interact with others in natural settings. According to Creswell (2008), qualitative study is "An inquiry process of understanding a social or human problem based on building a complex, holistic picture, forming words, reporting detailed views of informants, and conducting the study in a natural setting" (p. 1). 
The qualitative design is used to explore and understand the depth inherent of a phenomenon from research participants' perspectives (Palinkas, Aarons, Horwitz, Chamberlain, Hurlburt, \& Landsverk, 2011; Palinkas, Sarah, Horwitz, Green, Wisdom, Duan, \& Hoagwood, 2015). "Qualitative research includes a variety of methodological approaches with different disciplinary origins and tools" (Lingard, Albert, \& Levinson, 2008 , p. 459) in order to gather an in-depth understanding of a complex issue in its reallife context. To understand the meaning that participants ascribe to their experiences, a phenomenological approach was selected to address the research questions. Phenomenology focuses on understanding the social, cultural, and psychological phenomena from the perspectives and experiences of participants (Creswell, 2008; Patton, 2015). "It is a particular way of doing science: doing qualitative research by substituting individual descriptions for statistical correlations and interpretations resulting from the experiences lived for causal connections" (Sadala \& Adorno, 2001, p. 283). Therefore, the phenomenological approach was the most suitable for the present study since it could help us understand the experiences and attitudes of EAP faculty members and EAP learners regarding the academic writing needs of EAP learners enrolled in the advanced EAP composition course. Knowing the possible best writing practices and techniques could eventually help identify EAP learners' academic writing needs that may produce high attitudes toward learning academic writing.

While the qualitative method is intended to achieve the depth of understanding, the quantitative method is intended to achieve breadth of understanding (Etikan, Musa, \& Alkassim, 2015). Quantitative is an inquiry of social and human problems "based on testing a theory composed of variables, measured with numbers, and analyzed with 
statistical procedures, in order to determine whether the predictive generalizations of the theory hold true" (Creswell, 2008, p. 2). The quantitative approach is concerned with collecting and analyzing data that can be represented statistically, measured, and quantified. "Researchers measure, evaluate, and generalize the findings to a population and encourage replication of the findings" (Park \& Park, 2016, p. 4). Additionally, quantitative research is used to make causal inferences, test theories, and confirm hypotheses in order to achieve the research goal, seek valid and reliable results, and strive to identify specific variables (Guetterman, Fetters, \& Creswel, 2015; Palinkas et al., 2015). Therefore, "quantitative design strives to control for bias so that facts, instances, and phenomena can be understood in an objective way" (Park \& Park, 2016, p. 4). By understanding that both qualitative and quantitative approaches have their own shortcomings, using elements from both methods provides a better understanding of the research issues. In addition, the quality of the study is improved by minimizing biases and limitations, yielding more credible results to ensure that "the data converge or triangulate to produce greater insight than a single method could" (Palinkas et al., 2015, p. 460).

To ensure richness of data, triangulation was implemented by using multiple methods of data collection which included semi-structured interviews, short online learner surveys, and an analysis of written documents. Semi-structured interviews were used to explore the writing tasks taught in the advanced EAP composition course and understand the experiences and attitudes of both EAP faculty members and EAP learners toward these tasks. The interviews were conducted with 13 participants from three Southeastern state colleges and collected over a 6-month period during Fall 2018 and 
Spring 2019 semesters. Each interview lasted an average of 60 minutes. They were recorded and fully transcribed for analysis. The interviews were designed with the intention of giving voice to EAP faculty members and EAP learners who provided extensive details about the writing tasks and their experiences and attitudes.

The study also entailed a short online learner survey that was developed to unveil the diverse population among EAP learners, identify the writing tasks currently being taught in the advanced EAP composition course, and explore EAP learners' experiences and attitudes toward the writing tasks. The survey was administered to a population of 169 EAP learners currently enrolled in the advanced EAP composition course from EAP programs in three Southeastern state colleges. Participants completed the survey that included demographic and background items and six open-ended questions regarding the content of the course and their perceptions. The learner survey was administered over a period of nine months during Spring 2019, Summer 2019, and Fall 2019 semesters. Participants took approximately 10 to 15 minutes to complete the survey, which was completely anonymous. The learner survey was selected to describe characteristics of a large and diverse population and to gather valid and accurate data.

Finally, the study incorporated an analysis of written documents in order to identify the writing tasks that EAP learners were currently being taught in the advanced EAP composition course, as well as the real content-level writing tasks EAP learners would need to complete across different majors. The purpose for implementing the document analysis in the study was to understand whether the current EAP course writing tasks were aligned with the real content-level writing tasks completed in different disciplines. Faculty members from the EAP programs and from several disciplinary 
courses across all three Southeastern institutions under study were invited via email to share samples of their course assignments, assessments, rubrics, and syllabi. A total of 51 written documents were shared by 18 EAP faculty members. These materials were comprised of syllabi, course schedules, essay and research instructions, rubrics, outline templates, and editing guidelines. Disciplinary instructors from varied departments also shared a total of 393 course documents, which included syllabi, course assignments, and handouts. The academic areas of study included architecture and interior design; English and literature; music, theater, arts and philosophy; business; criminal justice; mathematics and statistics; physics; computer science; psychology; political science; and history. Course materials for the document analysis were requested during Fall 2019.

Via diverse sources and methods, this study implemented triangulation of data in order to address four research questions. Research question one (RQ1) uncovered the diverse population of EAP learners currently enrolled in the advanced EAP composition course. The short online learner survey was the instrument used to unveil the diverse population among EAP learners. A chi-square test was used to determine the significant differences in diversity among EAP learners across the three Southeastern institutions. For research question two (RQ2), interviews, learner surveys and written documents were employed in order to identify the real-world writing tasks currently being taught in the EAP composition course. Regarding research question three (RQ3), the interviews and learner surveys were used to explore how EAP faculty members and EAP learners perceived the writing tasks performed in the advanced EAP composition course, prioritizing their experiences and attitudes. Finally, documents analysis was the method used to address research question four (RQ4). RQ4 investigated the writing tasks 
performed across diverse disciplinary courses and whether the writing tasks currently taught in the advanced EAP composition course were aligned with those taught across disciplines.

\section{Setting and Course Description}

To maximize the representation of the study, three large Southeastern state colleges in the United States were the focal institutions of the study. The academic deans from the EAP departments in each institution were contacted by email and provided a summary of the study. IRB documentation was then submitted under study for human subject approval to conduct a study on behalf of Florida International University (FIU). All three institutions granted permission for data collection and approval from the Institutional Review Board at FIU was obtained to begin the study.

The three post-secondary institutions were classified as College A, College B, and College $\mathrm{C}$ for the purpose of this study. By including institutions with different geographic characteristics, it was expected that a more complete picture of the topic of interest could be obtained. The inquiry began by selecting these institutions due to their advanced EAP composition course offered by their EAP program to a large and diverse L2 student population that was available and willing to participate in the study. According to the course catalogs from the three institutions, the advanced EAP composition course aims to help EAP learners improve their academic skills for coursework, as well as prepare them for written communication at the university level and in their professional career. EAP learners are also provided intensive practice to develop the ability to write a variety of college-level assignments with fluency and accuracy while developing writing skills and strategies. The advanced EAP composition 
course was selected because it seemed important to identify its present issues with the curriculum, teaching materials, and learning activities since this is a credit-bearing course that EAP learners need to complete before enrolling in courses offered during the first year of college. An analysis was used to accommodate the needs of EAP learners for better development of instructional practices and improvement of performance.

In addition, the advanced EAP composition course could enhance the study due to its inclusion of a variety of L2 learners with a large range of diverse backgrounds. Results from this study could be shared with other EAP faculty members who are part of the EAP programs and teach advanced academic composition courses. Table 2 describes an overview of the writing competencies used in the advanced EAP composition course in all three institutions.

Table 2

Overview of the EAP Writing Competencies

\begin{tabular}{|c|c|}
\hline Essay Development & The Writing Process \\
\hline $\begin{array}{l}\text { 1. Write appropriate thesis statements } \\
\text { 2. Write appropriate topic sentences with } \\
\text { relevant supporting details } \\
\text { 3. Use appropriate and logical patterns of } \\
\text { organizations } \\
\text { 4. Use effective introductory paragraph, } \\
\text { supporting paragraphs, and concluding } \\
\text { paragraph }\end{array}$ & $\begin{array}{l}\text { 1. Generate ideas through brainstorming, } \\
\text { clustering, listening, or free writing } \\
\text { 2. Develop an outline prior to writing the } \\
\text { first draft } \\
\text { 3. Edit and revise the final draft }\end{array}$ \\
\hline Introduction to Research & Effective Use of Editing \\
\hline $\begin{array}{l}\text { 1. Distinguish between direct quotes and } \\
\text { paraphrasing } \\
\text { 2. Synthesize information from various } \\
\text { sources } \\
\text { 3. Cite appropriately credible sources } \\
\text { from a variety of sources } \\
\text { 4. Distinguish between cited materials and } \\
\text { plagiarism }\end{array}$ & $\begin{array}{l}\text { 1. Apply grammatical concepts to } \\
\text { compositions } \\
\text { 2. Use varied sentence structures } \\
\text { 3. Master punctuation, capitalization, and } \\
\text { spelling } \\
\text { 4. Use complete sentences free of run-ons, } \\
\text { comma splices, and fragment errors } \\
\text { 5. Understand purpose, audience, clarity, } \\
\text { unity, and coherence }\end{array}$ \\
\hline
\end{tabular}




\section{Timeline of the Study}

The study design was divided into three phases. Phase I was conducted prior to data collection for the purpose of first determining the research instruments and the credibility and reliability of these research instruments. Phase I began with the development of the interview questions so that an interview protocol could be generated. In order to identify the credibility of the interview questions, an expert panel was conducted. The expert panel included two EAP faculty members with experience teaching the advanced EAP composition course and one expert in qualitative design. The purpose of the expert panel was to refine the interview questions and modify the interview protocol. Survey questions were also developed in phase I. For validity and reliability, the survey questions were evaluated during a cognitive interview with three EAP faculty members with experience teaching the advanced EAP composition course and one expert in quantitative design. The survey questions were refined, and a final measurement was determined.

Data collection and analysis were completed in phases II, III, and IV. Phase II consisted of the collection of data from semi-structured interviews. EAP faculty members with experience teaching the advanced EAP composition course, EAP learners currently enrolled in the advanced EAP composition course, and former EAP learners who previously completed the course participated in phase II. Responses were transcribed and analyzed. Phase III included a short online learner survey that was distributed to EAP learners currently enrolled in the advanced EAP composition course and analyzed using Chi-square and content analysis. Lastly, phase IV included the collection and analysis of course documents shared by faculty members from the EAP programs and across 
disciplines. A detailed description of the needs analysis process is illustrated under Procedure of the Needs Analysis. Figure 6 represents the phases of the research design illustrated in a timeline.
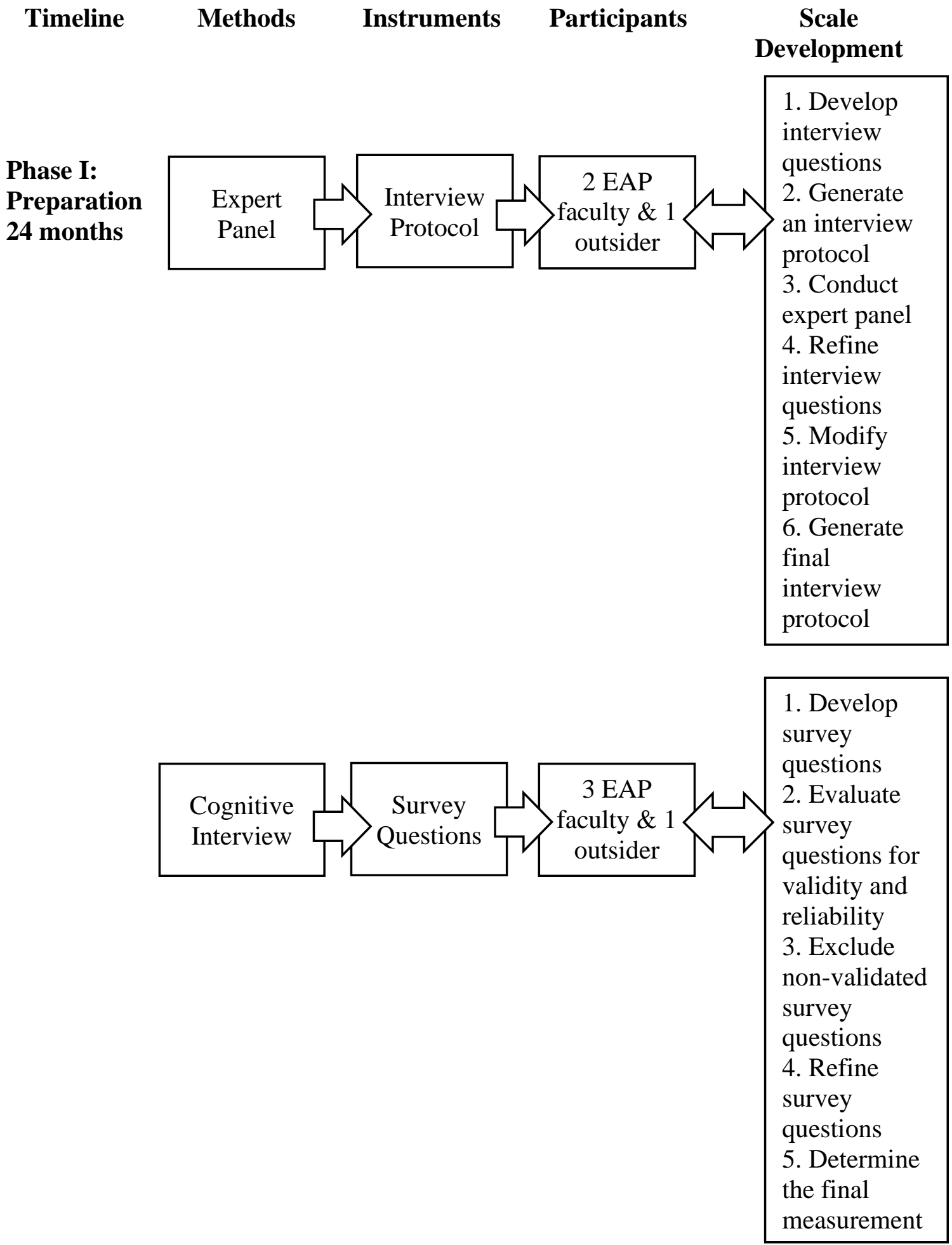
Timeline Study Phase Methods Participants
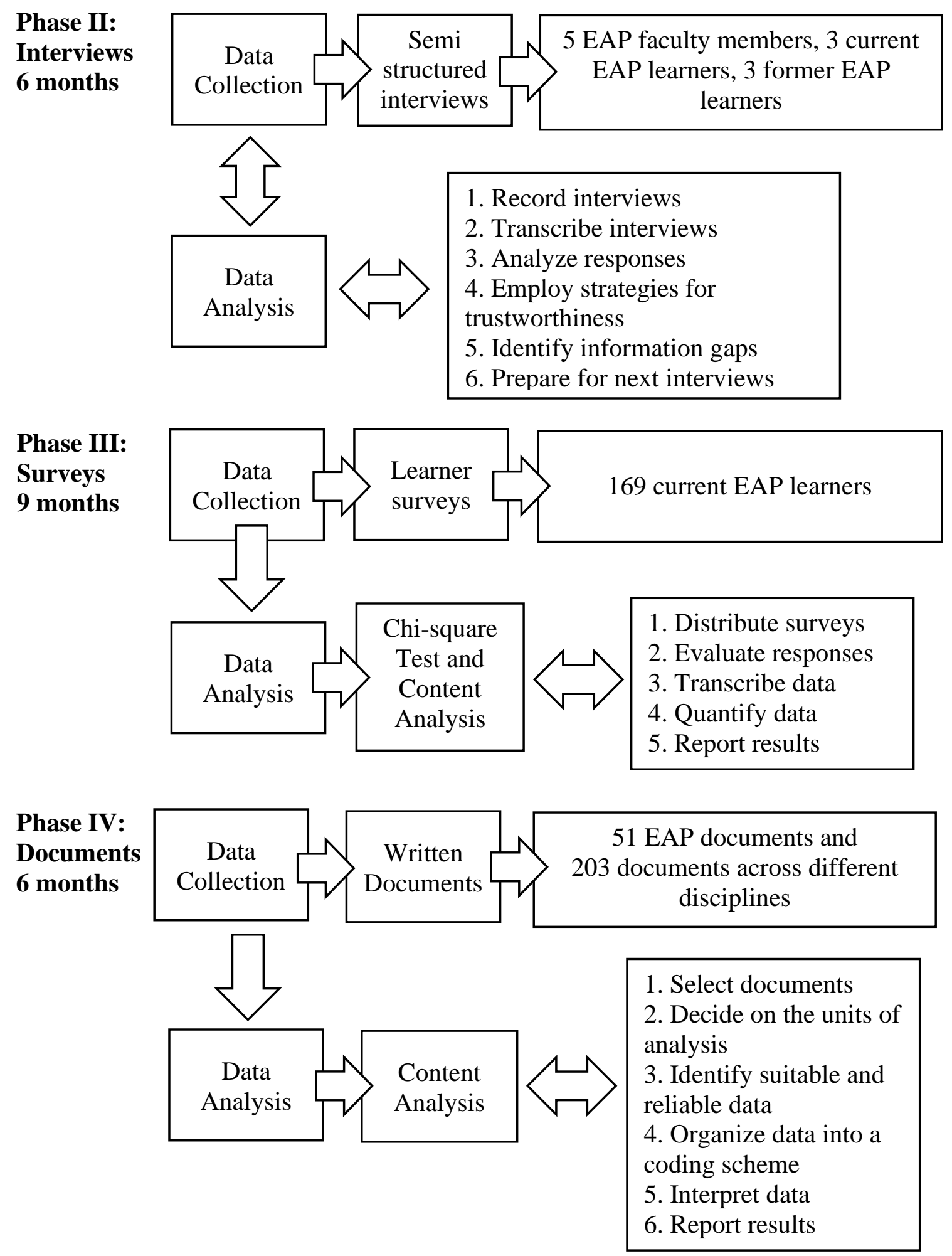

Figure 6. Timeline of the Research Design 


\section{Procedure of the Needs Analysis}

To conduct the needs analysis, data were gathered via sources of information, methods of collecting that information, and triangulation of data obtained from several sources via multiple methods. Long (2015) argued that triangulation is a process that involves the use of multiple data collection methods and sources with the attempt to validate data and contribute to the trustworthiness of the data and credibility of the interpretations. Following Long's (2015) recommendations, the procedure to carry out this needs analysis was divided into steps with the eventual goal of informing the design of the advanced EAP composition course. Figure 7 illustrates the procedure used for this needs analysis.

\begin{tabular}{|c|c|}
\hline Step 1 & Identify the problem \\
\hline Step 2 & $\begin{array}{l}\text { Conduct semi-structured interviews with a sample of domain } \\
\text { experts and EAP learners }\end{array}$ \\
\hline Step 2A & $\begin{array}{l}\text { Conduct an expert panel for trustworthiness and } \\
\text { credibility of the research instrument }\end{array}$ \\
\hline Step 3 & Analyze interview responses \\
\hline Step 4 & $\begin{array}{l}\text { Distribute learner survey to EAP learners currently enrolled } \\
\text { in the advanced EAP composition course }\end{array}$ \\
\hline Step 4A & Conduct cognitive interview \\
\hline Step 5 & Analyze and quantify survey responses \\
\hline Step 6 & $\begin{array}{l}\text { Collect written documents from EAP and disciplinary } \\
\text { faculty members }\end{array}$ \\
\hline Step 7 & Analyze the findings from the written documents \\
\hline Step 8 & Triangulate findings by sources and methods \\
\hline
\end{tabular}

Figure 7. Procedure of the Needs Analysis 
Before conducting the needs analysis, the research problem was identified in Step 1. Needs analysis has been conducted mainly for communicative purposes rather than for the writing needs of EAP learners from culturally and linguistically diverse backgrounds (Carroll \& Dunkelblau, 2011). Practices in EAP writing courses do not always match the writing demands that EAP learners need to address in disciplinary courses (Leki \& Carson 1997; Grabe, 2001; Carroll \& Dunkelblau, 2011). In addition, the writing needs of EAP learners enrolled in the three Southeastern institutions under study have never been identified. Therefore, the EAP curriculum does not reflect the writing requirements of the college-level content courses.

Step 2 included an open procedure to begin to identify the writing needs of EAP learners. The aim was to identify a comprehensive list of the academic writing tasks using participants' experiences and attitudes about the tasks currently taught in the advanced EAP composition course. Semi-structured interviews were conducted and recorded with a sample of domain experts and EAP learners. Prior to data collection, an expert panel was formed to identify reliable interview questions, obtain insider feedback, and determine the trustworthiness of the research instrument to further confirm credibility. In addition, the expert panel was incorporated to assess the effectiveness of the interview questions in order to avoid the researcher's perspectives and opinions and reduce bias. After the evaluation by the group of experts, a final list of three main questions and several sub-questions was included in an interview protocol. A detailed description of the expert panel process is demonstrated in Data Collection.

During Step 3, interviews were transcribed, and interview responses were analyzed in order to categorize EAP learners' writing needs into target tasks and target 
task types. At the end of step 3, data were also gathered to better understand participants' experiences and attitudes about the writing tasks that EAP learners were required to perform in the advanced EAP composition course.

Step 4 included a short online learner survey with the aim of identifying the writing tasks and exploring EAP learners' attitudes about these tasks. The survey inquired about demographic and background information and included six open-ended questions that generated a list of writing tasks and barriers to accomplishing those tasks. Before the survey was administered, the use of a cognitive interview was administered in order to further confirm credibility. The cognitive interview was incorporated to assess the effectiveness of the survey questions in order to avoid the researcher's perspectives and opinions, improve the data collection instrument, and reduce bias. A detailed description of the cognitive interview process is illustrated in Data Collection.

Step 5 involved the analysis of the survey responses. Comments from the openended questions were coded into themes and then categories. The collection of written documents was completed in Step 6. Faculty members from the EAP programs and from other disciplinary courses were asked to share the syllabi and writing materials used in their courses. During the analysis of the shared documents, Step 7 examined the tasks frequently completed in the advanced EAP composition course and those completed in disciplinary courses so that a comparison could reveal whether the tasks currently being taught in the advanced EAP composition course were aligned with those being taught across different disciplines. Step 8 triangulated the data via the multiple sources and methods used in this study. A final list of core writing tasks was developed to summarize the writing needs of EAP learners. 


\section{Sampling}

Sampling means a subset of a population that should be determined largely by the research question. There are two types of sampling methods: probability and non-probability. Probability sampling refers to "select a large number of individuals who are representative of the population or who represent a segment of the population (Creswell \& Plano Clark, 2007, p. 174). Moreover, participants are randomly selected, indicating that individuals have equal opportunity to be selected as a representative sample. On the other hand, non-probability sampling is "a sampling technique where the samples are gathered in a process that does not give all the participants or units in the population equal chances of being included" (Etikan et al., 2016, p. 1). Additionally, nonprobability sampling involves selecting individuals who are available and can be selected (Creswell \& Plano Clark, 2007).

To maximize efficiency and validity, a sampling method should originate from the theoretical framework, draw clear inferences and credible explanations from the data, be ethical, and transfer conclusions to other settings or populations (Palinkas et al., 2015). Purposeful sampling was the method implemented in the study. Purposeful sampling is a non-probability sampling method used in qualitative research to identify and select subjects or groups of subjects with knowledge and experience about a phenomenon of interest. Patton's (2002) description of purposeful sampling strategies was the starting point in deciding the sampling strategy applied in the present study. According to Patton (2002), a sampling strategy should be credible, efficient and ethical, and focus on a particular group of interest so the research problem and research questions can be addressed. Purposeful sampling was selected, using the purposive sampling strategy, as 
this technique aligned with the conceptual framework and research questions. Purposive sampling is a sampling strategy whose population shares similar characteristics or traits. "Purposive sampling is a nonrandom sampling technique in which the researcher solicits persons with specific characteristics to participate in a research study" (Johnson \& Christensen, 2014).

Researchers identify and recruit a small number of participants that provide indepth information about the central phenomenon or concept being explored in the study (Creswell \& Plano Clark, 2007). Additionally, the idea is not to generalize from the sample but to develop an in-depth understanding of the small sample, so more details can be gathered from each individual (Creswell \& Plano Clark, 2007). Therefore, particular groups can be described and in-depth knowledge on the issue central to the purpose of the study can be acquired. The rationale for using the purposive sampling strategy in the current study was to interview participants with knowledge about and experience with the field of study, ensuring that they met the specific criteria for being in the sample.

To produce generalizable results, sampling is also a process of selecting a group of people that represents the population, so results can be generalized to that population. According to Johnson and Christensen (2014), "the main purpose of sampling in quantitative research is to enable the researcher to make accurate generalizations about a population using sample data" (p. 249). In order to reduce sampling error and ensure appropriate sample size, a sufficiently large sample is needed for meaningful statistical tests (Creswell \& Plano-Clark, 2011).

The most appropriate sampling technique for the quantitative portion of the study was also the non-probability purposive sampling. Purposive sampling was selected 
because of certain characteristics represented in the sample and the objective of the study. Although non-probability sampling tends to less likely produce representative sample and provide equal chance to be included, the criteria for using this technique is that EAP learners enrolled in the advanced EAP composition course represented multiple groups with distinct writing needs and attitudes and from diverse backgrounds, including different cultural perspectives, ethnicities, educational levels, socioeconomic status, age groups, and abilities. Therefore, they could represent the diverse sample population under study. Review of sampling for each instrument is explained below.

\section{Semi-Structured Interviews}

Data were collected with two sets of groups to fulfill the goal of the study. The first set of participants was a sample of seven EAP faculty members with more than ten years of experience teaching the advanced EAP composition course. They were interviewed to understand their viewpoints and perceptions of the writing tasks taught in the advanced EAP composition course so that information could be gained from qualified and knowledgeable experts in the field. The rationale for interviewing these academic writing experts was to acquire knowledge beyond the literature review and to understand the point of view of those with extensive teaching experience and mastery of the subject and target language. The second set of participants was a sample of three EAP learners currently enrolled in the advanced EAP composition course and three former EAP learners who previously completed the course. They were also interviewed in order to investigate their viewpoints and experiences about the writing tasks taught in the advanced EAP composition course. This was for the purpose of identifying actual writing 
tasks performed in the advanced EAP composition course and to explore their experiences and attitudes toward the course under study.

For phenomenological studies, Creswell (1998) recommends 5 to 25 informants while Morse (1994) suggests a minimum of six participants. These suggestions can help estimate how many participants are needed; however, the required number of participants in the current study was achieved when data saturation was reached. According to Bogdan and Biklen (2007) "data saturation refers to a singular point in the research that occurs when the information gained from data collection becomes repetitive or redundant" (p. 69). The primary goal for selecting these participants was to understand their perceptions of the writing tasks taught in the advanced EAP composition course. Academic deans from all three institutions were contacted and asked for a list of EAP faculty members with experience teaching the composition course. Regarding the recruitment of EAP learners, EAP instructors shared a list with some of their EAP learners who would be interested in participating in the study. All participants were contacted by email and invited to participate in the study. Recruitment was voluntary. The following tables provide an overview of the participants.

Table 3

Description of EAP Faculty Members

\begin{tabular}{ccccc}
\hline Code & College & Gender & Age & Ethnicity \\
\hline 1 & A & Female & $50+$ & White \\
2 & A & Female & $50+$ & Hispanic \\
3 & A & Female & $50+$ & Haitian \\
4 & B & Male & $50+$ & White \\
5 & B & Female & $40+$ & Hispanic \\
6 & C & Female & $40+$ & Russian \\
7 & C & Female & $40+$ & White \\
\hline
\end{tabular}


Table 4

Description of Current EAP Learners

\begin{tabular}{cclll}
\hline Code & College & Gender & Age & Ethnicity \\
\hline 8 & A & Female & $30+$ & Hispanic \\
9 & B & Female & $20+$ & Hispanic \\
10 & C & Female & $30+$ & Brazilian \\
\hline
\end{tabular}

Table 5

Description of Former EAP Learners

\begin{tabular}{ccccc}
\hline Code & College & Gender & Age & Ethnicity \\
\hline 11 & A & Male & $20+$ & Brazilian \\
12 & B & Female & $30+$ & Hispanic \\
13 & C & Female & $30+$ & Brazilian \\
\hline
\end{tabular}

\section{Learner Survey}

Short-survey data were collected from 169 EAP learners currently enrolled in the advanced EAP composition course in three Southeastern institutions in the United States. The sample was purposive with the goal of selecting a group of EAP learners who could represent a sample and make informed predictions (Patton, 2002) about their writing needs. The rationale for using purposive sampling was to identify the writing tasks diverse EAP learners needed to perform in the advanced EAP composition course, as well as their perceptions about completing these tasks. Participants also provided their attitudes about completing these tasks.

Prior to data collection of the learner survey, EAP faculty members were introduced to the study and invited to share the online link of the survey with their students. EAP learners were targeted particularly because of their willingness to participate in the study and knowledge of the issues under investigation. They 
represented multiple groups with distinct writing needs and from diverse backgrounds, including different cultural perspectives, ethnicities, educational levels, socioeconomic status, age groups, and abilities. Their writing needs, attitudes, diversity, and sociocultural aspects of learning writing are aligned with the conceptual framework of the study.

\section{Written Documents}

Data were also gathered through faculty members from the EAP programs and from diverse disciplinary courses from all three Southeastern institutions under study. A list of faculty members was provided by the academic deans and chairs. The list included faculty members from the EAP programs and from varied disciplines across the three institutions. The total population included 51 EAP faculty members with experience teaching the advanced EAP composition course and 1960 faculty members across different disciplines. College A consisted of 14 EAP faculty members and 1073 disciplinary faculty members while College B included nine EAP faculty members and 673 faculty members across diverse majors. College C comprised of seven EAP faculty members and 217 faculty members from disciplinary courses.

The academic areas of study included architecture and interior design; English and literature; music, theater, arts and philosophy; business; criminal justice; mathematics and statistics; physics; computer science; psychology; political science; and history. The selection of the academic areas was based upon the similarity of the courses offered in each institution. If an academic area was not offered in all three institutions, then it was not included in the study. 
The rationale for using document analysis was to identify the writing tasks that EAP learners were currently being taught in the advanced EAP composition course, as well as the real content-level writing tasks EAP learners needed to complete across different majors. This was for the purpose of understanding whether the current EAP writing tasks were aligned with the content-level writing tasks taught across disciplinary courses. After review, written documents from 18 EAP faculty members and 203 disciplinary faculty members from 11 academic areas of study were selected based on the content and quality of the documents, given the purpose and design of the study.

\section{Data Collection}

The study employed three data collection methods with the purpose of conducting a needs analysis in order to identify the real-world writing tasks that diverse EAP learners were required to perform in academic contexts. Via diverse sources and methods, data were collected using semi-structured interviews, short online learner surveys, and an analysis of written documents. The research instruments were developed using a comprehensive framework for needs analysis suggested by Dudley-Evans and St. John (1998). Their current concept of needs analysis includes present situation analysis (PSA), learning situation analysis (LSA), and target situation analysis (TSA) along with the subcategories: necessities, wants, and lacks.

PSA was first used to identify the writing tasks being currently taught in the advanced EAP composition course. LSA was included to explore EAP learners' attitudes toward these writing tasks. Finally, TSA was incorporated to better understand the writing tasks that would be required of EAP learners once they leave the EAP program. A final analysis revealed what EAP learners would need to complete in order to effectively 
function in the target situation (necessities), what they feel they need (wants), and the gap between what they learn in the advanced EAP composition course and what would be expected of them in college-level content courses.

\section{Semi-structured Interviews}

The primary focus of the interviews was to identify the writing tasks EAP learners were required to complete in the advanced EAP composition course, as well as understand participants' experiences and attitudes about the academic writing tasks. Data collection consisted of in-depth interviews that were purposefully semi-structured. Interviews allow for in-depth cross-examination of results to understand participants' background knowledge and meet specific research needs. It is a method of data collection that has been stressed in the literature of needs analysis (Brown, 1995; Long, 2005). After revision of the semi-structured interviews conducted in previous studies, the interviews questions were adapted from Cai (2013) and lizuka (2019), concerning needs analysis, as well as Graham, Berninger, and Fan (2007) and Zhu (2004), regarding attitudes about academic writing. Figure 8 demonstrates the interview questions aligned with the research questions.

The interviews were also conducted with an interview protocol, an important tool that allows the interviewer to pose questions relevant to the topic of interest. Having a protocol not only helps keep researchers organized, but also provides a record of information gathered during the interview in the event of failure of the recording device (Creswell \& Plano Clark, 2007). To obtain a strength-based protocol, interview questions should be aligned with the research questions and provide an inquiry-based conversation (Charmaz, 2014). Following this line of thought, the researcher developed an interview 
protocol with a list of open questions initially taken from the conceptional framework, theoretical knowledge, institutional course competencies, and researcher's familiarity with the topic.

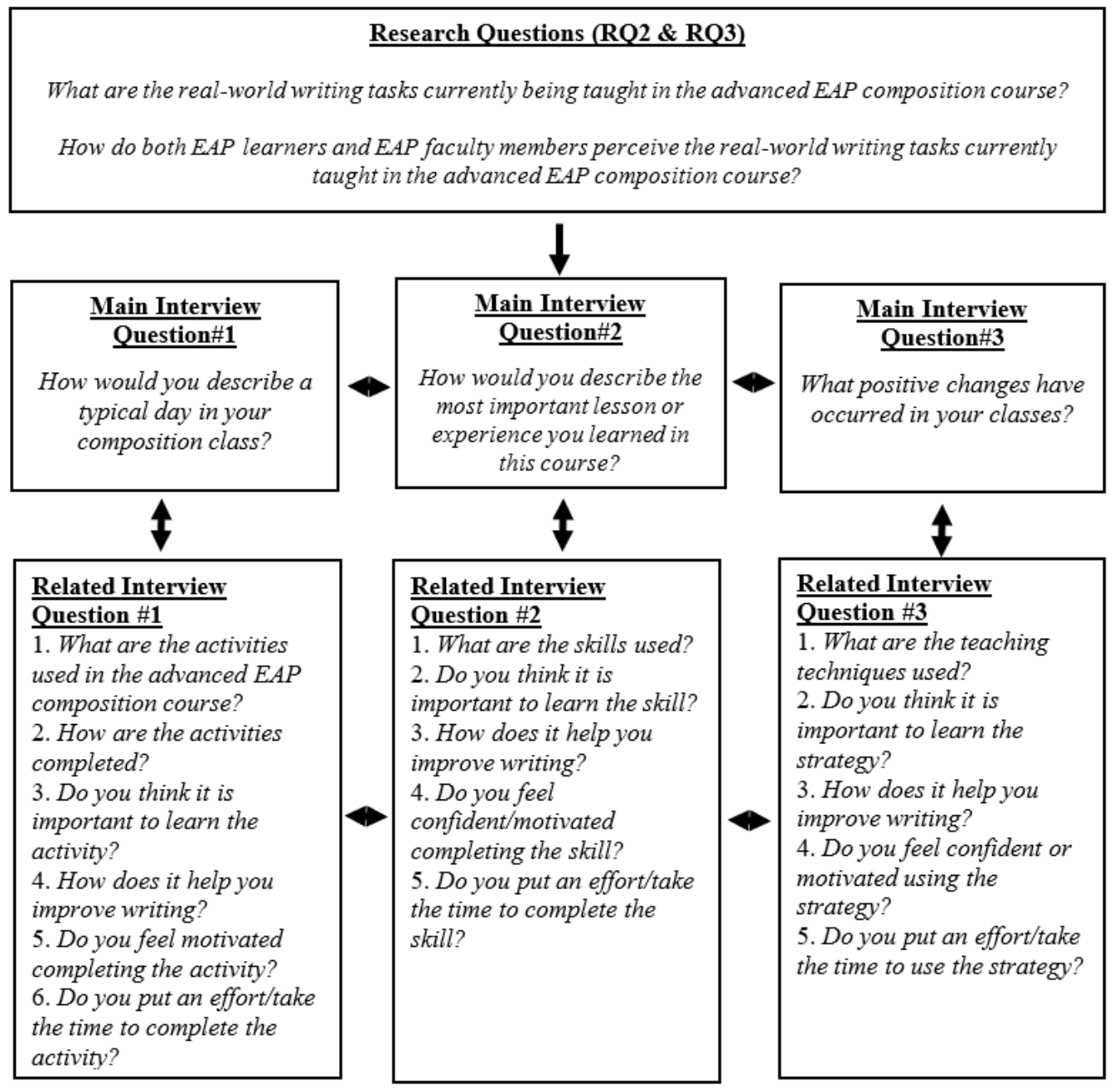

Figure 8. Relative Structure of Interview Questions

The interview protocol entailed three main interview questions to identify the writing tasks assigned to EAP learners along with sub-questions to understand the experiences and attitudes of participants regarding the writing needs of EAP learners. Aligned with the main interview questions, other sub-questions were also included to understand the beliefs, feelings, and behaviors of participants about the writing tasks 
taught in the advanced EAP composition course. Individualized follow-up and probing questions were also included when needed to obtain further detail, to ask for clarification, and to clarify themes (Rubin \& Rubin, 2012).

The interviews were outlined into three stages. The first stage was to understand interviewees' backgrounds, using introductory questions. The second stage included the main questions with emphasis on the writing tasks performed in the advanced EAP composition course, as well as the sub-questions with focus on the details of respondents' experiences and attitudes about the writing tasks. In the third stage, closing questions were used so respondents could share other important issues not previously addressed. Interviews lasted approximately 60 minutes and were completed over the course of six months. The rationale for using semi-structured interviews rather than a focus group was driven by the limited time of participants and to their availability to openly discuss their views in front of other participants. Furthermore, semi-structured interviews are flexible and adaptable and allow conversational communication modified according to respondent's perception of interview appropriateness (Rubin \& Rubin, 2012). The interviews were recorded and fully transcribed.

The process for collecting and coding raw qualitative data was followed the recommendations of Saldana (2009) for coding, wherein the purpose of coding is not limited solely to reduction of data, but can also include summarizing, distilling or condensing data. Transcripts were then analyzed in an effort to categorize data from emerging themes. Identifiable concepts and themes were recorded in a journal during the ongoing process, so a credible qualitative study could be generated in order to identify the descriptions and interpretations of the phenomenon (Bogdan \& Biklen, 2007; 
Charmaz, 2014; Corbin \& Strauss, 2008). Data analysis occurred during data collection in order to cycle the thinking and allow changes through the course of analysis (Strauss \& Corbin, 1998).

Interview Process. The purpose of interviews is "to help the researcher understand the experiences of the respondents and the conclusions the respondents themselves have drawn from them" (Soklaridis, 2009, p. 721). When employing interviews, researchers communicate with those with knowledge or experience about the problem of interest to explore in detail the experiences and opinions of others so that they can reconstruct events never experienced by them and "learn to see the world from perspectives other than their own" (Rubin \& Rubin, 2012, p. 3). In addition, "qualitative interviews examine the complexity of the real world by exploring multiple perspectives toward an issue" (Rubin \& Rubin, 2012, p. 4). To foster quality interviews, it is important to select and gain access to participants, to establish trust, to select an appropriate and quiet location, to establish the length of time spent in an interview, to develop right questions for quality and clarity, and to manage the overall interview process effectively (Rubin \& Rubin, 2012).

During the recruitment phase, participants were initially contacted by email and invited to participate in the study. After their approval and prior to the interviews, participants were approached and provided with an approved Institutional Review Board (IRB) consent form and a copy of the interview questions. During the interview process, participants were provided with a brief explanation about the purpose of the study and the interview process. They were also assured confidentiality of data. They were interviewed 
and asked to respond to a set of questions. A schedule was created for each participant with their interview availability.

According to Rubin and Rubin (2012), a good interview is when the interviewee talks more than the interviewer. Interviewees were encouraged to share their viewpoints and experiences without interruptions unless clarification to understand the phenomenon was necessary. They were invited to express themselves and share their experiences. To reduce anxiety during the interviews, respondents were initially asked to share information about their background. They shared their experiences and attitudes about the writing needs of EAP learners, including their beliefs, feelings, and behaviors about the writing tasks taught in the advanced EAP composition course. Finally, respondents were asked about any other important issue that had not been addressed.

Bogdan and Biklen (2007) stated that interviews should occur at a place where participants feel comfortable and spend their time. Each participant was individually interviewed during a one-hour session in quiet and private settings such as their offices or a conference room, according to their availability. Participants appeared comfortable during the interviews. Interviews were audio recorded, transcribed and completed over the course of six months. To ensure credibility and validity within an interview, member checking and peer debriefing were administered to identify whether themes and findings were consistent with participants' experiences and attitudes. Finally, follow-up interviews were scheduled to help define the meaning of the interview responses provided by some participants. Faculty members received a copy of their transcripts along with a summary of their themes. They read and commented on their transcription during the researcher's writing process. 
Expert Panel. To maintain credibility during the qualitative data collection process, interview questions should be developed from the literature review and researcher's knowledge of the research topic (Rubin \& Rubin, 2012). To determine the validity of a research instrument, the use of an expert panel can also be an essential stage in identifying reliable items to further confirm credibility. An expert panel is incorporated in a study when a specialized opinion is required for evaluation.

In this study, a panel of three experts was selected to assess the effectiveness of the interview questions, to avoid the researcher's perspectives and opinions, and to provide additional themes missed in the interview protocol. Experts also discussed the research topic and made recommendations about the instrument questions in order to improve the data collection instrument and reduce bias. Rubin and Rubin (2012) suggested that experts need to be selected because of their relevant knowledge and experience to the research topic. The criteria for the selection of experts needs to consist of a variety of background experiences with balanced responses, "including alternative points of view and a range of perspectives" (p. 63).

To recruit internal experts, two EAP faculty members with knowledge and experience in teaching the advanced EAP composition course were contacted. In addition, one faculty member with expertise in qualitative analysis was recruited externally. They were provided a copy of the interview protocol which included the three main interview questions along with the sub-questions. They evaluated and reviewed the interview questions and rated the items on the basis of whether the questions were understandable, whether the questions could be clarified, whether the questions were relevant, and how participants could respond to each question. 
After the conclusion of the expert panel, the interview questions employed in the interview protocol needed review. Four irrelevant questions were removed so satisfactory questions could address the research questions of the proposed study. A debriefing session was held with each panel member individually for clarification and for lingering questions regarding their comments.

\section{Learner Survey}

Following the relevant literature and models of previous studies that tackled the needs of L2 learners in L2 writing context, a short online learner survey was developed as data collection in order to identify the writing tasks and any barriers to accomplishing those tasks, prioritizing EAP learners' culturally and linguistically diverse backgrounds. "The purpose and goal of a survey is to describe specific characteristics of a large group of persons, objects, or institutions and to understand present conditions, rather than the effects of a particular intervention" (Park \& Park, 2016, p. 5). Leedy and Ormrod (2005) pointed out that the goal of a survey research is "to learn about a large population by surveying a sample of that population" (p. 183). The survey approach was selected as an efficient means to collect a relatively large amount of data in a short time period in order to obtain the greatest number of responses and "attempt to measure many different kinds of characteristics" (Johnson \& Christensen, 2014, p. 227).

Before survey distribution, modified versions of the survey items used in Cai (2013) and Iizuka (2019) were used to collect data on needs analysis, while adapted items from Graham, Berninger, and Fan (2007) and Zhu (2004) were applied to address EAP learners' attitudes about academic writing. The online learner survey was administered to a population of 169 EAP learners representing the EAP programs in all three 
Southeastern institutions. The survey was two-fold. The first section consisted of demographic and background items composed of eight variables: gender, ethnicity, age, nationality, language, educational level, employment status, and academic pathways. The second portion of the survey included six open-ended questions that asked EAP learners to individually describe the writing tasks that they completed in the advanced EAP composition course. Through the survey, they also described their needs from their perspectives, as well as the problems and successes caused by their cultural and linguistic differences.

Qualtrics software was used to create the survey instruments. The survey link was distributed via email to all EAP learners currently enrolled in the advanced EAP composition course during Spring 2019 and Summer 2019. Participants who voluntarily decided to participate were given an online written IRB approval consent form that was included on the first page of the online survey. Participants then completed the online survey, which lasted approximately 10-15 minutes. Participation was anonymous and voluntary. Follow-up emails were also sent as a reminder of the importance of the study.

Survey Construction. To maintain credibility during the data collection process, the survey questions were developed under the support of the literature review and researcher's knowledge of the research topic (Rubin \& Rubin, 2012). The development of the survey included the following steps. The first step was to determine the purpose in conducting a research study and ensure the survey questions aligned with the research purpose and problems. To elaborate the survey questions, an initial review of the existing literature and survey instruments already used were carefully reviewed. It was also important to understand the potential research participants so that the survey could be 
constructed properly based on natural and familiar language as well as the ability to think like the participants. The item pool generated short items that ask a single question at appropriate reading levels; items were also clear and precise so each participant could interpret the meaning of each item similarly. Finally, it was important to avoid questions that contained double negatives and "emotionally charged words" (Johnson \& Christensen, 2014, p. 196).

The organization of the survey is also essential for the high quality of the data collection. Researchers and professionals in survey research have argued that organization of the survey is important and demographic questions should be placed at the end of the survey. Roberson and Sundstrom (1990) found that "placing questions that respondents considered most important first and demographic questions last in a survey resulted in the highest return rate" (p. 211). For this reason, questions probing the writing tasks required from EAP learners were placed before the background and demographics section.

Cognitive Interview. In order to improve the survey design, the use of a cognitive interview was an essential stage in identifying reliable survey questions to further confirm credibility. The cognitive interview was conducted in order to assess the effectiveness of the survey questions in order to avoid the researcher's perspectives and opinions, improve the data collection instrument, and reduce bias. The survey was distributed to three EAP faculty members with knowledge and experience teaching the course under study. One faculty member with expertise in quantitative analysis was also recruited externally. Respondents first analyzed the questions for the content, clarity, relevance, and language appropriateness, providing a score ranging from 1, not relevant, 
to 4 , relevant. After the evaluation of the items by the group of experts, the content validity index calculated for proportional agreement was $83 \%$, with a variation between $60 \%-100 \%$. Additionally, the inter-rater reliability using Cohen's Kappa was calculated between the experts' scores, which were also based on the content, clarity, relevance, and language appropriateness. Cohen's Kappa was .81, revealing substantial agreement among raters.

Although the agreement among raters was considerable, modifications to the survey were still needed. Most revisions were related to lack of clarity of wording and selection of relevant open-ended questions, considering the large and diverse number of participants who could potentially respond to the survey. The members of the cognitive interview also recommended questions in order to improve the data collection instrument. The learner survey questions were revised based on their responses after taking their suggestions into consideration. The goal was to assess respondents' understanding of the survey questions and to improve the instrument design. After review of the open-ended questions, Cohen's Kappa was calculated as .89.

The in-depth review of the literature followed by the cognitive interview seemed necessary to help develop an adequate learner survey. The new instrument demonstrated overall consistency with the conceptual framework of the needs analysis models, the aspects of attitudes in terms of cognition, affect and behavior, and diversity, taking into consideration the sociocultural aspects of learning writing.

\section{Written Documents}

In order to identify the writing tasks that EAP learners were currently being taught in the advanced EAP composition course, and the writing tasks they would need to 
complete across different disciplines, document analysis from course materials was the next method of data collection used in this study. Document analysis is a systematic procedure for reviewing and interpreting documents to uncover meaning, gain understanding, and produce empirical knowledge relevant to the research problem (Bowen, 2009; Corbin \& Strauss, 2008). Document analysis involves preparation, organization, and reporting of results through an iterative process which combines both content analysis and thematic analysis (Bowen, 2009). The rationale for using document analysis relies on methodological and data triangulation which combines methods in a study of the same phenomenon. The study of instructional documents helps make inferences about a message and draw conclusions from a text. Furthermore, this method provides data on the background and content, shows how a program is organized, and helps verify findings or corroborate evidence from other sources (Bowen, 2009).

Document analysis combines elements of thematic analysis and content analysis through an analytical procedure. Bowen (2009) explained that "the analytic procedure entails finding, selecting, appraising (making sense of), and synthesizing data contained in documents. Documents analysis yields data - excerpts, quotations, or entire passages that are then organized into major themes, categories, and case examples specifically through content analysis (p. 28). Following Bowen's (2009) suggestions for doing document analysis, a clear procedure with an iterative process incorporated in order to explore the content of the course materials shared by faculty members from the EAP programs and from diverse disciplinary courses across the three Southeastern institutions under study. 
Through the comprehensive process of data coding, 51 written documents shared by EAP faculty members and 393 shared by disciplinary instructors were reviewed, placed in context, and coded for analysis. The course documents mostly shared by the instructors were syllabi, course assignments, essay and research instructions, and handouts. Course documents with no assignment and grading policies were excluded from the analysis in order to identify major themes and categories related to the writing tasks that EAP learners were currently being taught in the advanced EAP composition course, and the writing tasks they would need to complete across different majors. The academic areas of study included architecture and interior design; English and literature; music, theater, arts and philosophy; business; criminal justice; mathematics and statistics; physics; computer science; psychology; political science; and history. The shared course materials also helped analyze whether the writing tasks learned in the advanced EAP composition course were aligned with those taught in courses across disciplines.

\section{Data Analysis}

Via multiple sources of data and research methods, data were analyzed using thematic analysis and content analysis. Content analysis is a first-pass review of relevant passages of a text. This method explores the nature and meaning of a small unit of text in order to identify codes based on the frequency of its occurrences (Corbin \& Strauss, 2008). According to Bowen (2009), thematic analysis is, on the other hand, a form of pattern recognition that involves data review for coding and category construction of the selected data. The process involves careful, more focused re-reading and review of the data in order to uncover the major themes and categories related to the central questions of the study. 


\section{Semi-structured Interviews}

Interview data were audio-recorded and professionally transcribed for analysis. The interview audio recordings were listened to multiple times and read alongside the audio recordings to detect missing information from the transcriptions and for necessary corrections. Through thematic analysis, coding and organization of the major themes that emerged from the interview responses were manually organized and categorized using colored pencils and sticky notes.

According to Bogdan and Biklen (2007), developing the coding system involves searching through the data for regularities and patterns and then writing down words and phrases that represent these patterns. According to Strauss and Corbin (1998), “coding represents the operations by which data are broken down, conceptualized, and put back together in new ways. It is the central process by which theories are built from data" ( $p$. 16). Once codes are developed, they are grouped for categorization (Charmaz, 2014).

During the data analysis of the study, open coding process was the strategy employed to break down the data into meaningfully coded segments. Creswell (2007) defined open coding as a form to dismantle qualitative data to identify themes that emerged during the analysis process. Charmaz (2014) explained that data during the open coding are broken down into individually coded segments so researchers can "remain open to all possible theoretical directions indicated by the readings of the data" (p. 46).

Following Saldana's (2009) recommendations for coding, process coding and values coding were selected as part of the first cycling coding method. Process coding is a form of coding that "uses gerunds ("-ing" words) exclusively to connote observable and conceptual action in the data" (Miles, Huberman, \& Saldaña, 2014, p. 75). Process 
coding was used to identify the writing tasks that EAP learners were required to complete in the advanced EAP composition course. Values coding, on the other hand, was applied in order to understand attitudes from the perspectives of EAP faculty members and EAP learners about the academic writing needs of EAP learners enrolled in the composition course. Values coding reflects “a participant's values, attitudes, and beliefs, representing his or her perspectives or worldview" (Saldana, 2009, p. 89). By incorporating varied types of coding, further understanding of the conceptual framework could be provided through the findings.

During the open coding process, thematic analysis was used as a means of structuring data in order to find themes that shared commonality. As the research progressed, the themes repeatedly mentioned by the participants were categorized into groups based on shared characteristics, and then further divided into sub-categories. The major five groups were (1) analysis of basic composition, (2) strategy for performance improvement, (3) peer strategy for writing improvement, (4) supplemental components to writing, and (5) introduction to advanced writing.

\section{Learner Survey}

The learner survey consisted of two sections. Section 1 aimed to address the culturally and linguistically diverse backgrounds of EAP learners. A consent document was the first page of section 1 of the learner survey. Section 1 also included eight demographic and background items related to gender, ethnicity, age, place of birth, education, language, employment status, and major by academic pathway. For better analysis, the variables were divided in two parts. The first part included gender, ethnicity, 
age, place of birth while the second part consisted of education, language, employment status, and major by academic pathway.

Section 2 included the six open-ended questions in order to identify the writing tasks performed by EAP learners in the advanced EAP composition course and explore their experiences and attitudes about the writing tasks. The questions explored the writing tasks EAP learners completed in the course under study, the writing steps they needed to complete these tasks, their successes and challenges in completing these tasks, their perceptions about these tasks, and improvement of the course content.

Qualtrics was the web-based survey tool used in the study. After data collection, data were exported to an excel file and reorganized for better interpretation. From the 169 participants who responded to the survey, 89 were from College A, 47 from College B, and 33 from College C. Regarding College A, only one respondent did not consent to participate. Although 88 consented to take part in the study, only 44 participants returned a complete survey, including answers for the open-ended questions. Sixteen respondents agreed only to the consent page, 12 simply responded to the first part of the demographic information, and 16 replied to both parts of the demographic information but did not reply to the open-ended questions.

All participants in College B consented to participate in the study. From 47 respondents, 23 returned a complete learner survey, including the open-ended questions. Twelve only agreed with the consent form, three only replied to the first part of the demographic information, and nine completed both parts of the demographic information. One respondent from College $\mathrm{C}$ did not consent participation. From 32 participants, 21 responded to all items and questions of the survey. Seven only 
consented participation, two completed up to the first part of the demographic information, and two answered only the items related to both parts of the demographic information, without reflecting on the open-ended questions. Respondents who returned a complete survey were included in the final analysis of the study. There was a total of 88 participants from the three EAP programs in three Southeastern state colleges. Table 6 displays participants' survey completion by school.

Table 6

Survey Completion by School

\begin{tabular}{lccccc}
\hline & \multicolumn{3}{c}{ Section 1 } & Section 2 \\
\hline & $\begin{array}{c}\text { No } \\
\text { Consent }\end{array}$ & $\begin{array}{c}\text { Consent } \\
\text { Only }\end{array}$ & $\begin{array}{c}\text { Demographic } \\
\text { Background }\end{array}$ & $\begin{array}{c}\text { Education, } \\
\text { Employment, } \\
\text { Major }\end{array}$ & $\begin{array}{c}\text { Open } \\
\text { Questions }\end{array}$ \\
\hline College A $(n=89)$ & 1 & 16 & 12 & 16 & 44 \\
College B $(n=47)$ & - & 12 & 3 & 9 & 23 \\
College C $(n=33)$ & 1 & 7 & 2 & 2 & 21 \\
\hline
\end{tabular}

As a consequence of the small sample size, descriptive statistics for the EAP learners' demographic and background responses were analyzed using SPSS 25 with the alpha level set at .05. The next step in the analysis was to perform the non-parametric chi-square test on each demographic factor in order to determine whether there was a statistically significant difference within the demographic factors among the three Southeastern institutions under study.

Data from section 2, on the other hand, were analyzed using content analysis. For credibility, an effective sampling plan was developed before the beginning of the coding process. The units of analysis were single words and phrases coded into an interactive set of categories to allow flexibility to add new codes into categories. To broaden the search 
for most frequently occurring concepts, codes with stemmed words and synonyms were also placed into the same category.

For validity, a coding scheme was also developed in order to classify rules to particular categories. Taking into consideration the emerging themes most discussed in the interviews, the rules were displayed in a code book that helped ensure systematic and replicable coding of data and record details of the codes applied to the data during the coding process (Bowen, 2009). The code book included the writing tasks discussed in the interviews and stated in the writing competencies of the advanced EAP composition course from all three institutions. Furthermore, the code book entailed attitudes from the perspectives of EAP faculty members and EAP learners about the writing tasks performed in the composition course. A number was applied to each code during the recoding of the data, as displayed in Table 7.

Table 7

Code book for Content Analysis

\begin{tabular}{ll}
\hline \multicolumn{1}{c}{ Concepts } & \multicolumn{1}{c}{ Codes } \\
\hline & $\begin{array}{l}\text { 1-essay, 2-rhetorical modes, 3-essay structure, 4-thesis, } \\
\text { 5-body paragraphs, 6-choose a topic, 7-brainstorming, 8- } \\
\text { outine, 9-revision, 10-reading, 11-grammar, 12- } \\
\text { vocabulary, 13-punctuation, 14-research, 15-citation, 16- } \\
\text { online source, 17-journal, 8-summary }\end{array}$ \\
$\begin{array}{l}\text { Attitudes about the Writing } \\
\text { Tasks }\end{array}$ & 1-positive, 2-negative \\
\hline
\end{tabular}

During the analysis process, data were uploaded to a qualitative data analysis computer software. Data from the open-ended questions were first transferred into electronic formats and organized into a NVivo's document browser. For pattern detection, data were analyzed and grouped into meaningful analytical units. After 
locating the meaningful segments, data were placed into code categories named writing tasks, attitudes about the tasks, attitudes about the course, and attitudes about learning writing. Due to participants' additional information on attitudes, the code book was revised, and new categories and codes were added to a revised code book since they had significant implications to the research questions. Table 8 illustrates the revised code book.

Table 8

Revised Code Bookfor Content Analysis

\begin{tabular}{ll}
\hline \multicolumn{1}{c}{ Concepts } & \multicolumn{1}{c}{ Codes } \\
\hline & $\begin{array}{l}\text { 1-essay, 2-rhetorical modes, 3-essay structure, 4-thesis, } \\
\text { 5-body paragraphs, 6-choose a topic, 7-brainstorming, 8- } \\
\text { outine, 9-revision, 10-reading, 11-grammar, 12- } \\
\text { vocabulary, 13-punctuation, 14-research, 15-citation, 16- } \\
\text { online source, 17-journal, 18-summary }\end{array}$ \\
$\begin{array}{l}\text { Attitudes about the Writing } \\
\text { Tasks }\end{array}$ & $\begin{array}{l}\text { 1-positive, 2-negative } \\
\text { Attitudes about the Course } \\
\text { Attitudes about Learning }\end{array}$ \\
\begin{tabular}{l} 
Writing \\
\hline
\end{tabular} & $\begin{array}{l}\text { 1-very poor, 2-poor, 3-fair, 4-good, 5-excellent } \\
\text { very satisfied }\end{array}$ \\
\hline
\end{tabular}

Frequencies of the participants' responses to each question were also recorded using SPSS 25. Percentages were displayed in order to summarize the number of participants who cited the writing tasks they were required to complete in the advanced EAP composition course and their attitudes about the writing tasks, about the course, and about learning writing. Findings were then represented in tables in order to present the responses visually, in a more understandable way. The findings of the short online learner survey are displayed in Chapter IV. 


\section{Written Documents}

Upon the data collection process, 51 course documents from the EAP faculty members and 393 from different disciplines were the means of the document analysis. Document analysis was supplementary to the research method employed in the study. Therefore, predefined codes from the interviews and learner surveys were applied to the content of the written documents in order to compare the similarities and differences of data. The code book developed during the analysis of the learner survey was employed during the document analysis. The documentary data were analyzed together with data from interviews and learner surveys so that themes would emerge across all three sets of data.

During the analysis of the written documents, qualitative content analysis was also used as the means of structuring data into categories. Following the structure of the survey analysis, the first step of the iterative process was to select the documents to be examined and decide on the units of analysis. Suitable and reliable data were then identified and organized. Regarding the EAP course documents, they were organized based on the revised code book and placed into the four categories from the course competencies. The four categories were essay development, the writing process, introduction to research, and effective ways of editing. Course documents shared by disciplinary instructors were, however, grouped based on their academic areas of study by pathways, which included AHCD - Arts, Humanities, Communication, and Design (architecture and interior design; English and literature; music, theater, arts and philosophy); Business; Public Safety (criminal justice); STEM - Science, Technology, Engineering, and Mathematics (mathematics and statistics; physics; computer science); 
and SBSHS - Social, Behavioral Sciences, and Human Services (psychology; political science; history). The shared course materials helped compare whether the writing tasks performed in the advanced EAP composition course were aligned with those taught in other disciplines.

After data analysis, two raters were needed to calculate the inter-rater agreement. The raters analyzed 50 EAP course documents, as well as 50 randomly assigned course documents shared by instructors across disciplines. A training with the independent raters was scheduled to discuss the scoring guide. Both raters independently scored the responses by using the code book developed during the survey analysis. The coders independently rated the content of the written documents based on the writing tasks included or not included in the revised code book. To measure inter-rater reliability, a Cohen's kappa coefficient analysis was used in order to measure the agreement among the raters. The inter-rater reliability was calculated as 0.94 . Therefore, data from the written documents and interpretations of the data were valid.

\section{Validity and Reliability}

For learners to be prepared as agents of social change, tasks should be adapted to individual needs and proficiency level. However, the needs of EAP learners are usually identified from the point of view of institutions and rely on their own advantages (Long, 2015). Moreover, curricula do not inform learners' voices and needs and do not take into account their cultural background and the social context of their lives (Serafini et al., 2015). A well-conducted needs analysis can lead to courses that are designed to ensure that students learn precisely what they need to learn (Long, 2015; Serafini et al., 2015). 
Reliability and validity are important concepts that indicate the quality and usefulness of the test. Research reliability means that the result of a measurement is accurate while validity refers to the truthfulness of inferences and appropriateness of score interpretation (Creswell, 2007). According to Johnson and Christensen (2014), "Reliability refers to the consistency or stability of a set of the test scores and validity refers to the accuracy of the inferences or interpretation you make from the test scores" (p. 165). To increase reliability and validity, data should be collected from two or more sources using two or more methods. Long (2005) advocates for the triangulation of data collected from different informants "to increase the credibility of their interpretations of those data (p. 28). Therefore, triangulation can help validate the data and increases the credibility of the results, as well as identify data gaps (Brown, 2009).

In order to validate the data obtained in this study, triangulated data from multiple sources by multiple methods were employed. This study employed both qualitative and quantitative methods, multiple sources, use of expert panels for credibility of data collection instruments, detailed report on the content of the course under study, and triangulation of multiple sources and methods. To identify valid tasks, the sources were comprised of EAP learners, domain experts, and disciplinary faculty members across different majors. EAP learners were included in the study so they could describe their needs from their perspectives, as well as their attitudes toward the writing tasks.

To identify valid tasks, consulting only EAP learners could however be insufficient and unlikely to produce a reliable inventory of tasks required of them to successfully function since they might not be aware of their present and future communicative needs due to their lack of knowledge of the tasks that need to perform 
(Serafini et al., 2015). According to Brown (2009), in order to investigate the language students need to learn, it is necessary to gather information not only from students but also from various groups of instructors. He also stated that including instructors in the process of conducting the concept of needs analysis is crucial because any larger curriculum project requires instructors "to make changes in their working habits, to do extra work, and, more importantly, to relinquish some portion of their classroom sovereignty" (p. 287). Therefore, insider knowledge from domain experts was a minimum requirement for validity. However, Long (20015) argued that domain experts usually lack linguistic knowledge while applied linguists lack content knowledge. Thus, it is necessary to include informants who are competent in the academic area of interest and also knowledgeable about language use in that area.

In this study, domain experts were the sole source of information for the development of a needs analysis. Domain experts were full-time EAP faculty members with more than ten years of experience teaching the advanced EAP composition course. They reported on the writing needs of EAP learners enrolled in the advanced EAP composition course. Furthermore, disciplinary faculty members across different majors were included in the study to enhance validity and credibility of the study. Through documents analysis, participants identified the real-world writing tasks frequently performed in the advanced EAP composition course and the real content-level writing tasks that EAP learners would need to complete across different majors. A comparison of these tasks would reveal whether the writing tasks learned in the advanced EAP composition course were aligned with those taught across disciplines. Bowen (2009) stated that corroborating findings across data sets can reduce the issue of bias. Therefore, 
diverse sources were incorporated in this study to reduce biases and increase the rate of certainty of the research findings.

This study was also comprised of multiple methods, which contributed to the trustworthiness and credibility of the data and increased the confidence in the research findings. Semi-structured interviews and learner surveys provided the opportunity to confront informants with open-ended questions about the writing needs of EAP learners while document analysis provided information about the writing tasks taught in the advanced EAP composition courses and across different disciplines. To determine the trustworthiness and credibility of the interview protocol, this study used three forms of validity procedure: expert panel, member checking, and peer debriefing to enhance the quality of the study. For validity evidence, the use of a cognitive interview was an essential stage in identifying reliable survey questions to further confirm credibility. To maintain credibility during the data collection process, the survey questions were developed under the support of the literature review and researcher's knowledge of the research topic (Rubin \& Rubin, 2012).

To support the trustworthiness of document analysis, the process of the content analysis was reported accurately. Furthermore, a group of experts evaluated the provisional coding categories to determine their relevance and representativeness. Two experts with experience with quantitative content analysis, knowledge of the construct, and familiarity with the context of the coding protocol participated to ensure the credibility of the study. In this study, documentary evidence was combined with data from interviews and learner surveys to minimize bias and establish credibility. Furthermore, the authenticity and usefulness of the written documents were considered, 
taking into consideration the purpose of each document, the context in which it was produced, and the intended audience.

\section{Trustworthiness and Credibility}

Qualitative researchers employ a variety of strategies to increase the trustworthiness and credibility of a study and to ensure that data are appropriately and ethnically collected, analyzed and reported. To determine the trustworthiness and credibility of the data, this study used two forms of validity procedure: member checking and peer debriefing to enhance the quality of the study.

\section{Member Checking}

Member checking is an aspect of qualitative inquiry used to increase trustworthiness. Member checking seeks to "actively involve participants in assessing whether the interpretation accurately represent them" (Creswell \& Miller, 2000, p. 125). This procedure was used in this study to support the selection of credible participants in order to strengthen the validity of the data. "It consists of taking data and interpretations back to the participants in the study so that they can confirm the credibility of the information and narrative account" (Creswell \& Miller, 2000, p. 127). After conducting the semi-structured interviews, some participants were provided copies of their transcribed interviews and an individualized interview summary with identifiable themes. They could then comment on the accuracy of the data as well as on the interpretation of themes and categories to confirm whether the data were congruent with their experiences and perceptions. Merriam (2002) suggested that findings derived from the raw data and a summary of the interview should be returned to some participants for their interpretation 
of their reality. The participants responded with feedback and clarification which were used to improve the research findings and conclusions.

\section{Peer Debriefing}

Credibility of data ensues that researchers minimize bias during the data collection. Creswell (2007) claimed that credibility must include some level of neutrality. For research to be credible, interviewees need to be knowledgeable about the topic of interest so they can share their experience. "The credibility of your research can depend on demonstrating how well informed your interviewees actually are" (Rubin \& Rubin, 2012, p. 65).

A peer debriefing is a process that establishes credibility to qualitative research. It is "the review of the data and research process by someone who is familiar with the research or the phenomenon being explored" (Creswell \& Miller, 2000, p.129). External reviewers not affiliated with the study can help add credibility and establish validity due to their support and assumptions (Onwuegbuzie \& Leech, 2007). Two external peer debriefers were selected for their expertise in qualitative and their background in second language learning. The peer debriefing was included at the final stage of the data collection process to ensure the consistency of data analysis.

\section{Research Reflexivity}

Researchers' experiences and distortions can influence the research process by impacting how they approach the research process, interpret the outcome of the study, and report the findings (Creswell \& Miller, 2000; Straus \& Corbin, 1998). Additionally, awareness of misperceptions enables the design of specific research questions that informs and clarifies the researchers' understanding of the outcome. The researchers need 
then to critique their own subjectivities and objectivities by encouraging the use of research reflexivity. Reflexivity is defined as the researcher's own voice and critical reflection on a particular study in order to explore and understand how the researcher can influence it (Bogdan \& Biklen, 2007; Johnson \& Christensen, 2014).

Reflexivity in qualitative research methods means establishing a strong relationship with the interviewee in order to enhance trustworthiness and credibility of the research. Patton (2002) defined reflexivity as an important element to consider when designing and conducting qualitative research. Creswell and Miller (2000) referred to reflexivity as a form "for researchers to self-disclose their assumptions, beliefs, and biases" so they can report on "personal beliefs, values and biases that may shape their inquiry" thus reflecting on "the social, cultural, and historical forces that shape their interpretation" (p. 127).

Bogdan and Biklen (2007) also explained that researchers' own feelings and prejudices could be a source of bias. Thus, researchers could transcend some of their biases while collecting data. To raise the awareness of the research process, some strategies can be used to reduce prejudice. In this study, the researcher of the current investigation was open to different viewpoints and was as transparent as possible, so the interpretation of data could not be influenced, and the experiences and views of the participants could be reported precisely. The primary goal was to better understand the writing needs of EAP learners and participants' experiences and attitudes about the writing tasks taught in the advanced EAP composition course. As such, the role of the researcher was to be a researcher rather than an instructor or colleague. Participants' viewpoints and perceptions were listened carefully without passing any judgment. 
To explore the subjectivities and objectivities in qualitative analysis, the researcher maintained a reflective journal. A journal contributes as a key component to the final analysis and enriches the research design by documenting research bias and misconceptions that could influence the findings. The main purpose for using a reflective journal was to help address the researcher's distortions and preconceptions that could be unwittingly introduced to the research design and research conclusions about what went well or should be altered or avoided. The journal helped the researcher become more reflective, so personal assumptions and goals could be examined, and individual beliefs and prejudices could be clarified.

\section{Ethical Considerations}

Before the data collection process, IRB documentation was submitted to all three institutions under study for human subject approval to conduct a study on behalf of Florida International University (FIU). All three institutions granted permission for data collection and approval from the Institutional Review Board at FIU was obtained to begin the study. During the interview recruitment process, emails were sent to participants to invite them to take part in the research project. Before the purposeful sampling began, permission was requested and granted from all participants. Prior to each scheduled interview, each respondent received a copy of the questions and an informed consent form. During the interview, they were asked to read and sign an approved consent form that contained the purpose of the study and the interview process. They were assured that what was said in the interview would be treated confidentially. In addition, it was clarified that they were not in danger or put in risk and their participation would be voluntary. Interviews were audio-recorded and then transcribed into a word document. 
Respondents were assigned code names, so their identity could be removed and not identified. All respondents were informed their right to withdraw from the study without penalty and to self-disclose within their level of comfort. The goal was to provide respondents a safe environment where they could discuss their experiences. A secured file cabinet was used to store the audio recordings, transcripts and signed consent forms.

Prior to data collection of the learner survey, oral announcements about the study were made via emails and during faculty meetings. EAP faculty members were introduced to the study and asked to share the online link of the survey with their students. Students who voluntarily decided to participate could complete the learner survey at their own time outside of the classroom. They were given an online written IRB approval consent form that were included on the first page of the learner survey so they could review and sign prior to taking the online learner survey. They were given assurance of confidentially and guaranteed protection of their rights as participants. They completion of the survey lasted approximately 10-15 minutes. This part of the study was conducted over the course of nine months and administered in different advanced EAP composition courses during Spring 2019 and Summer 2019. Volunteer participants were selected based on their enrollment in the advanced EAP composition course.

During the recruitment of written documents, participants were contacted via email and introduced to the study. EAP faculty members were asked to share the syllabi, writing assignments, rubrics, and assessments that were used in their advanced EAP composition course. Faculty members from diverse disciplinary courses were also contacted and introduced to the study by email. They were invited to share the writing assignments, syllabi, rubrics, assessments used in their disciplinary courses. By email 
attachment, participants were provided with the purpose of the study and given a written IRB approval consent form to review and sign. They were also given assurance of confidentially and guaranteed protection of their rights as participants. Follow-up emails were also sent as a reminder of the importance of the study.

\section{Chapter Summary}

This study employed diverse sources and methods of data. Semi-structured interviews were used to explore EAP learners' needs and understand attitudes from the perspectives of EAP faculty members and EAP learners. A learner survey was also used as a means of data collection in order to examine EAP learners' attitudes toward writing and their needs. Written documents were used to identify the real-world writing tasks that EAP learners were required to complete in the composition course, as well as the real content-level writing tasks taught across different disciplines. A comparison revealed whether the writing tasks taught in the advanced EAP composition course were aligned with the writing tasks taught in different majors. Conclusions were derived from EAP faculty members, former EAP learners, EAP learners currently enrolled in the advanced EAP composition course, and faculty members from diverse disciplinary courses. Three Southern institutions were selected for this study due to their particular EAP programs and location. EAP experts assisted with review before research data were collected. Furthermore, validity procedures such as cognitive interview, member checks and peer debriefing were included from the participants to ensure trustworthiness and credibility. 


\section{CHAPTER IV \\ FINDINGS AND DISCUSSION}

Academic writing has become an integral component that influences L2 learners' ability to succeed in post-secondary education. The results from this study were interpreted using triangulation of data from different sources and methods in order to explore the real-world writing tasks that diverse EAP learners were required to perform in academic contexts. The results chapter begins with a report on the interview findings collected from seven EAP faculty members with experience teaching the advanced EAP composition course, three EAP learners currently enrolled in the advanced EAP composition course, and then three former EAP learners who previously completed the course. Results from the semi-structured interviews are then reported on, which were used to address research question two (RQ2) and research question three (RQ3). The chapter proceeds with the results of the learner survey distributed to 169 EAP learners currently enrolled in the advanced EAP composition course in order to respond to research question one (RQ1), research question two (RQ2), and research question three (RQ3). The chapter continues with a document analysis from 51 written documents shared by EAP faculty members and 393 documents received from faculty members across disciplinary courses with the purpose of address research question four (RQ4). The chapter concludes with a discussion for each applied method, which reveals the main findings of the study. Figure 9 demonstrates how the applied methods aligned with the research questions. 

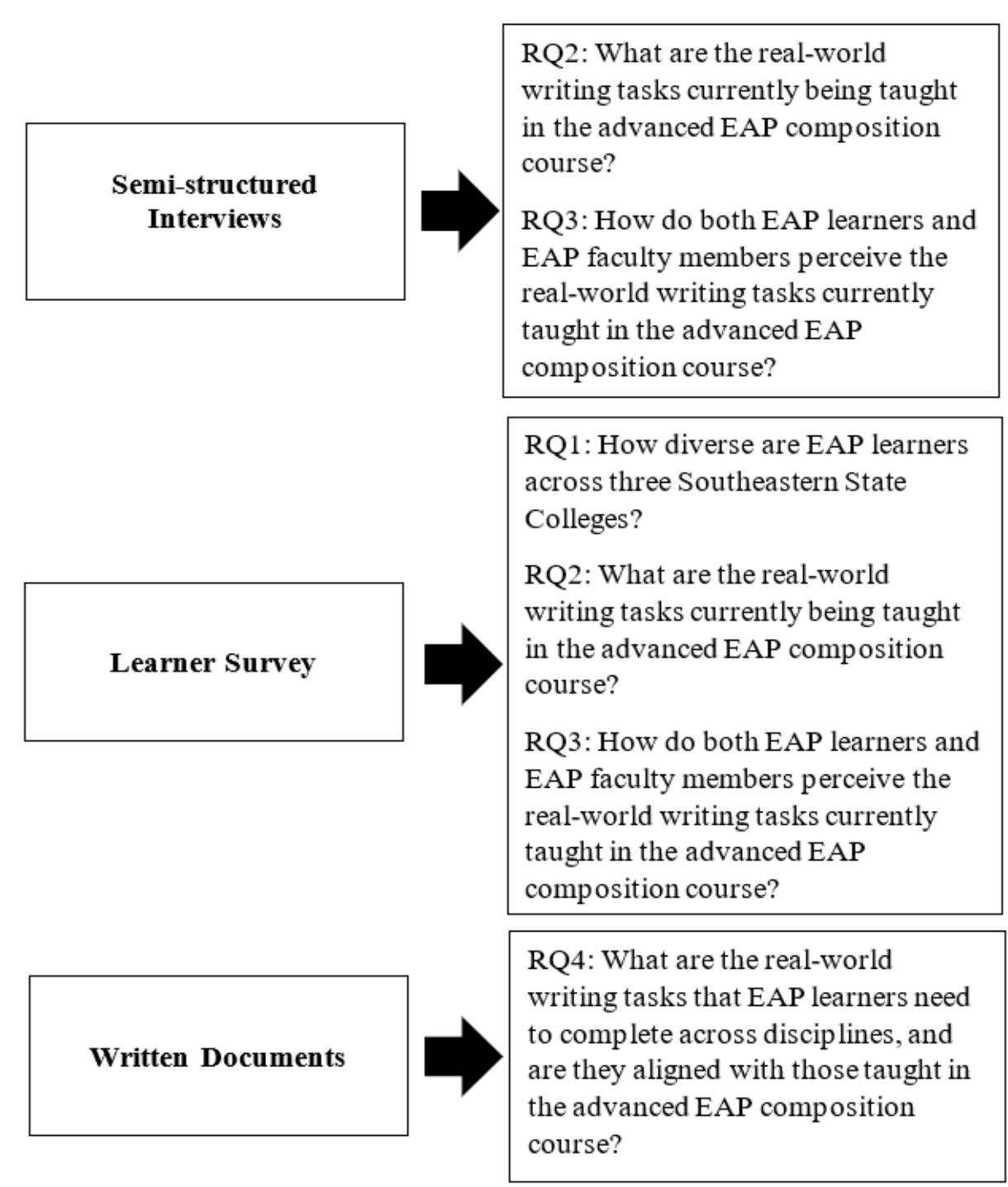

Figure 9. Applied Methods Aligned with the Research Questions

\section{Findings of the Interview Responses}

For the purpose of exploring the writing needs of EAP learners from the perspectives of EAP learners and EAP faculty members, semi-structured interviews from thirteen participants in three Southeastern state colleges were collected over a 6-month period. The interviews entailed questions and sub-questions to identify the writing tasks that EAP learners needed to complete in the advanced EAP composition course (RQ2) 
with follow-up questions regarding the beliefs, feelings, and behaviors of participants towards these writing tasks (RQ3).

The interviews were audio-recorded and transcribed into a word document. For pattern detection, codes that emerged from the interview responses were manually organized and categorized by physically breaking down the data into coded segments and writing the codes on the margin of the paper, next to the text it represented, by using different highlighter pens and colored pencils. Following Saldana's (2009) recommendations for coding process, the first cycling coding method included the process coding and values coding. A systematic way of colored pencils and sticky notes was then used for each participant, who was assigned a unique color to highlight their responses on the writing tasks that EAP learners were required to complete in the advanced EAP composition course, as well as the EAP learners' attitudes toward completing these tasks and learning writing from the perspectives of EAP faculty members and EAP learners.

During the open coding process, thematic analysis was also used as a means of structuring data in order to find themes that shared commonality. As themes began to emerge from the data, codes were then placed under each theme. The writing competencies used in the advanced EAP composition course in all three institutions under study suggested initial categories for analysis. Some categories were retained while others were added as they emerged from the data. Although the names are not referred throughout the relay of the results, the color schemata pertain to each individual. Table 9 describes the colored schema applied to each participant. 
Table 9

Colored Schema for Each Participant

\begin{tabular}{ll}
\hline EAP Faculty Members & EAP Learners \\
\hline Lucy & Olga \\
Mara & Renne \\
Sara & Kathy \\
Karla & John \\
Mark & Martha \\
Anna & Violeta \\
Eva & \\
\hline
\end{tabular}

After completion of the analysis process, many dominant themes were identified from the interview responses. The themes repeatedly mentioned by the participants were categorized into groups based on shared characteristics, and then further divided into subcategories. The major five groups were (1) analysis of basic composition, (2) strategy for performance improvement, (3) peer strategy for writing improvement, (4) supplemental components to writing, and (5) introduction to advanced writing. Themes were also grouped into two sub-categories under (1) analysis of basic composition, named (1.1) understanding the essay structure and (1.2) developing the essay. The themes placed into the groups: (1) analysis of basic composition, (4) supplemental components to writing, and (5) introduction to advanced writing were based on the writing competencies used in the advanced EAP composition course. However, the categories (2) strategy for performance improvement and (3) peer strategy for writing improvement were added as they emerged from the data. Figure 10 illustrates the organizational schema of the themes emerged from the interview findings. 
1. ANALYSIS OF BASIC COMPOSITION

1.1 Understanding the Essay Structure

$\checkmark$ sample essays

$\checkmark$ rhetorical modes

$\checkmark$ essay structure

1.2 Developing the Essay

$\checkmark$ brainstorm

$\checkmark$ outline

2. STRATEGY FOR PERFORMANCE IMPROVEMENT

$\checkmark$ feedback

$\checkmark$ revision

3. PEER STRATEGY FOR WRITING IMPROVEMENT

$\checkmark$ peer-review

$\checkmark$ group work

4. SUPPLEMENTAL COMPONENTS TO WRITING

$\checkmark$ reading

$\checkmark$ grammar

$\checkmark$ punctuation

$\checkmark$ vocabulary

5. INTRODUCTION TO ADVANCED WRITING

5.1 Research Paper

$\checkmark$ citations

$\checkmark$ online sources

6. OTHERS

$\checkmark$ summary

$\checkmark$ discussion

$\checkmark$ journal entry

$\checkmark$ portfolio

$\checkmark$ test/quiz

Figure 10. Organizational Schema of the Interview Findings 


\section{EAP Faculty Members}

Analysis of basic composition. Results from the EAP faculty members'

responses indicated that essay was the writing task mostly used in the advanced EAP composition course. Varied strategies and techniques were employed for the instruction of the essay. Themes were grouped into two sub-categories named (1.1) understanding the essay structure and (1.2) developing the essay.

Under "understanding the essay structure," the most discussed technique that led to the teaching of the writing structure by EAP instructors was the analysis of different sample essays and the explanation of different rhetorical modes. According to participants, the use of sample essays as a model for learning the elements of the essay not only introduced the organization of the essay but also helped to prepare EAP learners to compose their own essay. Examples of faculty comments included:

I bring in other essays and we talk about argument within an essay, trying to see how it's organized and what goes where and then looking at thesis statements.

...they can see what an essay looks like. They have to see what it looks like to know what to produce themselves.

I go back and discuss the form of the essay. How did the writer communicate what structures or what modes he or she used in the writing? And then they can use that as a model towards how they would structure their [essay].

We always look at samples. They are in the book or I can bring them from somewhere else. I also showcase student's best works. I display to the classroom and go through all the elements. 
Regarding their perceptions of the use of samples, positive attitude was evident during the interview process. Some of the comments focused on the importance of introducing the structure of the essay through samples, as described below:

...when students are reading essays, they're learning about writing. They're

seeing an example of writing, a model, so I think when they do it, they gain an

appreciation of what it takes to do that well and that it's hard and it's going to take work

and process.

That gives them an idea. They see how those words are used to connect the ideas, so I think that helps them.

I think it's important for them to see examples before they just jump into it.

EAP instructors also agreed that using samples from the course textbook or other sources could help with the analysis of different rhetorical modes. In searching for effective ways of expressing ideas and communicating with the audience, deeply understanding the different modes could help EAP learners organize their thoughts and better understand the writing structure of the essay, as stated below:

They have to be able to write a good essay that is well constructed, so they can get their points across clearly. With the modes, you have your introduction; the thesis statement is a particular way for that mode. The body paragraphs... We have an organized pattern to follow.

I tell them there are reasons for those modes. So not all essays are equal. So, they have reasons to have the different modes.

Studying the rhetorical modes could also help with the analysis and development of a thesis statement. 
I spent time with the thesis statement and the introduction because some of them are still [in need]. I like having the modes to teach them. Because if I go through the modes, I show them the different thesis statements that based on this thesis statement you know what type of essay it is. The thesis has to be there clearly, just to get them organized so they can write a well-organized essay.

Their attitudes toward the use of different rhetorical modes was positive throughout participants' responses since the study of these rhetorical modes could also help with the development and organization of the essay structure. Some examples of faculty comments included:

I like it because it gives me something to hang on to it. This is what we're aiming for.

The truth of the matter is that [with] the modes [...] I'd like to just teach them. I like to have something to look at or go online and find something or present something.

From the analysis of the sample essays and the explanation of the concepts of each rhetorical mode, the writing structure was the next writing element most mentioned by participants. The instruction of the basic parts of the essay could provide a fundamental framework for writing. Therefore, it could help EAP learners clarify their ideas and demonstrate their thinking process, so they could learn how to write an effective essay, as shown below:

The idea is that when you learn the different parts of something, you'll be able to understand the whole. You're analyzing basically what an essay is and you'll be able to create it. I think that that's helpful.

It's not just teaching them the strategy. It's actually facilitating it with them. 
How they incorporated the structure in their classes is shared below:

I have them to look first at the development of each paragraph. In the introduction I like them to have a hook, and some development, and then the thesis statement, and then the body paragraphs, the topic sentences, the support, transitions. I teach them something called the third body paragraph transition, which is when they get to that third body paragraph, they remind the reader of the other two examples. A decent conclusion. Every paragraph with at least three sentences including the... the conclusions should have at least three sentences.

Where do you place it in the introduction? Then how do you connect those paragraphs, so your writing goes smoothly, and the reader can see where you're coming from. So those are the techniques and structures they really must follow.

We take each chunk of the essay. Um, work on the introductory paragraph first, how to write a good thesis, how to have a real good hook. And then we spend a lot of time on the body, how to develop essay, major, minor details, and then how to conclude.

EAP instructors mainly emphasized that studying the essay structure could help their EAP learners develop a focused thesis statement since their struggles are evident in their writing. Therefore, understanding the structure of the essay could help with the production of a clear and concise main idea. Examples of faculty comments included:

When I do the parts of an essay, I start with a thesis statement. Before getting into anything else like the introduction, we just go through the thesis, and then we talk about what it is part of the introduction and what should be in an introduction.

First, they need to know the structure because writing a thesis is the most difficult thing. 
We're working on a thesis statement and we look at different thesis statements and try to come up with our own or look at some supporting details and then try to come up based on those supporting details.

They also stated that their EAP learners welcomed the structure because it is organized and clear and provides a fundamental framework for writing.

I think that EAP students in particular welcome that structure. The basic structure that will get you... that you'll be able to use and succeed with. I say as you get stronger, you can depart from the structure somewhat.

Once they get the hang of it, they like it because it's organized. It's clean.

Regarding "developing the essay", the second sub-category of the analysis of basic composition, the writing process was the strategy most used by participants. Its organization helps increase the writing proficiency among students and improve the quality of writing since it provides assistance with planning, drafting, and evaluating.

The idea is that when you learn the different parts of something, you'll be able to understand the whole. I think that that's helpful.

I think that, at the end of the day, if you are teaching the student the writing process is what really counts.

The most discussed steps of the writing process were brainstorming the topic and developing an outline. According to EAP instructors, following the steps of the process could help their EAP learners develop their first draft. They explained that brainstorming was usually done through discussions in order to gather ideas that could be used in their essay. The outline, on the other hand, was completed as a sample in class for a potential essay. Examples are demonstrated below: 
Before they do their first essay, we do talk about the whole writing process. We'll do a brainstorming as a class for a topic and we'll come up with an outline for a potential essay in class that day. Not that they we're going to write that topic but just an example to go through the process with them.

I introduce the writing process. I have them come in with topics and we talk about them, and then I have them brainstorm. I show them examples, I have them freewrite it. I have them do a little outline so that I can organize their papers and paragraphs, and then they write a draft.

Well, at the beginning we do a lot of brainstorm. We read something. We talk about it, then I show them how to brainstorm because they really don't.

The first few essays we do brainstorming and then they're using their notes to create the first paragraph the introduction paragraph because I ask them to sort of signal in their thesis what their body paragraph will look like.

I do require an official brainstorming. Outlining is mandatory. So, brainstorming, outlining, and then of course the first draft and as many drafts.

From the interview findings, EAP instructors showed positive attitude in using an outline for the organization and development of ideas. They also indicated that they used this step-by-step approach so their EAP learners could organize their paragraphs into a logical order in order to attain an ultimate quality of the final product, as described below:

We can take an essay and we put it into an outline just to show the organization because I want them to see here's an outline and if you have this, then you can write the essay. 
I tell them an architect cannot build without his blueprint, so my students know

how to outline very well. We do the outlining with the umbrella type thing so they can see the big picture and how we can categorize that big picture all the way down. They have to show me how those steps are achieved.

Outlines, maps, mind maps, tremendously, they're a tremendous help. Take everything step by step.

We talk about brainstorming, outlining, different types of outlines, and then I give them a traditional outline with blanks, um, we do essays. I tell them that the ticket to get in is the outline.

Strategy for performance improvement. Results from the EAP faculty members' interview responses indicated that feedback from the instructor and revision were the strategies most used to improve EAP learners' writing abilities. Feedback was stated as an effective tool for adjusting instruction, evaluating the performance of EAP learners, and fostering their achievement. Feedback as a learning strategy was then individualized to better accommodate the writing needs of these learners. Participants also asserted that they provided high-quality feedback on their students' writings during the varied stages of the writing process. They also stressed the importance of providing feedback on grammar for clear communication. Examples are displayed below:

I do draft one and two. They are EAP students; they need that practice. I don't fix it for them, but I give them lots of feedback of their grammar mistakes.

A lot of feedback and they have my little symbols to follow and I go over the papers with them individually. 
I give them feedback on the thesis which I think is the most important part of setting up the essay.

There's written feedback. I write extensively. I also point out the grammar.

[Feedback] based on whether there's a main idea, how well it's developed, the format of the essay, are the paragraphs indented, and then of course the grammar. And most importantly, that's just for the surface errors, I say also this is missing extra details or there isn't a good hook here or your conclusion was weak.

Participants also perceived feedback as a positive and effective strategy that can help their EAP learners improve all aspects of their writing, as mentioned below:

They want people to tell them they're making a mistake. I still feel that they like to be told that if they're making a mistake and how to correct it.

I think that's really important before a student can even submit any other class writing.

I know it's helpful for them. I think that last step is the most important in their development of learning to use the grammar and learning to identify their own mistakes. I think that hopefully by the end if they've improved their writing then they'll look back on it with appreciation.

They're always so grateful. I think ESL students are so happy to be told. I'm helping you, and they're like yes yes please.

However, feedback is only successful if students use it to improve their writing performance. EAP instructors repeatedly noted that writing was an ongoing process of discovery, and because of this their EAP learners were given opportunities to look critically at their previous drafts in order to improve their writing performance. 
Findings revealed that revision was important and useful for reviewing arguments and reorganizing main points, as well as for awareness of corrections.

I think the curriculum needs to include more editing, a real focus on revision and editing. You need to develop your editing eye and it helps you to edit another people's work as well.

Editing is definitely important. Well, because they can see their errors. The student can see the mistakes they make, and they can correct their mistake.

Their first essay they get to make corrections for a better grade because ultimately, I want them to learn.

I think that helps them, they take it, they keep as an error journal in their notebook of their mistakes. And that helps them identify sort of by midterm at least what were their most frequent errors.

They are all allowed to revise their papers because writing is a process.

Peer strategy for writing improvement. Results from the EAP faculty members' responses were divisive regarding some peer strategies completed in the advanced EAP composition course. The majority of participants stated that in-class peerreview sessions could be an ineffective technique because their EAP learners were unable to provide useful assistance to others since they did not yet possess the linguistic abilities to edit a writing assignment. Examples are demonstrated below:

I don't find it helpful for some reason. Because those students, some of them don't even know why this person got this wrong because they are at the same level. I don't feel it is constructive, the peer editing. I waste more time on that. It doesn't work. For me it didn't work. I tried that in the past. 
When you peer review in class, the students don't really say anything meaningful. I find they don't say meaningful comments when they're speaking. So, I ask them to write their feedback and write their comments so the student can go home and read the comments in the discussion board.

I don't see how, and it isn't always successful. They correct something that doesn't need to be corrected and vice versa.

Only a few participants indicated that peer-review was an effective technique that could help their EAP learners improve their writing skills from organization and topic development to grammar and punctuation. In addition, they stated that the peer-review process could be beneficial not only for the person whose writing is being edited but also for the reviewer. Therefore, editing the work of another person could help EAP learners understand their own writing. How they incorporated their peer-review sessions in their classes is shared below:

It's basic, an outline that I made for students to follow in these workshops. I have them look at it as the big picture first - the form, content, and organization. Then they go through the introduction and I just ask questions. They can ask these questions. The body paragraphs for each one, the conclusion. Once that is complete, the group discusses questions of grammar and punctuation. I think that the editing, and the revision, and the workshop will make them aware.

The peer review, it's just the structure of the essay and the content, as well as the grammar. When I have them do peer reviews, we put together the things that they are having the most problems with and I will have a lesson on grammar. 
We do peer review. They don't correct each other's grammar that's mostly for the

essay content. That's really for the reviewers benefit more than the reviewees benefit

(laughs), because I tell them yes you can get some feedback from your partner but more

importantly, if you look at someone else's writing, then it makes you think about what you

did.

The group work was a peer technique that was not collaboratively implemented in most of the participants' composition classrooms. Only a few responses indicated that group work engaged their EAP learners in cooperative learning that promoted achievement and enhanced communication. Participants used group work, peer-review sessions, and online discussions during grammar activities in order to provide feedback on the organization of the essay. How they implemented group work in their classes is shared below:

I'll put them in groups of two. When they're writing their rough draft in the classroom, they're writing it together.

We're studying mechanics like fragments, I'll put them in groups and then I'll have them identify the fragment, where's the comma splice, and they'll sort of help each other correct the samples. I also have them put their essays into discussion forum, and then I put them in groups so they can read their classmate's essays and then instead of speaking to them, they're typing feedback into the discussion, so the feedback gets saved.

Supplemental components to writing. Results revealed that some writing elements needed to be emphasized to help EAP learners structure and organize their writing. EAP faculty members reported that the instruction of advanced grammatical structures was important because it helped EAP learners express themselves in English in 
a clear and sophisticated manner. Instruction included fragments, sentence variety, and parallelism; however, these grammatical structures were taught as needed depending on the strengths and weaknesses of their EAP learners.

I go over the sentence types because you want to have a variety of sentences because that makes your writing flow and be coherent, but it also makes it clear. I do this whole grammar thing that I connect everything with clauses, independent clauses, dependent clauses. I'm showing them basically coordination and subordination and how to fix the comma splices.

I do not spend a lot of time on grammar. If I keep seeing the same grammar mistakes, that's when I address those, with them individually in my office.

We will take a look at the difference between the different sentence types: simple sentence, compound, compound complex, complex sentences.

I try to flip the class on grammar so they can watch videos about the grammar presentation at their own speed.

We'll look at the parallel construction and depending on what grammar point, topic we're covering, so we work with those. We do look at the grammar. If we see there is a problem, we revisit, but I do have a manual with advanced grammar topics, and I do cover those, and I test them on it.

So, one of the lessons I do, that I spend a lot of time on, is the sentence types lesson. We review what a clause is, independent and dependent clauses, and then we go through simple, compound, complex and compound-complex sentences, so, um, the activity is pre-specific activity, is pre-hands on. 
EAP instructors perceived the aspects of the advanced grammatical structures as useful components of writing. These aspects were incorporated in many tasks, such as board discussions, group works, and journal entries, as described below:

See how those grammar experiences help you be a better writer and help you communicate more clearly. I think the grammar is more useful in editing.

They want to not only understanding how to write an essay, how to have a thesis, and how to develop it, but obviously how to express themselves in English clearly and sophisticated, in a sophisticated way. They enjoy it because it gets them to that next level of thinking. However, teaching grammar in isolation is not very helpful, so it's all about applying it right away.

All participants reported that reviewing some aspects of punctuation was important to make the written texts of their EAP learners more logical and readable. Runons and comma splices were the common punctuation errors mostly mentioned by participants:

Now, I know what's needed by now that we'll be dealing with comma splices. When I go over, I'll go over the five ways to fix a comma splice and run-ons.

Ah punctuation, I do that yes. When we are doing run-on sentences and comma splices, I review that more than anything else. They do think it's important. If your sentences won't make sense, if the comma is not in the right position or you put a period after a dependent clause, it has no connection with the rest.

I'll bring more exercises on punctuation, mechanics, we will take a look at them. Vocabulary was also perceived as an essential element that could help EAP learners with their written production. Vocabulary could help them express themselves 
more precisely and sharpen communication skills. However, participants only indicated that their EAP learners struggled to understand and learn new academic words. Although there was a lot of review on grammar, they lacked on the teaching of vocabulary.

I think is not as strong in the curriculum for the class is that if you want to be a good writer, you have to be a good reader.

I don't do explicit vocabulary acquisition. But if we have an example essay from our text or from somewhere else, we will talk about words that students don't know, we'll

\section{talk about vocabulary in context.}

Vocabulary knowledge, however, is highly correlated with reading comprehension and reading achievement. However, only a few participants mentioned that vocabulary could be improved by reading. Some expressed that a student should be a good reader in order to be a good writer. Therefore, intensive reading assignments should be implemented in the course under study so EAP learners can better explore subjects in-depth and gain a deeper understanding of the world around them. By using examples of essays, reading can introduce different rhetorical modes, the writing process, and the different parts of the essay for reading and writing growth.

There are readers that talk about the modes. They present the modes, the present examples like a paragraph. They have the methods and they talk about the writing process. They talk about reading, and then they illustrate the different parts of the draft and then they go into each one.

If you are going to teach, for example, an essay and its process of writing, you would take a look at different readings: some of the essays, or a section in a book that relates to that mode. 
Reading was implemented through discussion boards, journal entries, and summaries, as described below:

I have them keep a reading log. Actually, I call journal entries, but they were really summaries of what they were reading and responses to reflect on their experience of reading these essays.

They have reading journal assignments, it is what I call them, and then they have discussions and they are all related to different types of readings from articles to magazines and looking at different essays.

I do about 8-10 journals a semester and they write the journal in class. And then they have to go back and use that grammar structure in the journals. The journals I try to connect closely to the grammar chapters that we're working on. I also do some readings and summary response. I'll give them an article; they have to summarize it and write their own response to it.

Reading could also develop critical thinking and vocabulary. They read and so we get critical thinking and vocabulary and all these other things because to me reading is crucial. I think reading and writing improves your thinking. I don't think you can learn to write well as you learn to read more critically. I think that it helps you become a better reader as well. You don't improve one without improving the others. They're all learned together. Writing and thinking critically is all best learned together.

Introduction to advanced writing. Another writing task discussed in the interviews was the implementation of a research paper in the advanced EAP composition course. All EAP faculty members discussed the development of a research paper based 
on an argumentative essay. However, results were divisive regarding the extent of the project. Some participants provided detailed instructions on how to write a research paper, as indicated below:

I do teach research, as well. We will have a 5-10 minute presentation on a research paper. We will take a look at an example and then I'll show them how to use a database, how to research articles or journals, peer reviewed and most importantly, scholar. I'll have them research for a journal. For the next class I'll have them do a quotation exercise. The first one I'll ask them to do a short quote. Write to cite and then I'll have them do a paraphrase.

They're writing their first essay where they have to integrate research into at least one body paragraph and then from that we build up to a complete research paper where they have to integrate the research throughout the paper. They give their own opinion about a particular topic that they have to support the opinion based upon evidence and research and other expert sources. They look for articles on the internet, so we talk a lot on being able to determine if the source is an adequate source. We talk about the reliability and the bias before we get into the research so they can evaluate the articles.

And I also do a mini research paper. I actually require two research papers. One is like a practice research paper that usually is the third paper. I ask them to look for three different outside sources.

Others, on the other hand, only introduced the concept of online sources and citations during the instruction of the essays due to length and difficulty of writing a research paper. Some instructors also indicated that EAP learners were not well prepared to develop a full research study. 
I don't do full research. But when they do the argumentative essay, that's when I pull in research and finding a couple sources to help support your argument. we work a little bit with the work cited. I have them do citation, but we don't spend a lot of time. I don't push too much because you get to learn all that in 1101.

I like to introduce them to it. They shouldn't do a huge, a big research paper, but I think you can teach them some aspects, so they get their feet wet and they're not completely surprised by. We look at the websites. I show them how to cite sources and how to find sources. They have to quote, so I'm actually showing them when you say the word, you have to put it in quotation marks.

Results also indicated that the attitude regarding the detailed implementation of a research paper was, however, contentious. Some EAP instructors showed negative attitude towards a research paper, as shown below:

I wish I could get rid of the research.

I don't' really stress it, I leave that for the 1101 teacher to spend more time on it.

There's no research paper in this class, um, we struggle with whether or not to include one. In 1101 is where most American students learn what MLA formatting is and citations and things like that.

Others, on the other hand, perceived full completion of a research paper as a process that could be useful in developing better organizational and planning skills. 
It's hard at the beginning. Some struggle with the research paper. Yea, they put a lot of effort into it. Believe it or not, they like the fact of researching things. It's exciting to be able to use some of their words instead of always yours, but they have a hard time incorporating it. Yea, very handy, you know they are always very grateful.

It seems to work. They see the purpose of it.

\section{EAP Learners}

\section{Analysis of basic composition. Results from EAP learners' responses also}

indicated that the essay was the most common writing task in their composition

classrooms. Although most of participants indicated that learning how to write an essay was challenging and different from their native languages, they also affirmed that the instruction of the essay development was important and helpful for improving their writing skills.

I feel good, but sometimes I feel some difficulties. However, how to write essays is really important because if you don't know the concept, step by step, you cannot write it. It is helpful for every single class in the future.

In Brazil, I always write what comes in my mind. I never planned some essay, I never had classes teaching how, because here is like a recipe.

I have wrote essays before, but not like this time. This time, they have been more harder or difficult, not the same like the other times before. I didn't know how to write an essay. Now I know, that I didn't know how to write an essay. But I have learned to make essays. I have noticed that I improved. I learned how to make essays, and for me that's the best part of the class. 
For the sub-category "understanding the essay structure," the element most cited by participants was the essay structure, along with brief discussions about sample essays and rhetorical modes. Regarding the essay structure, participants stated that they were provided with explicit explanations of all organizational steps, including introduction along with the thesis statement and hook, body paragraphs, and conclusion. Despite some responses on the difficulty of developing an essay, their perceptions of the task were positive. According to EAP learners, learning the basic format of an essay could provide the fundamental framework for writing an effective essay. Examples of their responses include:

He say we had to include in the first paragraph is a hook, and then the thesis statement, and then he say we had to do after: the hook. We had to do another introduction, then after the introduction, we have to do the body, had to be all the information. We had to put all the details. And then after all that, in the last page, we had to do the closing. Oh, conclusion.

We had to do the introduction, the thesis statement, the body paragraphs. It become easier to do the structure because you know what you have to do. I've been writing more fluently. Like more easily. It's easier to write now.

He go straight to the characteristic of each essay that we're going to write at that moment. Introduction and conclusion for me are the most important. Introduction first and then conclusion is the hard, harder, hardest part of the essay. Because I don't know how to start, and I don't know how to finish.

Regarding the second sub-category of the analysis of basic composition, "developing the essay," the writing process was the strategy most discussed by EAP 
learners. They reported that learning the writing process steps encouraged creative thinking which helped them improve their writing skills. The elements of the writing process repeatedly mentioned were brainstorming and outline, which led to the gathering of ideas before the development of the first draft. According to participants, brainstorming helped generate topics, organize ideas, and structure the essay as described below:

For future classes, it is really important to know the process of the essay, isn't it?

Because he say that, that's the best strategy, pre-write it, and then write it. And he also say we have to do a brainstorm first. We have to put all our ideas together.

We wrote it down [as] a draft in our house. We were able to think, to brainstorm, because at this point, I understand now, thinking back to where I was, that this is actually really hard for students to do.

He talk about the graphic organizer, that we have to, it is easy, it's an easier way to make the essay.

Participants also explained that brainstorming guided them on the construction of an outline. The outline was portrayed as an essential element of writing during the development of the first draft. Although they expressed difficulties in expanding the outline, especially at the beginning of the semester, they appreciated learning how to develop it. The outline helped them construct their thoughts, organize their ideas, and structure their essay, consequently improving their writing skills.

At the beginning I was kind of confused because I didn't know what outline was, but then I ask him, so he explain not only to me, he explain to the whole class. I feel more confident. 
She hands out a very good outline sample, that if, if we follow the steps, the essay should be great. And actually, it was. Like my best essay was the, this one.

Something that I found really helped us, and I still utilize this method, is to, for example, I write the thesis, then I write the first sentence of the first paragraph. This is actually really helpful. When you do an outline, you can better construct the thought. It helps me in a way of, organizing, as I said the thoughts that I want to portray.

Strategy for performance improvement. Results from EAP learners' responses also indicated that feedback and revision were the techniques EAP learners primarily welcomed. Feedback was mostly provided on their grammar, followed by structure and content. Participants also stated that receiving feedback was important to detect and remedy their own errors. Furthermore, they embraced receiving feedback with a positive attitude, especially from their instructors. They believed that feedback could help them improve their writing skills.

Getting feedback is good because I learn from those mistakes.

Because of his feedback, it has been helping me. I read it completely, and then I see that I didn't complete the idea. I know what is wrong and I know how to fix it. And I know I have some mistakes maybe with commas sometimes, but it's not like before. I improve a lot.

Ah yeah, comfort. he's very explicit. Like there's a word in Spanish, move this part to this, use this word, change this, revise the grammar here.

Through revision guided by their instructors' comments, participants indicated that they could improve their performance. They also perceived revision as a positive technique to help them better organize and express their ideas, as demonstrated below: 
Revision was really important for me. I always review. I always think it is

important to review.

He revised it, then I fix the errors. He revise again (laughs); there were other errors I have to fix. I feel confident. I feel comfortable, confident [revising].

Peer strategy for writing improvement. The peer strategies most discussed by EAP learners were peer-review and group work. However, only half of participants indicated that they participated in peer-review sessions. During their sessions, peers reviewed others' grammatical structures, content, and essay organization. The EAP learners who participated in the peer-review sessions shared positive attitude towards the strategy, as in the example below:

I was afraid. Having my second language and now that I am learning, I have to correct someone, I get to find where the mistakes are, and if I don't get to find them. I was motivated in a sense that when I was correcting a type of sentence, I would help my peer. Then, I am correcting, and I am observing others, others writing and comparing to my own writing, and seeing if actually I do the same mistakes.

Group work was also perceived as an important technique to be used in their classrooms. EAP learners stated that they interacted meaningfully with their peers which contributed to their learning. Group work was usually completed during grammar revision, writing style, and essay development.

I like to interact with people. I think that when you have this type of dynamics, it helps break the ice, to keep the class with energy, in order to absorb better the content. And I think that is just another type of learning tool that you can learn, because there are different people with different types of methods to learn. 
Supplemental components to writing. Results revealed that EAP learners perceived grammar, punctuation, and vocabulary as important aspects of writing. They indicated that mastering the elements of grammar could help them understand the construction of clear and precise sentences and paragraphs. Grammar was reviewed using diverse strategies like journal entries, group works, and videos.

Whatever, what happened through the day, just write in the agenda, and then you go back and you see if you make mistakes. And to me that help.

I think that's great because some people has different issues in the language, and I think that she covered most of our problems. It helps me to write in a coherent form, trying to answer the questions. And um, I always have concern about grammar. When I start to learn English, I wanted to speak in the right way, correctly, like, perfectly.

Punctuation was also discussed by participants as an essential component of writing. Using proper rules of punctuation could help them communicate their intended message and express themselves clearly and concisely.

We recognize our own mistakes, how to recognize to the run-ons.

I think once she realize that most people has this kind of problem, she did a review and handout some papers with rules. I like rules.

I have gotten some essays from others, or even emails, that one comma would change a lot the meaning.

Finally, EAP learners expressed the importance of vocabulary in the advanced EAP composition course. Learning new academic words would enhance their use of sophisticated words in their writings, consequently helping them express themselves 
more effectively. Furthermore, they indicated that a broad vocabulary repertoire was needed so they could better demonstrate their ability to communicate effectively.

I feel good, but um, I try to do my best every day to learn more words and vocabulary is really important. If you don't know, then you don't have much to say. We should yes; it's really important for me.

The formal vocabulary [is important] because you can try to say something, or you can try to share your thought with informal language, but writing will give you a formal way of saying and people will better understand what you're trying to say. Because in my mind sometimes when I don't have the vocabulary, what I try to do is to translate from the Portuguese, which is my last option. I found that if you don't know that word, you're not sometimes able to express yourself.

Introduction to advanced writing. Another writing task discussed in the interviews was the implementation of a research paper in the advanced EAP composition course. Only three EAP learners indicated that they learned the process of writing a research paper. Although this process was challenging, they valued the research experience. Learning how to write it was helpful because they improved their cognitive and research skills.

We have a research essay, 5 pages minimum, with citations and MLA format, and uh, word cite. Best experience!

We had a research paper about our own career. And this was really nice. I didn't find harder, hard as I was researching. Nowadays I can really narrow it down and scan through the internet and even see what, what is like, good sources of information. 
Yeah, he explain [the research paper]. And he gave examples, there's examples

how to make, cites, cites. We also have to use quotations, quotes. It's useful, there's important information in library.

\section{Discussion of the Interview Findings}

The purpose of using semi-structured interviews was to explore the writing needs of EAP learners from the perspectives of all participants in order to understand their experiences and attitudes about the writing tasks performed in the advanced EAP composition course. The themes that were repeatedly mentioned were categorized into (a) analysis of basic composition, (b) strategy for performance improvement, (c) peer strategy for writing improvement, (d) supplemental components to writing, and (e) introduction to advanced writing. After each category, a table was included so the dominant themes and participants' references and attitudes toward the writing tasks could be better visualized. The plus sign (+) was used to indicate a positive attitude, while the minus sign (-) and the letter $\mathrm{N}$ indicated a negative attitude and neutral attitude, respectively.

Regarding the emerging themes placed into Analysis of Basic Composition, the essay was the writing task most completed in the advanced EAP composition course. Diverse writing strategies were employed to understand the structure and development of the essay. To understand the structure of the essay, all EAP faculty members agreed on the importance of using essay samples as writing models to introduce the elements and organization of the essay. They stated that essay samples could help their EAP learners develop ideas in preparation for their written production. 
They also stated that the explicit explanation of rhetorical modes was important for organization of the essay and effective communication. Due to EAP learners' struggles in developing an adequate thesis statement, some EAP instructors perceived the analysis of rhetorical modes as an important aspect of writing. Therefore, learning varied types of rhetorical modes could help their EAP learners analyze not only the basic types of academic writing, but also the different styles of thesis statements that differ depending on a particular type of essay. The essay structure was also a writing technique employed by all EAP instructors. They welcomed the structure because it provided a fundamental framework for writing. EAP learners could better plan and organize their thoughts as well as structure their ideas in a logical manner.

EAP learners, on the other hand, did not perceive sample essays and rhetorical modes as important practices to be completed in the advanced EAP composition course. Only two participants mentioned that they analyzed sample essays in their courses; however, they did not provide their perceptions of using them in class. Although rhetorical modes were mentioned by all EAP learners as a writing practice completed in class, some questioned the arduous undertaking and significance of the practice.

Responses instead showed that the essay structure was the most valued component to improve their writing skills. Although some indicated that learning the basic components of the essay structure was unlike the rhetoric in their first language, all EAP learners stated the importance of learning the basic components since it could guide them through the development of an effective essay. They also affirmed that the instruction of the essay structure was important and helpful for improving their writing skills. Despite some responses on the difficulty of developing an essay, their perception 
about the task was positive. According to EAP learners, the basic format of the essay was considered the primary source in developing an effective essay. Pertaining to the organization of the essay, both groups indicated the importance of the essay structure.

Table 10 provides insights on participants' references and their attitudes and perceptions towards these writing practices.

Table 10

Analysis of Basic Composition - Understanding the Essay

\begin{tabular}{|c|c|c|}
\hline Writing Tasks & EAP Faculty Members & EAP Learners \\
\hline Sample Essays & $\begin{array}{l}\text { Lucy }(+) \\
\text { Mara }(+) \\
\text { Sara }(+) \\
\text { Karla }(+) \\
\text { Mark (+) } \\
\text { Anna (+) } \\
\text { Eva }(+)\end{array}$ & $\begin{array}{l}\text { Kathy }(\mathrm{N}) \\
\text { John }(\mathrm{N})\end{array}$ \\
\hline Rhetorical Modes & $\begin{array}{l}\text { Lucy (+) } \\
\text { Mara (+) } \\
\text { Sara (+) } \\
\text { Karla (+) } \\
\text { Mark (+) } \\
\text { Anna (+) } \\
\text { Eva (+) }\end{array}$ & $\begin{array}{l}\text { Olga (-) } \\
\text { Renne (-) } \\
\text { Kathy (-) } \\
\text { John (N) } \\
\text { Martha (N) } \\
\text { Violeta (N) }\end{array}$ \\
\hline Essay Structure & $\begin{array}{l}\text { Lucy (+) } \\
\text { Mara (+) } \\
\text { Sara (+) } \\
\text { Karla (+) } \\
\text { Mark (+) } \\
\text { Anna (+) } \\
\text { Eva (+) }\end{array}$ & $\begin{array}{l}\text { Olga }(+) \\
\text { Renne (+) } \\
\text { Kathy (+) } \\
\text { John (+) } \\
\text { Martha (+) } \\
\text { Violeta (+) }\end{array}$ \\
\hline
\end{tabular}

Regarding the development of the essay, the writing process was perceived as an important and helpful component of writing. Although the writing process consists of different steps, the most applied step to help with the development of the essay was prewriting. Prewriting is the initial stage of the process in which students engage with a 
writing activity, allowing them to generate and organize their ideas. According to all EAP faculty members, brainstorming and outlining were the most important steps of the prewriting section before planning and drafting. They stated that brainstorming the topic could help their EAP learners develop ideas to incorporate in their introductions, thesis statements, and body paragraphs. Outlining, on the other hand, could help their EAP learners better structure their essay. They also specified that their EAP learners could improve quality and increase proficiency by generating ideas before writing their first draft.

Similarly, EAP learners also perceived brainstorming and outlining as essential elements of the writing process. Although a few explained that organizing ideas and structuring the essay were challenging due to their lack of prior writing knowledge, most welcomed the practice. Learning how to brainstorm helped them gather ideas and develop an effective outline. Furthermore, outlining was helpful for organizing the ideas and structure of the essay during the development of the first draft. They also stated that they improved their writing skills since they learned how to construct and organize ideas if they followed the writing process steps. Table 11 describes participants' references and their attitudes and perceptions towards these writing practices.

The emerging themes placed into Strategy for Performance Improvement consisted of feedback and revision. Pertaining to feedback, most of participants reacted to the overall structure of the essay, its quality, and its coherence. Only fewer than half of EAP faculty members stated they provided extensive feedback only on grammar and mechanics. Besides the discrepancy of the proper way of providing feedback, all participants perceived it as an important and useful element of writing. They stated that 
feedback could help their EAP learners improve their essay organization and content, as well their grammar and mechanics. Therefore, their EAP learners could become more self-aware and, consequently, develop their writing skills through teacher correction techniques. EAP instructors also showed positive attitude towards revision. To promote student growth and better accommodate students' learning needs, revision was described as a powerful technique that could help their EAP learners review their arguments and reorganize the main points of the essay.

Table 11

Analysis of Basic Composition - Developing the Essay

\begin{tabular}{|c|c|c|}
\hline Writing Tasks & EAP Faculty Members & EAP Learners \\
\hline \multirow[t]{7}{*}{ Brainstorming } & Lucy $(+)$ & Olga $(+)$ \\
\hline & Mara (+) & Renne (+) \\
\hline & Sara (+) & Kathy (+) \\
\hline & Karla (+) & John $(+)$ \\
\hline & Mark (+) & Martha (+) \\
\hline & Anna (+) & Violeta $(+)$ \\
\hline & Eva $(+)$ & \\
\hline \multirow[t]{7}{*}{ Outline } & Lucy (+) & Olga (+) \\
\hline & $\operatorname{Mara}(+)$ & Renne (+) \\
\hline & Sara $(+)$ & Kathy (+) \\
\hline & Karla (+) & John $(+)$ \\
\hline & Mark (+) & Martha (+) \\
\hline & Anna (+) & Violeta $(+)$ \\
\hline & Eva $(+)$ & \\
\hline
\end{tabular}

As with EAP instructors, EAP learners also shared positive attitude towards feedback and revision. They indicated that receiving feedback for revision was the key to help them acknowledge their own errors. This helped them adjust their essay organization and content, as well as grammar and mechanics. They also stated they felt confident and 
comfortable revising their own work. Table 12 illustrates participants' perceptions towards these writing practices.

Table 12

Strategy for Performance Improvement

\begin{tabular}{|c|c|c|}
\hline Writing Tasks & EAP Faculty Members & EAP Learners \\
\hline \multirow[t]{7}{*}{ Feedback } & Lucy $(+)$ & Olga $(+)$ \\
\hline & Mara (+) & Renne (+) \\
\hline & Sara $(+)$ & Kathy (+) \\
\hline & Karla (+) & John $(+)$ \\
\hline & Mark (+) & Martha (+) \\
\hline & Anna (+) & Violeta $(+)$ \\
\hline & Eva (+) & \\
\hline \multirow[t]{7}{*}{ Revision } & Lucy (+) & Olga (+) \\
\hline & $\operatorname{Mara}(+)$ & Renne (+) \\
\hline & Sara (+) & Kathy (+) \\
\hline & Karla (+) & John $(+)$ \\
\hline & Mark (+) & Martha (+) \\
\hline & Anna (+) & Violeta $(+)$ \\
\hline & Eva (+) & \\
\hline
\end{tabular}

Under Peer Strategy for Writing Improvement, peer-review sessions and group work were the themes repeatedly mentioned by participants. Results showed disagreements among EAP faculty members in regard to the effectiveness of in-class peer-review sessions. Fewer than half of participants implemented peer-review sessions in their courses and agreed that it was a successful strategy that could help their EAP learners practice proper revision principles, improve ideas and drafts, and engage in group exercises. The others, on the other hand, perceived it as an ineffective strategy. They affirmed that EAP learners never shared meaningful comments because they did not have the critical thinking and linguistic abilities to edit their peer's errors. Although all 
EAP instructors expressed their views about in-class peer-review sessions, fewer than half of participants indicated that they implemented group work as a classroom strategy.

In contrast, EAP learners perceived peer-review sessions and group work in a different way. Unfortunately, fewer than half of EAP learners indicated that they participated in in-class peer-review sessions. Yet, all agreed that a peer-review session could be challenging at first, but important and helpful for their future classes. They felt confident revising the work of their peers and were motivated to assist their partners improve their writing abilities. In addition, understanding their peers' points of view helped them in identifying their own errors.

In sum, more than half of the EAP instructors indicated that peer review was an ineffective technique to be used in class. However, EAP learners who had the opportunity to participate in peer review sessions said that this peer-learning strategy was beneficial in developing their writing skills. The reason for the negative attitudes towards peerreview sessions could be linked to the lack of knowledge on how to conduct a successful session. Studies have revealed that successful implementation of peer feedback is achieved through proper peer review training and teacher support. With proper training and support, students can become peer review experts by offering constructive strategies for improvement (Diab, 2011; Min, 2006; Rollinson, 2005).

Participants also faced controversial opinions regarding the importance of group work. Although not all EAP learners experienced working in groups in an academic setting, participants who shared their knowledge in group work perceived it as an effective technique to improve grammar and writing, to interact with peers, and to keep the class engaged. Therefore, empowering group work in classrooms could enrich 
students' learning experiences and make them aware of their own learning (Tsui \& $\mathrm{Ng}$, 2000). Table 13 shows participants' references and their attitudes and perceptions towards these writing practices.

Table 13

Peer Strategy for Performance Improvement

\begin{tabular}{lll}
\hline Writing Tasks & EAP Faculty Members & EAP Learners \\
\hline Peer Review & Lucy (-) & \\
Mara (+) & Renne (+) \\
Sara (-) & Kathy (+) \\
Karla (+) & \\
Mark (-) & \\
Anna (-) & \\
Eva (+) & Renne (+) \\
Group Work & & Kathy (+) \\
& Sara (N) & John $(+)$ \\
& Karla (N) & Violeta $(+)$ \\
\hline
\end{tabular}

The emerging themes placed into the Supplemental Components to Writing category were grammar, punctuation, reading, and vocabulary. All EAP faculty members agreed that grammar and punctuation were necessary elements of any piece of writing. Regarding grammar, they reported that the correct use of grammar could help with clarity, flow, and coherence. In addition, they stated that their EAP learners could express themselves clearly using sophisticated language if grammar was applied immediately rather than taught in isolation. Even though all EAP instructors perceived grammar as an important aspect of writing, some reviewed it only as needed while others provided full in-class lecture on advanced grammatical structures. In contrast, punctuation was 
explicitly taught in class by all EAP instructors. They stated that punctuation helped their EAP learners better organize and structure their writing. Regarding vocabulary, they mentioned that its instruction was important because learning new words increased their critical thinking abilities. They also acknowledged that their EAP learners struggled with academic language; however, the explicit instruction of new vocabulary was not stressed by instructors in class. Similarly, EAP learners revealed that grammar and punctuation were essential elements of writing because having knowledge of both components was the base of the English language. Some mentioned that learning the grammar rules could help improve their fluency and, consequently, their communication. Punctuation was important because its correct use could help produce written texts with clear meaning.

Unlike EAP instructors, EAP learners highlighted the importance of vocabulary because a broad lexicon repertoire could improve their use of sophisticated words and allow them to communicate more effectively. EAP learners also expressed their difficulties in learning grammar, punctuation, and vocabulary. Therefore, some advanced aspects of grammar should be explicitly studied throughout the semester rather than only reviewed when EAP learners faced difficulties. Furthermore, vocabulary should be incorporated in the advanced composition course. Contrary to EAP instructors, EAP learners perceived vocabulary as an essential element of writing since it could improve their communication skills. According to (Zhang, 2009), "communicative competence involves knowing how to use grammar and vocabulary of the language to achieve communication goals" (p. 184). Therefore, grammar and vocabulary, like punctuation, should be explicitly studied in the advanced EAP composition course. 
Regarding reading, fewer than half of the EAP instructors implemented it in their classrooms in order to introduce different rhetorical modes, the writing process, and the different parts of the essay. Although they perceived vocabulary knowledge as highly correlated with reading comprehension, EAP learners did not have the same point of view. EAP learners mentioned that they read articles from online sources, but only in order to complete their summary assignments. That showed that EAP learners did not hold a strong perception that reading could help improve written production and vocabulary. Therefore, explicit reading instruction should be incorporated in the course objectives since reading is highly related to writing production. Furthermore, reading could help EAP learners develop their skills for critical thinking and vocabulary growth. Table 14 displays participants' references and their attitudes and perceptions towards these writing practices.

The main emerging theme placed into Introduction to Advanced Writing was the research paper, which included citations and online sources. The research paper was the writing task with the most divisive views. Some EAP faculty members believed that the implementation of a research paper could help their EAP learners think deeply about a topic, develop organizational and planning skills, and develop good writing abilities. They included research studies in their classrooms so their EAP learners could learn how to research, organize, and compose information about a topic. They also included detailed instructions on citations and online sources. The others, on the other hand, had negative attitudes toward the application of research. They only briefly introduced the concept of citations and online sources during the instruction of the argumentative essay due to 
length and difficulty of writing a research paper, as well as the unpreparedness of EAP learners.

Table 14

Supplemental Components to Writing

\begin{tabular}{|c|c|c|}
\hline Writing Tasks & EAP Faculty Members & EAP Learners \\
\hline \multirow[t]{6}{*}{ Reading } & & Olga (N) \\
\hline & Mara (+) & \\
\hline & & Kathy (N) \\
\hline & Karla (+) & John $(\mathrm{N})$ \\
\hline & & Martha $(\mathrm{N})$ \\
\hline & & Violeta $(\mathrm{N})$ \\
\hline \multirow[t]{7}{*}{ Grammar } & Lucy $(+)$ & Olga (+) \\
\hline & Mara (+) & Renne (+) \\
\hline & Sara $(+)$ & Kathy (+) \\
\hline & Karla (+) & John $(+)$ \\
\hline & Mark (+) & Martha (+) \\
\hline & Anna (+) & Violeta $(+)$ \\
\hline & Eva $(+)$ & \\
\hline \multirow[t]{7}{*}{ Punctuation } & Lucy $(+)$ & Olga (+) \\
\hline & Mara (+) & Renne (+) \\
\hline & Sara (+) & Kathy (+) \\
\hline & Karla (+) & John $(+)$ \\
\hline & Mark (+) & Martha (+) \\
\hline & Anna (+) & Violeta (+) \\
\hline & Eva (+) & \\
\hline \multirow[t]{6}{*}{ Vocabulary } & & Olga (+) \\
\hline & Mara $(\mathrm{N})$ & \\
\hline & & Kathy (+) \\
\hline & Karla $(\mathrm{N})$ & John $(+)$ \\
\hline & & Martha (+) \\
\hline & $\Gamma$ & Violeta $(+)$ \\
\hline
\end{tabular}

Due to the lack of research instruction in the advanced EAP composition course, fewer than half of the EAP learners had prior experience completing a research project. Those who had the opportunity to develop a research study shared positive attitudes 
toward the task. They affirmed they enjoyed the experience because they were able to exchange ideas and use citations and online sources in their writing. Although research is perceived as a difficult task, it should be incorporated so EAP learners can learn the basics of research and become an effective writer. In addition, studies (Leki \& Carson, 1994; Carroll \& Dunkelblau, 2011; Leki \& Carson, 1997) have shown that the writing tasks required in EAP writing courses do not correspond to the types of assignments required in courses across disciplines.

Findings from the interviews supported the concept that most EAP learners continue to develop personal essays rather than advanced academic discourse such as library and research skills. Therefore, EAP writing instructors need to provide more content-based assignments, such as summaries, annotated bibliographies, reports, and research projects, rather than drafts and personal essays. Since writing across disciplines required extensive critical thinking and problem-solving skills, EAP instructors should prepare their EAP learners for the types of writing they could encounter once they enter a full academic program. Therefore, the importance of research is to not only to learn the skills, but to also become successful in other disciplinary courses in which English is the medium of instruction (Chou, 2011). Table 15 presents participants' references and their attitudes and perceptions towards these writing practices.

In sum, responses from the interviews revealed that the themes repeatedly mentioned by all EAP instructors and EAP learners were the essay and its elements, such as the writing structure (introduction, body paragraphs, and conclusion) and the writing process (brainstorm, outline, drafts, and revision). Grammar and punctuation were also a center of discussion. Although grammar was perceived as an essential element of writing, 
only Eva explicitly instructed the grammatical structures in their classrooms. Grammar was only revisited by the other EAP instructors as needed depending on the strengths and weaknesses of their EAP learners. Instead, grammar was emphasized by all EAP instructors when they provided feedback to their EAP learners' written work. Regarding punctuation, all EAP instructors incorporated activities so that the complex aspects of punctuation could be revised.

Table 15

Introduction to Advanced Writing

\begin{tabular}{lll}
\hline Writing Tasks & EAP Faculty Members & EAP Learners \\
\hline Research Paper & Lucy (-) & Renne (+) \\
Mara (+) & John (+) \\
Sara (-) & Martha (N) \\
Karla (+) & \\
Mark (+) & Renne (+) \\
Anna (+) & John (+) \\
Eva (+) & Martha (+) \\
Lucy (N) & \\
Mara (+) & \\
Sara (N) & Karla (+) \\
Mark (+) & Renne (+) \\
Anna (+) & John $(+)$ \\
& & Martha (+) \\
Online Sources & Kara (+) & \\
& Karla (+) & \\
& Anna (+) &
\end{tabular}

EAP instructors did not agree on implementing peer-review sessions and research in their classrooms even though these tasks were directly related to the writing content mentioned in the course competencies. Lucy, Sara, Mark, and Anna perceived peer 
review as an ineffective technique because their EAP learners were unable to provide useful assistance to others due to their lack of linguistic abilities to edit a writing assignment. Mara, Karla, and Eva, on the other hand, agreed that peer review could help their EAP learners improve their writing skills. The reason for the negative attitudes towards peer-review sessions could be linked to the lack of knowledge on how to conduct a successful session. Studies have revealed that successful implementation of peer feedback is achieved through proper peer review training and teacher support so that students can become peer review experts by offering constructive strategies for improvement (Diab, 2011; Min 2006; Rollinson, 2005).

In regard to research, Mara, Karla, Mark, and Anna implemented not only essays, but also research in their classrooms, while Lucy, Sara, and Eva focused solely on the essay and its elements with an analysis of sample essays with varied rhetorical modes. Johns (1997) noted that "too many literacy classes are devoted to one kind of writing text, generally the pedagogical essay" (p. 122). Therefore, responses from this study provide additional evidence that EAP learners continue to complete mainly essays in their composition courses. It can also be suggested that Lucy, Sara, and Eva follow a productoriented approach to writing, in which the writing is adhered to rhetorical conventions that include the writing of a five-paragraph essay with emphasis on the thesis statement at the end of the introduction, three body paragraphs with supporting details, and a conclusion (Nunan, 1991). In addition, modeling from samples is the focus of this approach (Nunan, 1999), and the final written production is supposed to be coherent with no grammatical errors (Kroll, 2011). 
Similar to EAP instructors' responses, EAP learners also shared similar perceptions of the writing tasks completed in the advanced EAP composition course. However, most EAP learners (except Renne) shared positive attitudes toward vocabulary, which was not incorporated in their classrooms. Mara and Eva only indicated that their EAP learners struggled to understand and learn new academic words; however, they did not include vocabulary practices in their composition courses. Only Mara emphasized the importance of vocabulary knowledge for reading comprehension and reading achievement. She also expressed that a student should be a good reader in order to be a good writer. Therefore, Mara emphasized that intensive reading assignments needed to be implemented in the composition course.

Contrary to some EAP instructors, EAP learners expressed positive feelings about peer review and research. Although they were difficult tasks to complete without the support of the instructor, EAP learners enjoyed participating in peer-review sessions and developing a research study. Indeed, there is a good reason to believe peer review and research should be incorporated more in the advanced EAP composition course. According to Ferris and Hedgcock (2014), research promotes higher order thinking and problem solving where writers engage in mental strategies such as planning, formulating, and revision. Figure 11 illustrates a summary of participants' concurrences and discrepancies in relation to the writing tasks completed in the advanced EAP composition course. 


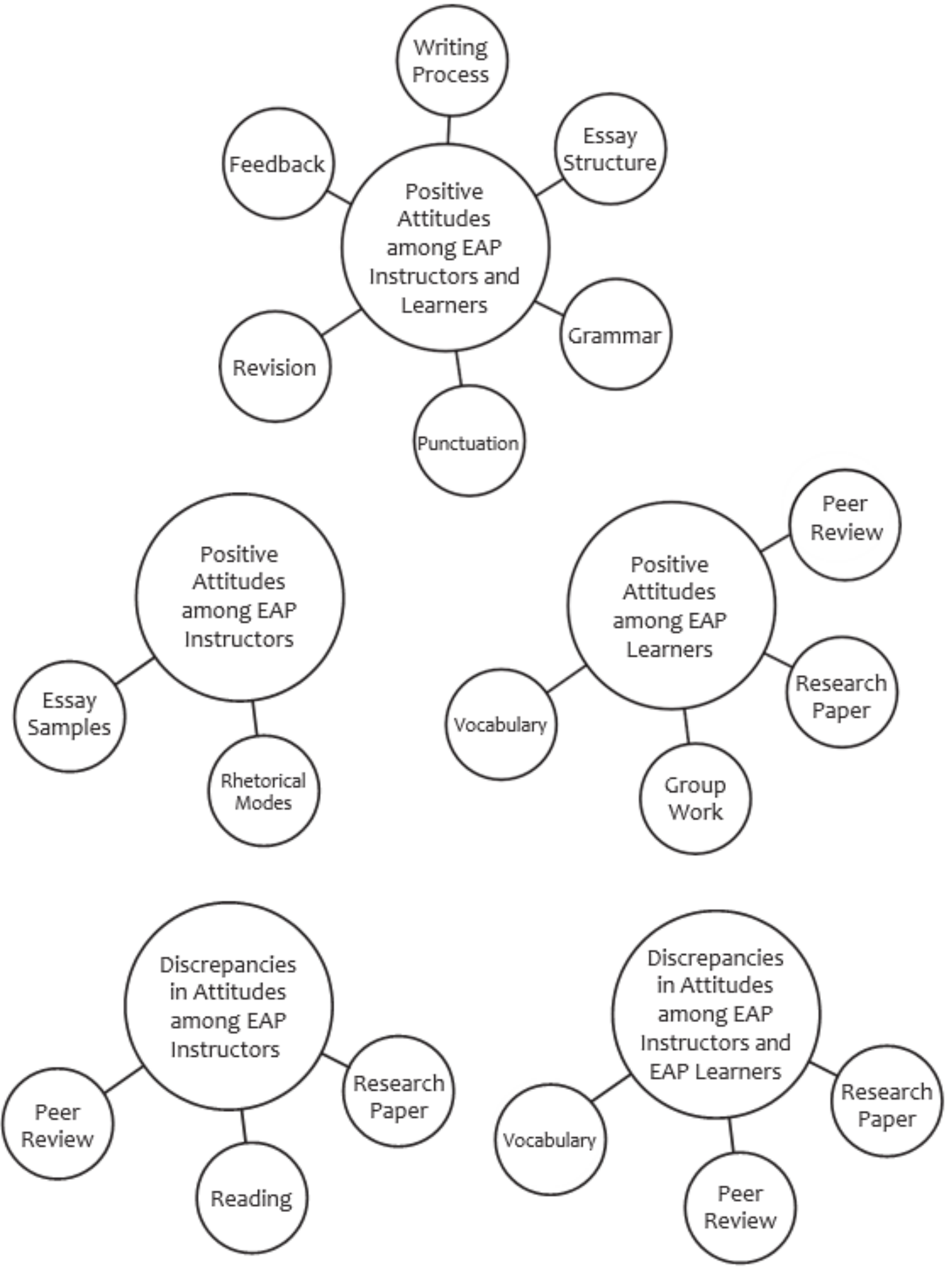

Figure 11. Concurrences and Discrepancies of the Writing Tasks 


\section{Findings of the Learner Survey}

The short online learner survey was distributed to a population of 169 EAP learners currently enrolled in the advanced EAP composition course across three Southeastern institutions. The survey consisted of two sections. The first section consisted of demographic and background items composed of eight variables: gender, ethnicity, age, nationality, language, educational level, employment status, and academic pathways. The purpose was to address research question one (RQ1), which aimed to report the diverse population among EAP learners with culturally and linguistically diverse backgrounds.

The second section included six open-ended questions that asked EAP learners to individually describe the writing tasks that they completed in the advanced EAP composition course (RQ2). Through the survey, they also shared their experiences and attitudes about the writing tasks (RQ3). The questions explored the writing tasks EAP learners completed in the course under study, the writing steps they needed to complete these tasks, their successes and challenges in completing these tasks, their perceptions about these tasks, and improvement of the course content.

\section{RQ1: How diverse are EAP learners across three Southeastern campuses?}

To address the culturally and linguistically diverse backgrounds of EAP learners, descriptive statistics for the EAP learners' demographic and background responses were computed. The first step in the analysis was to perform chi-square analysis on each demographic factor in order to determine whether there was a statistically significant difference within the demographic factors throughout the three Southeastern institutions under study. 
Regarding gender, analysis of the data revealed that the relation between gender and schools was not statistically significant, $X^{2}(1, \mathrm{~N}=88)=.195, p=.907$. Results suggested that gender was similar for all three schools with no association between the two variables. Therefore, a small difference between the observed values and the expected values indicated no correlation between the variables. Ethnicity, however, was shown to have a relationship with schools. Results revealed a statistically significant difference between the two variables, $X^{2}(3, \mathrm{~N}=88)=18.484, p=.047$. For White and Asian participants, the observed distribution of data did not fit with the distribution that was expected, meaning no relationship between White and Asian participants in each school. Similarly, a relationship did not exist for Hispanic and Black participants in College A. However, results showed a large difference between the observed values and the expected values for Hispanic and Black participants across College B and College C. College B included a large number of Hispanic (69.6\%) but was represented by only $13.3 \%$ of Black. College $\mathrm{C}$, on the other hand, embodied a large number of Black (50\%) but covered only $4.5 \%$ of Hispanic. Overall, College A was the institution which encompassed a diverse population from all ethnicities; College B had a large Hispanic population while College $\mathrm{C}$ had a large enrollment of Black students.

A chi-square test for age also revealed interesting results. Age was significantly different across schools, $X^{2}(3, \mathrm{~N}=88)=16.979, p=.030$. From looking at the observed frequencies compared to those expected, College A had fewer students aged 18-24 (27.3\%) with more students aged 25-34 (71\%). On the other hand, College B showed that the majority of the population was among ages 18-24 (60.9\%) with a small percentage of students aged 25-34 (4.8\%). For College C, the observed frequencies were similar to the 
expected frequencies; thus, EAP learners' ages were distributed equally as expected. All institutions had an equally distributed population aged 35-44. However, College A consisted of $83.3 \%$ of learners ranging from 45-54 years of age.

Students across the three schools came from diverse places around the world; however, places with $40 \%$ or more participants were included. Results indicated that country was statistically significant across schools, $X^{2}(5, \mathrm{~N}=88)=38.315, p=.000$. College A embodied a large student population from Venezuela (83.3\%) and Colombia (77.8\%). Haitians were predominantly in College A (45\%) and College C (50\%) while Cubans were largely encountered in College B (83.3\%). Peruvians, on the other hand, were spread across all schools. Students from other countries were primarily from Europe and Asia. College A was the school with the most diverse population, while College B was predominantly Hispanic from Cuba and College $\mathrm{C}$ was mainly Black from Haiti. The descriptive statistics for the four variables is displayed in Table 16.

Language, education, employment status, and academic pathway were also tested using Chi-square. Regarding language, only predominant languages spoken by $40 \%$ or more participants were included. Spanish and Creole were the major languages spoken across schools; "other" encompassed languages such as Portuguese, French, Arabic, Russian, Turkish, Persian, Ukrainian, Korean, Chinese, Vietnamese, and Hindi. Results revealed that language was statistically significant across schools, $X^{2}(2, \mathrm{~N}=88)=$ $15.514, p=.004$. Spanish is predominantly spoken in College A (44.7\%) and College B (40.4\%); however, Creole was mainly used in College A (47.6\%) and College C (47.6\%). College A had similar observed and expected values for Spanish and Creole; however, the observed values (63.2\%) were greater for other languages. Therefore, College A 
embodied the most diverse population with varied languages from many countries.

College B was predominantly Spanish while College C was mainly Creole.

Table 16

Descriptive Statistics for Demographic Factors by School

\begin{tabular}{|c|c|c|c|c|c|}
\hline \multirow[b]{2}{*}{ Gender } & \multirow[b]{2}{*}{ College A } & \multicolumn{4}{|c|}{ School } \\
\hline & & College B & College C & $\chi^{2}$ & $P$-value \\
\hline Male & $14(50 \%)$ & $8(28.6 \%)$ & $6(21.4 \%)$ & .195 & .907 \\
\hline Female & $30(50 \%)$ & $15(25 \%)$ & $15(25 \%)$ & & \\
\hline \multicolumn{6}{|l|}{ Ethnicity } \\
\hline White & $5(45.5 \%)$ & $3(27.3 \%)$ & $3(27.3 \%)$ & 18.484 & .047 \\
\hline Hispanic & $23(51.1 \%)$ & $16(35.6 \%)$ & $6(13.3 \%)$ & & \\
\hline Black & $10(45.5 \%)$ & $1(4.5 \%)$ & $11(50 \%)$ & & \\
\hline Asian & $4(66.7 \%)$ & $1(16.7 \%)$ & $1(16.7 \%)$ & & \\
\hline \multicolumn{6}{|l|}{ Age } \\
\hline $18-24$ & $12(37.5 \%)$ & $14(43.8 \%)$ & $6(18.8 \%)$ & 16.979 & .030 \\
\hline $25-34$ & $15(71.4 \%)$ & $1(4.8 \%)$ & $5(23.8 \%)$ & & \\
\hline $35-44$ & $10(40 \%)$ & $8(32 \%)$ & $7(28 \%)$ & & \\
\hline $45-54$ & $5(83.3 \%)$ & $0(0 \%)$ & $1(16.7 \%)$ & & \\
\hline $55-64$ & $2(50 \%)$ & $0(0 \%)$ & $2(50 \%)$ & & \\
\hline \multicolumn{6}{|l|}{ Country } \\
\hline Venezuela & $5(83.3 \%)$ & $1(16.7 \%)$ & $0(0 \%)$ & 38.315 & .000 \\
\hline Colombia & $7(77.8 \%)$ & $1(11.1 \%)$ & $1(11.1 \%)$ & & \\
\hline Peru & $2(40 \%)$ & $2(40 \%)$ & $1(20 \%)$ & & \\
\hline Haiti & $9(45 \%)$ & $1(5 \%)$ & $10(50 \%)$ & & \\
\hline Cuba & $1(8.3 \%)$ & $10(83.3 \%)$ & $1(8.3 \%)$ & & \\
\hline Other & $15(55.6 \%)$ & $7(25.9 \%)$ & $5(18.5 \%)$ & & \\
\hline
\end{tabular}

Note. Numbers in parentheses indicate column percentages.

Education, on the contrary, was not equally distributed in the population,

$X^{2}(2, \mathrm{~N}=88)=12.364, p=.417$. The observed value for High School Graduate $(50 \%)$

was greater than expected for College B, which was anticipated since EAP learners in

College B ranged from 18-24 years of age. In contrast, the expected count of High School

Graduates (39.3\%) for College A was greater; thus, many EAP learners not only

possessed a high school diploma but had also completed some college (54.5\%), a 2-year

degree $(66.7 \%)$, a 4-year degree $(56.3 \%)$, or a Master's degree (80\%). For College C, the 
observed values were similar to the expected values; thus, EAP learners' education was distributed equally as expected.

Contrasted to education, employment revealed a slightly significant difference across schools, $X^{2}(3, \mathrm{~N}=88)=12.713, p=.048$. For College A, 55\% of EAP learners had a full-time job while $52 \%$ held a part-time position. EAP learners in College C held $27.5 \%$ of the full-time position. It was expected to have students with full-time and parttime jobs in College $\mathrm{A}$ and College $\mathrm{C}$ due to the age range of the population. College $\mathrm{B}$, on the other hand, consisted of some students with full-time $(17.5 \%)$ and part-time $(28 \%)$ jobs, but many being only a student $(58.3 \%)$. Therefore, the observed frequencies for "full-time" were smaller than expected while the observed values for "student only" were greater than expected for College B. Surprisingly, College C had the most unemployment (50\%) across schools.

Regarding academic pathway, results showed that pathway was not significantly different across schools, $X^{2}(6, \mathrm{~N}=88)=11.325, p=.501$. Therefore, EAP learners across schools enrolled in similar academic areas of study. After analysis of the results by Chi-square, the researcher revealed that the majors EAP learners tended to enroll in the most were Business, STEM and Health Science.

Although results indicated that there were no statistically significant differences between gender, education, and academic pathways across the three institutions, results revealed interesting insights about the diversity among EAP learners from the three EAP programs. Therefore, it is reasonable to say that EAP learners come from culturally and linguistically diverse backgrounds. The descriptive statistics for the four variables across the three institutions is displayed in Table 17. 
Table 17

Descriptive Statistics for Demographic Factors by School

\begin{tabular}{|c|c|c|c|c|c|}
\hline \multirow[b]{2}{*}{ Language } & \multirow[b]{2}{*}{ College A } & \multicolumn{4}{|c|}{ School } \\
\hline & & College B & College C & $\chi^{2}$ & $P$-value \\
\hline Spanish & $21(44.7 \%)$ & $19(40.4 \%)$ & $7(14.9 \%)$ & 15.514 & .004 \\
\hline Creole & $10(47.6 \%)$ & $1(4.8 \%)$ & $10(47.6 \%)$ & & \\
\hline Other & $12(63.2 \%)$ & $3(15.8 \%)$ & $4(21.1 \%)$ & & \\
\hline \multicolumn{6}{|l|}{ Education } \\
\hline Less than HS & $2(33.3 \%)$ & $3(50 \%)$ & $1(16.7 \%)$ & 12.364 & .417 \\
\hline HS Graduate & $11(39.3 \%)$ & $11(39.3 \%)$ & $6(21.4 \%)$ & & \\
\hline Some College & $12(54.5 \%)$ & $4(18.2 \%)$ & $6(27.3 \%)$ & & \\
\hline 2-y Degree & $6(66.7 \%)$ & $1(11.1 \%)$ & $2(22.2 \%)$ & & \\
\hline 4-y Degree & $9(56.3 \%)$ & $3(18.8 \%)$ & $4(25 \%)$ & & \\
\hline Master's & $4(80 \%)$ & $0(0 \%)$ & $1(20 \%)$ & & \\
\hline Doctorate & $0(0 \%)$ & $0(0 \%)$ & $1(100 \%)$ & & \\
\hline \multicolumn{6}{|l|}{ Employment } \\
\hline Full-time & $22(55 \%)$ & $7(17.5 \%)$ & $11(27.5 \%)$ & 12.713 & .048 \\
\hline Part-time & $13(52 \%)$ & $7(28 \%)$ & $5(20 \%)$ & & \\
\hline UnempJob & $2(25 \%)$ & $2(25 \%)$ & $4(50 \%)$ & & \\
\hline Student Only & $5(41.7 \%)$ & $7(58.3 \%)$ & $0(0 \%)$ & & \\
\hline \multicolumn{6}{|l|}{ Pathways } \\
\hline AHCD & $2(40 \%)$ & $1(20 \%)$ & $2(40 \%)$ & 11.325 & .501 \\
\hline Business & $12(60 \%)$ & $5(25 \%)$ & $3(15 \%)$ & & \\
\hline STEM & $10(71.4 \%)$ & $3(21.4 \%)$ & $1(7.1 \%)$ & & \\
\hline SBSHS & $2(28.6 \%)$ & $2(28.6 \%)$ & $3(42.9 \%)$ & & \\
\hline Health Science & $10(45.5 \%)$ & $7(31.8 \%)$ & $5(22.7 \%)$ & & \\
\hline Public Safety & $1(33.3 \%)$ & $0(0 \%)$ & $2(66.7 \%)$ & & \\
\hline IMCT & $1(100 \%)$ & $0(0 \%)$ & $0(0 \%)$ & & \\
\hline
\end{tabular}

Note. Numbers in parentheses indicate column percentages.

RQ2: What are the real-world writing tasks currently being taught in the advanced EAP composition course?

Results from the learner survey also uncovered writing tasks that EAP learners completed in the advanced EAP composition course. Responses from six open-ended questions were first coded into categories with single words and phrases as units of analysis. Figure 12 displays the organizational schema of the survey results in which the writing tasks are placed into categories. 
1. BASIC COMPOSITION

$\checkmark$ introduction/thesis statement

$\checkmark$ body paragraphs

$\checkmark$ conclusion

$\checkmark$ MLA format

$\checkmark$ citation

2. WRITING PROCESS

$\checkmark$ choose a topic

$\checkmark$ brainstorming

$\checkmark$ outline

$\checkmark$ revision

\section{RHETORICAL MODES}

$\checkmark$ narration, description, comparison and contrast, cause and effect, and argumentation

\section{SUPPLEMENTAL COMPONENTS TO WRITING}

$\checkmark$ reading

$\checkmark$ grammar

$\checkmark$ punctuation

$\checkmark$ vocabulary

\section{INTRODUCTION TO ADVANCED WRITING}

$\checkmark$ research paper

Figure 12. Organizational Schema of the Survey Results

A qualitative content analysis of the learner survey responses from the six openended items were then examined using conceptual analysis. Frequencies of the selected terms were then recorded using the revised code book. A number was applied to each code during the recoding of the data. EAP learners indicated that the writing task most completed in the advanced EAP composition course was the essay. Thirty-six participants provided general information about the completion of essays throughout the course. The 
emphasis, however, was on the coherent structure of the essay. More specifically, 18 EAP learners stated that they were required to develop suitable essays which included an introduction with an effective hook to catch the reader's attention and a compelling thesis statement that clearly expressed the main point or claim of the essay. Ten participants affirmed that the thesis statement was an important component in the development of any essay.

Eight EAP learners also indicated they learned strategies to develop body paragraphs with effective topic sentences and supporting details. Topic sentences were emphasized so the writer's point of view could be stated, and paragraphs could be organized. Supporting details, on the other hand, were highlighted to support the main points with facts, statements, and examples. Conclusions were also mentioned by nine participants as part of the essay structure. During the completion of the finishing paragraph, EAP learners revisited and summarized the main points of the entire essay. While composing these essays, a total of 17 EAP learners asserted they learned how to cite and format an essay using the MLA style of academic formatting. They used citation to ensure that their sources were clearly credited and were instructed on how to format their essays as a uniform academic way for easy reading. Table 18 displays the frequencies and percentages for each selected term under the category "basic composition."

The "writing process" was also mentioned by EAP learners. They stated they followed a series of actions in order to produce a quality essay. The steps of the writing process most discussed were choosing a topic, brainstorming, outlining, and revision. 
Table 18

Frequencies for Basic Composition by Schools

\begin{tabular}{|c|c|c|c|}
\hline \multirow{2}{*}{$\begin{array}{c}\text { Writing Tasks } \\
\text { Basic Composition }\end{array}$} & \multicolumn{3}{|c|}{ Schools } \\
\hline & College A & College B & College C \\
\hline Essay $(\mathrm{N}=36)$ & $10(28.7 \%)$ & $14(38.9 \%)$ & $12(33.3 \%)$ \\
\hline Structure $(\mathrm{N}=18)$ & $11(61.1 \%)$ & $3(16.7 \%)$ & $4(22.2 \%)$ \\
\hline Thesis Statement $(\mathrm{N}=10)$ & $6(60 \%)$ & $2(20 \%)$ & $2(20 \%)$ \\
\hline Body Paragraphs $(\mathrm{N}=8)$ & $5(62.5 \%)$ & $2(25 \%)$ & $1(12.5 \%)$ \\
\hline Conclusion $(\mathrm{N}=9)$ & $4(44.4 \%)$ & $3(33.3 \%)$ & $2(22.2 \%)$ \\
\hline MLA Format $(\mathrm{N}=6)$ & $4(66.6 \%)$ & $2(33.3 \%)$ & $0(0 \%)$ \\
\hline Citations $(\mathrm{N}=11)$ & $7(63.6 \%)$ & $4(36.4 \%)$ & $0(0 \%)$ \\
\hline
\end{tabular}

The "writing process" was also mentioned by EAP learners. They stated they followed a series of actions in order to produce a quality essay. The steps of the writing process most discussed were choosing a topic, brainstorming, outlining, and revision. Before writing the first draft of their essays, five EAP learners stated they selected a topic based on a search done using the school online library. Twelve participants then indicated they brainstormed their ideas in order to write about that specific topic. Eighteen also used outlines to structure and organize these ideas in a logical order. After the completion of the first draft, thirteen used revision as a form of correction of their own errors and for coherence. Table 19 shows the frequencies and percentages for "writing process."

Table 19

Frequencies for Writing Process by Schools

\begin{tabular}{ccccc}
\hline Writing Tasks & & \multicolumn{3}{c}{ Schools } \\
Writing Process & & College A & College B & College C \\
\cline { 1 - 1 } \cline { 5 - 6 } Choose a Topic $(\mathrm{N}=5)$ & & $3(60 \%)$ & $1(20 \%)$ & $1(20 \%)$ \\
Brainstorming $(\mathrm{N}=12)$ & & $10(83.3 \%)$ & $1(8.3 \%)$ & $1(8.3 \%)$ \\
Outline $(\mathrm{N}=18)$ & & $9(50 \%)$ & $1(16.7 \%)$ & $6(33.3 \%)$ \\
Revision $(\mathrm{N}=13)$ & & $10(76.9 \%)$ & $1(7.7 \%)$ & $2(15.4 \%)$ \\
\hline
\end{tabular}


Pertaining to "rhetorical modes," 17 EAP learners stated that they were required to compose essays on narration, description, comparison and contrast, cause and effect, and argumentation. Learning the different types of written discourse helped them learn the differences in conventions and purposes, which led them to write more effective styles of essays. Regarding the "supplemental components of writing," grammar was the writing component most completed in the advanced EAP composition course. Thirtythree EAP learners indicated that they studied the advanced rules of grammar, including types of sentences, fragments, passive voice, and parallel structure. Punctuation was also mentioned by ten respondents. Punctuation rules were introduced so EAP learners could properly use commas and avoid run-on sentences and comma splices. Eight EAP learners mentioned they did some reading in order to identify the thesis statement and analyze the structure of the texts. Although vocabulary was perceived as an important component of writing, it was hardly discussed by the participants. They indicated that EAP learners did not complete practices or activities related to vocabulary improvement of new words.

Frequencies of selected terms under rhetorical modes and supplemental components for each school is displayed in Table 20.

Table 20

Frequencies for Rhetorical Modes and Supplemental Components of Writing by Schools

\begin{tabular}{|c|c|c|c|}
\hline Writing Tasks & \multicolumn{3}{|c|}{ Schools } \\
\hline Rhetorical Modes & College A & College B & College C \\
\hline Modes $(\mathrm{N}=17)$ & $13(76.5 \%)$ & $2(11.8 \%)$ & $2(11.8 \%)$ \\
\hline Supplemental Components & & & \\
\hline Grammar $(\mathrm{N}=33)$ & $3(9.1 \%)$ & $13(39.4 \%)$ & $17(51.5 \%)$ \\
\hline Punctuation $(\mathrm{N}=10)$ & $1(10 \%)$ & $2(20 \%)$ & $7(70 \%)$ \\
\hline Reading $(\mathrm{N}=8)$ & $4(50 \%)$ & $2(25 \%)$ & $2(25 \%)$ \\
\hline Vocabulary $(\mathrm{N}=2)$ & $0(0 \%)$ & $1(50 \%)$ & $1(50 \%)$ \\
\hline
\end{tabular}


Although EAP learners used the MLA style of academic formatting and citations while writing the first draft of their essays, they did not have the opportunity to be introduced to a "research paper." Ten EAP learners experienced the steps of writing a small but full study. They indicated they used their argumentative essay to reorganize it into a research paper. They learned how to properly summarize the main points of a text using their own words, to restate the meaning of a text or passage using other words, and to quote phrases and brief passages directly. Therefore, they were able to intertwine summaries, paraphrases, and quotations. In addition, they learned how to use the library for further research of the topic and evaluation of reliable online sources. Other writing tasks such as summary, journal, and discussion were hardly mentioned, indicating that they were not completed frequently in the course. Table 21 demonstrates the frequencies for research paper and "other" across the three schools.

Table 21

Frequencies for Research Paper and Others by Schools

\begin{tabular}{ccccc}
\hline $\begin{array}{c}\text { Writing Tasks } \\
\text { Research Paper }\end{array}$ & & College A & $\begin{array}{c}\text { Schools } \\
\text { College B }\end{array}$ & College C \\
\cline { 1 - 1 } \cline { 5 - 6 } Research $(\mathrm{N}=10)$ & & $3(30 \%)$ & $6(60 \%)$ & $1(10 \%)$ \\
Other & & & \\
Summary $(\mathrm{N}=6)$ & & $3(50 \%)$ & $3(50 \%)$ & $0(0 \%)$ \\
Journal $(\mathrm{N}=4)$ & & $4(100 \%)$ & $0(0 \%)$ & $0(0 \%)$ \\
Discussion $(\mathrm{N}=1)$ & & $1(100 \%)$ & $0(0 \%)$ & $0(0 \%)$ \\
\hline
\end{tabular}

\section{RQ3: How do both EAP learners and EAP faculty members perceive the real-world writing tasks currently taught in the advanced EAP composition course?}

Results from the second section of the learner survey also intended to explore EAP learners' attitudes about the writing tasks they completed in the advanced EAP 
composition course. From the six open-ended questions, results revealed not only the writing tasks and attitudes about completing these tasks, but also their attitudes about the composition course and about learning academic writing. Data were then placed into code categories named as followed: attitudes about the tasks, attitudes about the course, and attitudes about learning writing. The units of analysis were single words and phrases that were then examined using the content analysis' basic method called conceptual analysis. Frequencies of selected terms were then recorded using the revised code book. A number was applied to each code during the recoding of the data.

Regarding EAP learners' attitudes about the writing tasks completed in the advanced EAP composition course, results from EAP learners indicated mixed feelings about the writing tasks. Most participants indicated that writing an essay was the most challenging writing task to complete since the writing structure of the first language differed from the English structure. Some respondents indicated that brainstorming to generate new ideas was also difficult because of their lack of knowledge about the written prompts. Understanding the rules of advanced grammar and punctuation was emphasized as a challenge since applying these rules in their writing were not as clear as the practices they completed on grammar and punctuation. Finally, the absence of vocabulary instruction in the composition course was also perceived negatively. Their lack of knowledge of academic words was an obstacle while writing their essays. Therefore, many participants perceived vocabulary as an important component of writing, so incorporating practices to boost their vocabulary acquisition could help them express their ideas in more sophisticated and coherent ways. 
Although a few EAP learners had negative attitudes toward some writing tasks, many reported they were able to overcome their difficulties and improve their writing skills. Most revealed that they learned many strategies on how to write effectively in order to express their ideas in a careful and organized way. Furthermore, they stated that learning the essay structure and organization while writing an essay was their best experience while in the advanced EAP composition course. Most participants also stated that learning the varied rhetorical modes of discourse provided them with the ability to choose specific topics for a particular rhetoric. Even though grammar was perceived negatively by some EAP learners, many respondents affirmed that grammar was a central component of writing since eliminating grammatical errors from their writing could reward readers with clear communication. Research was also perceived as positive. Some EAP learners indicated that they learned how to write a research paper in an effective way using online sources from the library. Finally, vocabulary was also discussed. Although vocabulary was not explicitly instructed in the composition course, some selfreliant EAP learners stated they were able to learn new words while searching online for new topics and ideas, as well as by constantly reading supplemental materials that helped them come across new words.

Unexpectedly, the survey responses also revealed EAP learners' attitudes about the course and about learning academic writing. The units of analysis were single words and phrases that were examined using SPSS 25 to compute the occurrences of the selected terms within the texts. The units of analysis for attitudes about the course were placed based on the quality of the course. Table 22 displays the units of analysis by categories of quality. Results indicated that a few EAP learners did not like the course 
because it was hard and because they felt frustrated at times. However, the positive attitudes about the course overcame the negative responses. Thirty-nine EAP learners highlighted that the course was informative because they were provided with useful

Table 22

Units of Analysis by Quality for Attitudes about the Composition Course

\begin{tabular}{lll}
\hline & Quality & Units of Analysis \\
\hline 1 & Very poor & hate it \\
2 & Poor & I don't like it \\
3 & Fair & so so, it's ok, no complaints \\
4 & Good & good, useful, helpful, effective, instructive, \\
& informative, important \\
5 & Excellent & excellent, perfect, wonderful, great, key to learning \\
\hline
\end{tabular}

information that helped them see their flaws in writing and improve their writing skills.

The course was also helpful, especially for non-native speakers of English, since it helped them develop the ability to write a variety of college-level essays with sophistication, fluency, and accuracy in order to succeed in the advanced EAP composition courses. Many participants also stated that the course helped them become academically prepared for future college-level content courses. Table 23 displays the categories and frequencies for positive and negative attitudes about the course across the three schools.

Table 23

Attitudes about the Composition Course

\begin{tabular}{ccccc}
\hline $\begin{array}{c}\text { Attitudes about the } \\
\text { Course }\end{array}$ & & \multicolumn{3}{c}{$\begin{array}{c}\text { Schools } \\
\text { College B }\end{array}$} \\
\cline { 1 - 1 } \cline { 5 - 5 } Cery Poor $(\mathrm{N}=1)$ & & $0(0 \%)$ & $1(100 \%)$ & $0(0 \%)$ \\
Poor $(\mathrm{N}=1)$ & & $0(0 \%)$ & $1(100 \%)$ & $0(0 \%)$ \\
Fair $(\mathrm{N}=3)$ & & $1(33.3 \%)$ & $1(33.3 \%)$ & $1(33.3 \%)$ \\
Good $(\mathrm{N}=19)$ & & $8(42.1 \%)$ & $8(42.1 \%)$ & $3(15.8 \%)$ \\
Excellent $(\mathrm{N}=20)$ & & $10(50 \%)$ & $2(10 \%)$ & $8(40 \%)$ \\
\hline
\end{tabular}


The survey responses also uncovered EAP learners' attitudes about learning academic writing. Its units of analysis were categorized based upon their relevance. Table 24 displays the units of analysis by categories of relevance.

Table 24

Units of Analysis by Relevance for Attitudes about Learning Writing

\begin{tabular}{lll}
\hline & Relevance & Units of Analysis \\
\hline 1 & Very Unsatisfied & hate it \\
2 & Unsatisfied & I don't like it, frustrating, confusing \\
3 & Neutral & so so, it's ok \\
4 & Satisfied & satisfied, happy, good, comfortable \\
5 & Very Satisfied & very satisfied, amazing, best experience, very \\
& & interesting \\
\hline
\end{tabular}

Results suggested that EAP learners had positive attitudes toward learning academic writing. A few participants stated that writing was challenging and that they lacked confidence during the process of developing a written work. However, 32 EAP learners felt grateful because they accomplished personal satisfaction by improving their writing skills. Participants first argued that they were afraid of being in the course due to their lack of written proficiency which was an impediment to improvement. However, they felt satisfied after extensive training in writing. They also felt that they became a better writer and improved their confidence in writing outside of academia. Table 25 displays the categories and frequencies for positive and negative attitudes about learning writing across the three schools. 
Table 25

Attitudes about Learning Writing

\begin{tabular}{|c|c|c|c|}
\hline \multirow{2}{*}{$\begin{array}{l}\text { Attitudes about } \\
\text { Learning Writing }\end{array}$} & \multicolumn{3}{|c|}{ Schools } \\
\hline & College A & College B & College C \\
\hline Very Unsatisfied $(\mathrm{N}=0)$ & $0(0 \%)$ & $0(0 \%)$ & $0(0 \%)$ \\
\hline Unsatisfied (N=3) & $1(33.3 \%)$ & $0(0 \%)$ & $2(66.7 \%)$ \\
\hline Neutral $(\mathrm{N}=3)$ & $1(33.3 \%)$ & $1(33.3 \%)$ & $1(33.3 \%)$ \\
\hline Satisfied $(\mathrm{N}=18)$ & $9(50 \%)$ & $6(33.3 \%)$ & $3(16.7 \%)$ \\
\hline Very Satisfied $(\mathrm{N}=14)$ & $7(50 \%)$ & $1(7.1 \%)$ & $6(42.9 \%)$ \\
\hline
\end{tabular}

\section{Discussion of the Survey Findings}

The learner survey addressed the diverse population among EAP learners, the writing tasks they were required to complete in the advanced EAP composition course, and the attitudes about completing the writing tasks, about the course, and about learning academic writing.

\section{RQ1: How diverse are EAP learners across three Southeastern campuses?}

To respond to research question one (RQ1), the diverse population among EAP learners across three Southeastern state colleges were examined. There were no statistically significant differences between gender, education, and academic pathways across the three institutions; however, results revealed interesting insights about the diversity among EAP learners from the three EAP programs.

Overall, EAP learners from College A were more diverse compared to College B and College C. College A consisted of EAP learners from many ethnicities and countries ranging in ages from 25 to 44 . As expected, learners in College A had already acquired some college or a full college degree, as well as part-time and full-time jobs due to the age range. College B entailed EAP learners from 18 to 24 years of age, in which most 
were only students with a high school diploma. In addition, a fewer learners held a parttime or full-time job due to the age range. Most of the population were Hispanic with Spanish as the major language of communication. College $\mathrm{C}$, on the contrary, involved a large number of Black with Creole as the major language of communication. EAP learners in College $\mathrm{C}$ worked in part-time and full-time jobs, but also had the highest rate of unemployment. Based on the age group in College A and College C, it was expected to have a more educated student population with undergraduate and graduate degrees.

However, EAP learners were more diverse and educated in College A.

\section{RQ2: What are the real-world writing tasks currently being taught in the advanced EAP composition course?}

In order to address research question two (RQ2), the writing tasks EAP completed in the composition course were identified. The essay was the writing task most completed across all schools. Another writing task frequently discussed by EAP learners in the learner survey was the essay structure. The parts of the structure mainly mentioned were the introduction with hook and thesis statement, body paragraphs with topic sentences and supporting details, and the conclusion. The essay structure, however, was mainly discussed by EAP learners from College A. During the writing of the first draft of an essay, MLA formatting and citations were applied to their essay; however, components of MLA citations were predominantly completed by EAP learners in College A and College B.

During the writing process of developing an essay, respondents indicated the importance of selecting a topic for a specific essay, brainstorming, outlining, and revising. Although they stated that knowing how to choose a topic was important, there 
was no evidence of using online sources from the library, indicating that EAP learners may have relied on their personal knowledge rather than evidence-based knowledge. Carroll and Dunkelblau (2011) explained that curriculum and instruction for L2 learners needs to be prepared with writing assignments that will be required in their college-level content courses rather than writing assignments that reflect their personal experiences or general knowledge. Brainstorming, outline, and revision were also explicitly discussed. Participants implied that generating and organizing new ideas were difficult, but they were not exposed to online sources from the library. Therefore, they had difficulties finding their own topics and coming up with content ideas. Brainstorming and revision were most completed by EAP learners in College A while the outline was completed primarily in College A and College C.

The rhetorical modes such as narration, description, comparison and contrast, cause and effect, and argumentation were the rhetoric that EAP learners most completed in the composition course. Rhetorical modes were mainly discussed by participants in College A. Therefore, results suggested that EAP learners in College A could be better prepared for major types of language-based communication. Grammar and punctuation were also the center of discussion. Grammar and punctuation were mainly reviewed by instructors in College $\mathrm{C}$, indicating these learners may have retained better understanding of writing conventions.

Vocabulary, however, was hardly discussed by the participants. When mentioned, EAP learners stated that vocabulary was an important component of writing that was not implemented in the advanced EAP composition course. EAP Learners also indicated that learning new words was important in order to be able to use sophisticated lexicon in their 
written work and better express themselves. Research paper was implemented in some courses, but few participants had experienced developing their own research project. Although there was evidence of the use of MLA citation during the writing of the first draft of an essay, only a few EAP learners reported they used MLA citation while writing a research project. EAP learners in College B indicated they completed most of the research studies. Other writing tasks such as summary, journal, and discussion were barely mentioned, indicating that they were not completed frequently in the course.

To address research question three (RQ3), results from the learner survey also revealed EAP learners' attitudes about the writing tasks, about the course, and about learning writing. Although there were some negative attitudes about some writing tasks (essay structure, brainstorming, grammar, punctuation and absence of vocabulary), only a few students responded they were unsatisfied with completing some tasks due to its difficulty or lack of knowledge in completing them. Positive attitudes about other writing tasks overcame the negative responses. Most respondents stated they had positive attitudes toward the essay structure, rhetorical modes, grammar, research, and vocabulary with respect to the self-reliant learners.

Regarding their attitudes about the course and learning academic writing, many EAP learners felt satisfied being enrolled in the advanced EAP composition course, and their behavior led them to complete the course for different reasons, such as acquiring a passing grade. According to the affective, cognitive and behavioral aspects of attitude, students who engage in learning tend to have positive feelings about the course and, consequently, their behavior leads them to complete their practices and assignments. It is reasonable to speculate that attitudes toward learning writing are related to learners' 
success since learners with positive attitudes about writing put more effort into their writing tasks.

\section{Findings and Discussion of the Written Documents}

\section{RQ4: What are the real-world writing tasks that EAP learners need to complete across disciplines, and are they aligned with those taught in the advanced EAP composition course?}

Document analysis was the last method used in the study and aimed to address research question four (RQ4). The purpose of the document analysis was to identify the writing tasks currently being completed in the advanced EAP composition course, as well as the real content-level writing tasks EAP learners would need to complete across different majors. This was for the purpose of understanding whether the current EAP writing tasks were aligned with those required across disciplinary courses.

A total of 51 written documents shared by EAP faculty members and 393 shared by disciplinary instructors were reviewed and coded for analysis. The EAP course documents included syllabi, course schedules, essay and research instructions, rubrics, editing guidelines, and outline templates. The course documents were coded based on the revised code book and placed into the four categories from the EAP course competencies described under Chapter III, Methods. The categories included essay development, the writing process, introduction to research, and effective ways of editing.

Under "essay development," the course documents revealed that the essay was the most common writing task assigned to EAP learners by all EAP instructors. The rhetoric modes of discourse were classification, compare and contrast, cause and effect, process, definition, and argumentation. In regard to the essay structure, the essay development 
embodied the essay and its structure. The essay structure included an introductory paragraph that includes a hook, background information, and thesis statement. In addition, the multi-paragraph essay involved at least three body paragraphs with appropriate topic sentences and relevant supporting details. Finally, the structure needed a concluding paragraph that related to the main points of the text as a whole. There was evidence that practices were completed in order to help EAP learners identify the main ideas of diverse texts so that they could develop their own thesis statements and topic sentences. In addition, practices were employed to encourage the use of transitions in order to make clear the relationships among ideas and the text.

Regarding "the writing process," EAP learners needed to be able to follow some steps in order to develop an essay. Cluster diagrams and graphic organizers were used for brainstorming new ideas. After first using a diagram to brainstorm ideas individually or with a partner, students would then proceed with an outline to structure their ideas. The course documents revealed that the outlines were the writing element repeatedly assigned by EAP instructors. After the outline, students proceeded to complete the first draft of the essay. After receiving the first draft, EAP instructors provided feedback that EAP learners utilized to revise their written work through self-editing or peer editing. Under "effective ways of editing," error correction was done on content, grammar, punctuation, and essay format. Practices to learn how to revise and edit texts were also completed. For "introduction to research," the course documents revealed that only a few EAP instructors implemented an introductory research project in their courses. When explained on how to gather evidence-based research in formal academic writing, EAP learners were expected to use the MLA format, works cited, citations, and external 
credible sources. Other writing tasks that were included in a few course documents were weekly journals, discussions, and quizzes and tests on rhetorical modes, essay structure, grammar, and punctuation. Final exams were also mentioned, which included essays that needed to be completed in the classroom. Table 26 displays the writing tasks uncovered during the analysis of the course documents.

Table 26

Writing Tasks Aligned with Course Objectives

\begin{tabular}{lc}
\hline Categories & Writing Tasks \\
\hline Essay Development & $\checkmark$ \\
\hline Effective introductory paragraph & $\checkmark$ \\
$\quad$ thesis statements & $\checkmark$ \\
Effective body paragraphs & $\checkmark$ \\
$\quad$ topic sentences & $\checkmark$ \\
$\quad$ relevant supporting details & \\
Effective concluding paragraph & $\checkmark$ \\
The Writing Process & $\checkmark$ \\
Brainstorming & $\checkmark$ \\
Outline & \\
Revision & \pm \\
Introduction to Research & \pm \\
Research & \pm \\
Online sources & \pm \\
MLA format & $\leq$ \\
Citation & $\leq$ \\
Plagiarism & $\leq$ \\
Summaries & $\leq$ \\
Paraphrasing & $\leq$ \\
Syntheses & $\checkmark$ \\
Effective Use of Editing & $\checkmark$ \\
Grammar & $\checkmark$ \\
Punctuation & $\checkmark$ \\
Mechanics & \\
\hline
\end{tabular}

Note. The $\checkmark$ symbol indicates the completion of the tasks in all courses.

The \pm symbol indicates the completion of the tasks by some EAP instructors.

The $\leq$ symbol indicates the completion of the tasks by few EAP instructors. 
Results showed that, in general, EAP instructors followed most of the components mentioned in the course objectives of the advanced EAP composition course. However, the results from the EAP course documents indicated that the following writing tasks were merely mentioned: research projects, summaries, and practices on plagiarism, paraphrasing, and syntheses. Content analysis determined that in all, the writing tasks required of EAP learners in the composition course were most aligned with the course objectives.

In order to examine whether the writing tasks completed by EAP learners in the advanced EAP composition course were aligned with those completed across disciplines, the written documents shared by disciplinary instructors were also analyzed. Contrary to EAP course documents, the course materials shared by disciplinary faculty members were syllabi, course assignments, and handouts. The course documents were from different areas of study, such as architecture and interior design; English and literature; music, theater, arts and philosophy; business; criminal justice; mathematics and statistics; physics; computer science; psychology; political science; and history. Findings were grouped based on the academic pathways offered by the three institutions under study. The five academic pathways were AHCD, which included architecture and interior design; English and literature; music, theater, arts and philosophy; Business; Public Safety, which consisted of criminal justice; STEM, which entailed mathematics and statistics; physics; computer science; and SBSHS, which involved psychology; political science; history.

The course documents revealed that the writing tasks frequently completed across different academic pathways were chapter tests and quizzes, presentations, in-class and 
online discussions, final exams, and research projects. In AHCD, the writing tasks most required of students were writing assignments, research projects, presentations, discussions, and exams. Writing assignments entailed summaries, responses and arguments. Using effective and persuasive methods, students were required to include topics with great detail to prove a point. In addition, citations from reliable sources were essential for all writing assignments. Although courses documents revealed that these writing assignments were most often completed in English and philosophy classes, they were also completed in music, theater, and arts.

Research projects, however, were completed in all courses. Students were expected to select a topic, summarize the main points from the readings, paraphrase the ideas from the resources, and quote phrases and brief passages. They were also required to incorporate citations from external credible sources in order to support their arguments using either MLA or APA styles of academic formatting. Students in architecture, interior design, and theater also needed to present the findings of their research projects for the class. Regarding discussions and exams, discussions were mainly completed in English and interior design courses while exams were assigned to students in interior design, music, and philosophy.

Regarding the business pathway, all courses required their students to complete chapter quizzes, chapter assignments, chapter discussions, group projects followed by class presentations, a midterm, and a final exam. All writing tasks were related to the content of the course. Similarly, the STEM pathway entailed chapter quizzes, homework assignments, and a final exam that were related to the course content. Computer-related 
courses, however, expected their students to complete extra writing tasks, such as reflections, summaries, and online discussions.

Public safety consisted of a mix of writing tasks. Although a midterm and final exam were expected of all students, other writing tasks were not required of all of them. Journal entries, research assignments, and reflections were expected of most students in criminal justice courses. Critical thinking skills were an essential element that needed to be included in these types of assignments. Furthermore, students needed to incorporate summary, paraphrase, quotation, and academic sources into their research assignments. Portfolios, discussions, and group projects that led to some class presentations were also completed in some courses.

SBSHS also entailed a variety of writing tasks. Course documents revealed that chapter quizzes, a midterm, and a final exam were writing tasks assigned in all psychology, political science, and history courses. The exams were completed either in class or online in order to review the course materials covered in class. Writing assignments and research papers were also required in psychology and history classes. The writing assignments included reflections and essays that entailed an evaluation of the main themes. Research papers fostered critical thinking and problem solving so that students could not only approach problems and issues in a systematic and logical manner, but also identify credible sources in order to engage in their own thinking. Although many SBSHS instructors required the completion of writing assignments and research papers in their courses, course documents revealed that the exams still contributed to a larger proportion of the overall score. 
Other writing tasks assigned in some courses were discussions, group projects, and presentations. Under discussions, students in psychology and history were required to critically evaluate text materials. Discussions were not mentioned on course documents shared by the political science instructors. Group projects were also required in psychology and political science courses. These projects were mainly problem and solution term papers in which students identified and analyzed a problem in order to propose one or more solutions. Some group projects led to class presentations, which were mainly completed in psychology courses. Although these writing tasks were only required in some courses, there was indication that critical thinking was strongly involved in these assignments. Table 27 displays the writing tasks completed across disciplines.

Content analysis revealed that the writing tasks required of EAP learners in their composition courses differed from those they were expected to complete across disciplines, especially in terms of type, length, and complexity. The essay and its aspects were the most frequent type of task practiced in the advanced EAP composition course. However, very few course documents indicated that students were assigned personal essay writings. Personal essays were most often required of students in their first term of Freshman English Composition courses but not in other academic areas of study. Responses from this study aligned with Johns' (1997) concept that “classes are devoted to one kind of writing text, generally the pedagogical essay" leading EAP learners to believe that "this is the only way to write" (p.122). Research projects were only utilized by a few EAP instructors; however, course documents indicated that many disciplinary instructors employed these types of practices in their courses. 
Table 27

Writing Tasks Completed across Disciplines by Academic Areas of Study

\begin{tabular}{|c|c|}
\hline Academic Area of Study & Writing Tasks \\
\hline \multicolumn{2}{|l|}{$\underline{\mathrm{AHCD}}$} \\
\hline Writing assignments & $\geq$ \\
\hline summaries & $\geq$ \\
\hline responses & $\geq$ \\
\hline arguments & $\geq$ \\
\hline Research projects & $\checkmark$ \\
\hline Discussions & \pm \\
\hline Presentations & \pm \\
\hline Exams & \pm \\
\hline \multicolumn{2}{|l|}{$\underline{\text { Business }}$} \\
\hline Chapter quizzes & $\checkmark$ \\
\hline Chapter assignments & $\checkmark$ \\
\hline Chapter discussions & $\checkmark$ \\
\hline Group projects & $\checkmark$ \\
\hline chapter presentations & $\checkmark$ \\
\hline Midterm & $\checkmark$ \\
\hline Final exam & $\checkmark$ \\
\hline \multicolumn{2}{|l|}{ Public Safety } \\
\hline Journal entry & $\geq$ \\
\hline Research assignments & $\geq$ \\
\hline Reflections & $\geq$ \\
\hline Portfolios & \pm \\
\hline Discussions & \pm \\
\hline Group projects & \pm \\
\hline Midterm & $\checkmark$ \\
\hline Final exam & $\checkmark$ \\
\hline \multicolumn{2}{|l|}{$\underline{\text { SBSHS }}$} \\
\hline Chapter quizzes & $\checkmark$ \\
\hline Writing assignments & $\geq$ \\
\hline Research papers & $\geq$ \\
\hline Group projects & \pm \\
\hline Discussions & \pm \\
\hline Presentations & \pm \\
\hline Midterm & $\checkmark$ \\
\hline Final exam & $\checkmark$ \\
\hline \multicolumn{2}{|l|}{ STEM } \\
\hline Chapter quizzes & $\checkmark$ \\
\hline Homework assignments & $\checkmark$ \\
\hline Final exam & $\checkmark$ \\
\hline
\end{tabular}

Note. The $\checkmark$ symbol indicates the completion of the tasks in all courses.

The $\geq$ symbol indicates the completion of the tasks in most courses.

The \pm symbol indicates the completion of the tasks in some courses. 
Course documents revealed that students across disciplines were required to produce higher order thinking and problem solving in order to analyze problems and issues and engage in mental strategies. In addition, they were expected to effectively and efficiently use information from credible and reliable sources in order to properly cite sources to prevent plagiarism.

Similar circumstances occurred regarding in-class and online discussions and presentations. A few EAP instructors implemented these practices in their composition courses; however, many instructors across different disciplines frequently employed discussions and presentations that required students to develop higher-level thinking and problem solving, connect reflective activities to course objectives, and foster awareness of community needs. Finally, assessments were implemented in the advanced EAP composition course and across disciplines. However, the content of the quizzes and tests in the composition course was mainly related to rhetorical modes, grammar and punctuation, while the courses across majors required understanding and review of course-related materials. The final exam in the advanced EAP composition course was related to prompts that led EAP learners to write personal essays. The content of the assessments provided to disciplinary students was, however, related to the subject taught in that specific disciplinary course. Figure 13 displays a comparison of the writing tasks completed by EAP learners in the advanced EAP composition course and the writing tasks that they would be required to complete across disciplines. 


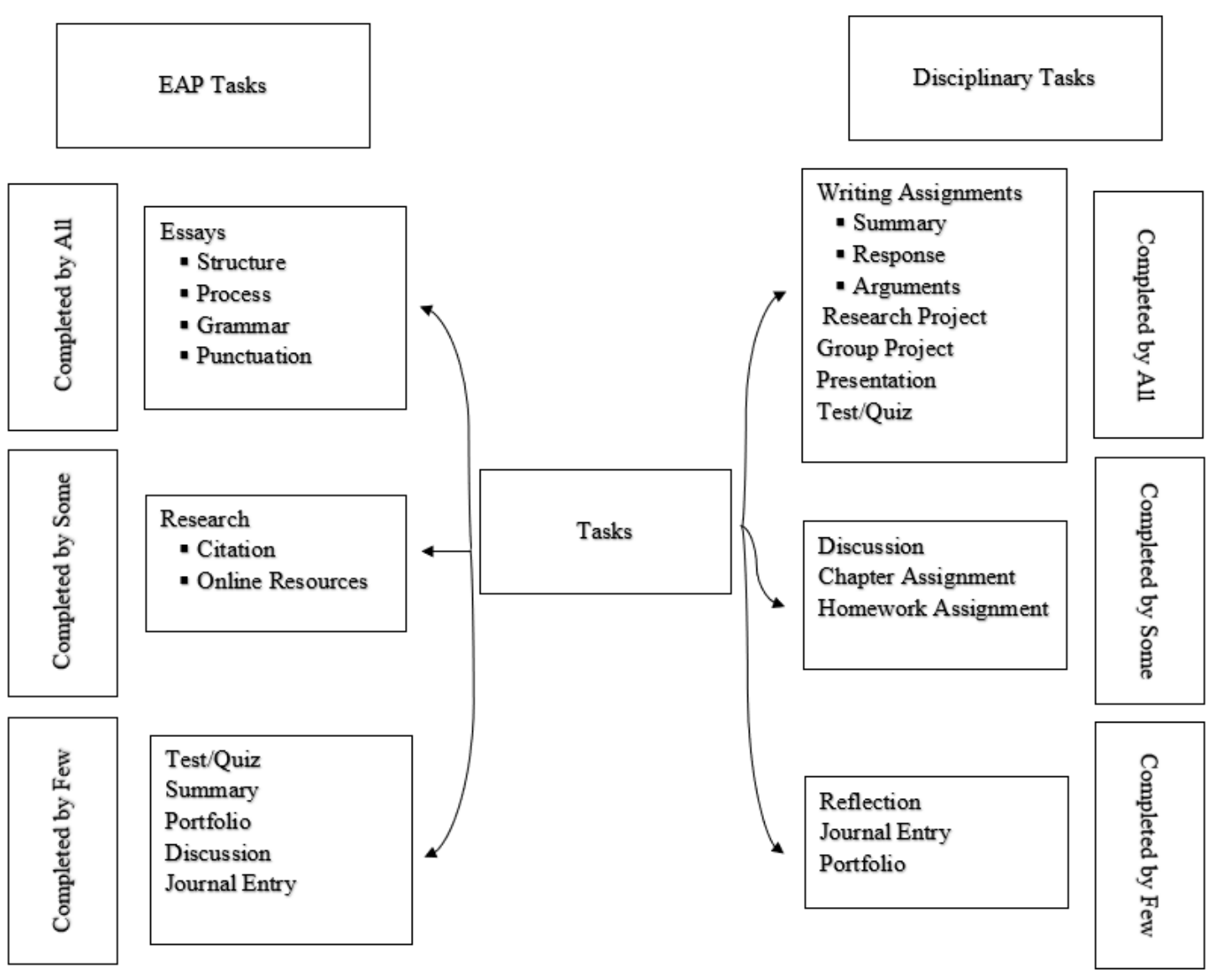

Figure 13. Comparison of the Writing Tasks

To sum up, content analysis revealed that instead of developing the advanced academic discourses expected of them across disciplines, EAP students instead continued to develop personal essays with basic elements of writing. The end result is that EAP learners produce a text rather than analyzing or attempting to reproduce a sample text (Clark, 2012), instead focusing on direct instruction and correcting grammar (Ferris \& Hedgcock, 2014; Matsuda, 2003a; Raimes, 1991). Therefore, the findings of this study are in line with the concept that EAP students produce more personal essays with fundamental elements of writing rather than complex assignments (Carroll \& Dunkelblau, 2011; Dudley-Evans \& St. John, 1998; Johns, 1997; Leki \& Carson, 1997). 
Because writing across disciplines requires extensive critical thinking and problem-solving skills, EAP instructors should prepare their EAP learners for the types of writing they are more likely to encounter once they enter a full academic program. Fox, Cheng, and Zumbo (2014) stated that EAP programs can greatly impact their EAP learners if their needs are better considered. Therefore, EAP instructors should focus more closely on the target goals of their EAP learners in order to help them master the types of tasks that they will likely be required to complete in their future courses. 


\section{CHAPTER V}

\section{CONCLUSIONS, IMPLICATIONS, LIMITATIONS, AND FURTHER}

\section{RESEARCH}

This study used triangulation of data from different sources and methods in order to identify the real-world writing tasks that diverse EAP learners are required to perform in academic contexts. Long (2005) advocates for the triangulation of data collected from different participants "to increase the credibility of their interpretations of those data" (p. 28). Moreover, Brown (2009) argued that triangulation in research increases the validity of data and the credibility of the results, thus ensuring that the end accumulation of data results in greater quality research.

To achieve the goals of this study, the conclusions are drawn by addressing each research question individually, with a focus on the framework for needs analysis suggested by Dudley-Evans and St. John (1998). Research question one (RQ1) aims to report the diverse population among EAP learners with culturally and linguistically diverse backgrounds. Research question two (RQ2) aims to identify the writing tasks that diverse EAP learners are required to complete in the advanced EAP composition course.

Research question three (RQ3) explores EAP learners' attitudes in order to better respond to EAP learners' writing needs in the advanced EAP writing course, focusing mainly on their culturally and linguistically diverse backgrounds. Finally, research question four (RQ4) examines the writing tasks performed across diverse disciplinary courses in order to make a comparison as to whether the writing tasks currently being taught in the advanced EAP composition course are aligned with those being taught across various disciplines. 


\section{Conclusions}

\section{RQ1: How diverse are EAP learners across three Southeastern campuses?}

The conceptual framework of this study is based on the concept that writing is influenced by social contexts and cultural differences. According to Grabe and Kaplan (1996), "Writing abilities are not naturally acquired; they must be culturally (rather than biologically) transmitted in every generation, whether in schools or in other assisting environments" (p. 6). Writing "is not an isolated phenomenon that can be understood out of its social context" (Gass \& Selinker, 2009, p. 280). It is connected to social practices, as well as to cultural contexts (Grabe \& Kaplan, 1996). Therefore, writing tasks should be adapted to individual needs since EAP learners may have different writing abilities and needs that may be influenced by their cultural values.

Addressing RQ1, this study concludes that EAP learners came from culturally and linguistically diverse backgrounds. Most participants across the three EAP programs were from Hispanic and Black ethnicities, especially in College B and College C. College A, however, had the most diverse group of students from ethnic origins. As expected, the majority of the languages spoken by respondents in the institutions were Spanish and

Creole. That is due to the large number of participants with origins such as Cuba, Colombia, Venezuela, and Haiti.

In addition, EAP learners were diverse in age across the three institutions. The majority of young participants were in College B, while the majority of older participants were found in College A. College $\mathrm{C}$, on the other hand, had a more diverse range of age groups. That also reflects on their employment. Due to their age range, young students in 
College B considered themselves to be "student only" or having only a part-time job, while many of the older students in College A reported that they held full-time jobs.

Results revealed that EAP learners from the three EAP programs have culturally and linguistically diverse backgrounds. Findings may serve to enhance the idea that EAP learners' writing needs could differ due to their diverse sociocultural experiences. Gee (1996) stated that writing is fully attached "to social relations, cultural models, power and politics, perspectives on experience, values and attitudes, as well as things and places in the world" (p. 7). With cultural and social support, EAP learners can become proficient in their ability to write in the target language. Drawing from the Vygotskyan perspective, learners develop higher order mental processes through the use of cultural tools and social interaction with teachers, peers, and other mediators, consequently, contributing to L2 writing development (Swain, 2005). Through social interaction, L2 learners can negotiate meaning that allows them to comprehend the written text and gain additional practice in their L2 writing (Ellis, 2008; Swain, 2001, 2005). Therefore, it is important to establish writing activities that aim not only at cognitive changes, but also at sociocultural changes (Ferris \& Hedgcook, 2014).

Results from the Present Situation Analysis (PSA) revealed that the writing tasks most required of EAP learners were essays and its aspects. In English text, the purpose of the writing is stated at the beginning and ideas are organized into body paragraphs along with main points and supporting details (Hinds, 1990). However, EAP learners with culturally and linguistically diverse backgrounds write in a non-linear sequence which can cause them to have difficulties writing in a second language, thus affecting their overall academic performance (Chou, 2011; McCarthey \& Garcia, 2005). Therefore, it is 
important to consider EAP learners' rhetoric patterns since rhetorical preferences and conventions are not acquired naturally but learned in schools (Ball, 2006). When developing a course or improving writing instruction and curriculum, EAP learners' writing needs should be considered so that their needs can also reflect their real-life experiences.

\section{RQ2: What are the real-world writing tasks currently being taught in the advanced EAP composition course?}

To respond to RQ2, this study used the three forms of methods for the purpose of identifying the real-world writing tasks currently taught in the advanced EAP composition course. PSA revealed that the writing tasks that originated from the triangulated data collection were the essay followed by its structure with varied rhetorical modes and its process, as well as feedback, grammatical conventions, punctuation, vocabulary, peer review, and research. All three forms of research methods showed that the essay, including its structure and process, was the writing task completed in all advanced EAP composition course. The main parts of the essay instruction were the essay structure, which included the introduction with the appropriate development of a hook, background information, and a thesis statement. The structure also consisted of three body paragraphs with appropriate topic sentences and relevant supporting details, as a well as a concluding paragraph. The rhetorical modes incorporated in the essays were classification, compare and contrast, cause and effect, process, definition, and argumentation. These varied rhetorical modes were mainly mentioned by EAP instructors in their interviews and by EAP learners in their learner surveys, but not by EAP learners 
in their interviews. Findings from course documents, however, revealed the completion of expository and problem/solution essays in the advanced EAP composition course.

Regarding the writing process, findings from all research methods also revealed that brainstorming and outlining were strongly mentioned by the participants. Revision was also repeatedly cited in the interviews and course documents as an important component of writing; however, responses from the learner survey revealed that revision was merely mentioned by EAP learners. Similar to revision, feedback was also perceived as an important component of writing, but this task was only referred to in the interviews and course documents.

Grammar and punctuation were central to discussion in the interviews, learner surveys, and course documents. Although these writing conventions were perceived as essential elements of writing, some EAP instructors stated in their interviews that they did not explicitly instruct on the grammatical structures in their classrooms. EAP learners, on the other hand, indicated that grammar was frequently revised in their composition courses. Course documents also revealed the comprehensive use of grammar in their classrooms. Punctuation was equally mentioned in all research instruments as a key skill used during the revision process. Therefore, explicit instruction was done so that EAP learners could better develop a piece of written work without misunderstanding the true meaning of the passage.

Findings also revealed that the implementation of some writing practices produced contradicting opinions among participants. According to EAP instructors, vocabulary was not a component that was explicitly emphasized in the composition course since their EAP programs offered reading courses that highlighted the vocabulary 
instruction. EAP learners, on the other hand, stressed the importance of implementing vocabulary instruction in the composition course since they constantly encountered difficulties implementing new academic words into their writing and expressing themselves using unknown lexicon. Results from the learner surveys and review of the course documents also revealed the absence of vocabulary practices in most of the courses.

Peer review and research also had discrepancies among participants. Findings from the interviews, learner surveys, and course documents showed that only a few EAP instructors incorporated them in their classrooms. EAP learners who had the opportunity to participate in these practices indicated that they perceived these writing tasks as important elements of writing. Quizzes and tests, as well as final exams were not mentioned in the interviews nor in the learner surveys; however, course documents revealed that they were frequently assigned to EAP learners. Quizzes and tests were based on grammar, punctuation, and rhetorical modes, while the final exam was a final essay that needed to be completed in the classroom. Other writing tasks were group work, discussions, summaries, and journals. However, these writing tasks were merely mentioned, meaning they may not be perceived as important aspects of writing.

Overall, findings from this study revealed that the writing tasks most often required of EAP learners in the advanced EAP composition course were the essay and its aspects, as well as grammar, and punctuation. The other writing tasks discussed by EAP instructors or EAP learners were revision, feedback, vocabulary, peer review, and research. However, findings indicated some discrepancies among participants regarding 
these tasks. Other writing tasks merely cited were quizzes and tests, final exam, group work, discussions, summaries, and journals.

\section{RQ3: How do both EAP learners and EAP faculty members perceive the real-world writing tasks currently taught in the advanced EAP composition course?}

Besides identifying the writing tasks that EAP learners completed in their composition courses (PSA), Learning Situation Analysis (LSA) revealed the attitudes about these writing tasks perceived from the viewpoints of EAP instructors and EAP learners. To address RQ3, responses from the interviews and learner surveys were analyzed. EAP instructors positively perceived the essay and its elements, such as the writing structure (introduction, body paragraphs, and conclusion) and the writing process (brainstorm, outline, drafts, and revision), as well as grammar and punctuation. However, they did not agree on implementing peer-review sessions and research in their classrooms even though these tasks were directly related to the writing content mentioned on the course competencies.

Although there were some negative attitudes about some tasks, only a few EAP learners responded that they were unsatisfied with completing those tasks due to their difficulty or their lack of knowledge in completing them. Positive attitudes about the writing tasks overcame the negative responses. Responses indicated that EAP learners also shared positive attitudes toward the essay, essay structure, writing process, grammatical conventions, and punctuation. Contrary to EAP instructors, EAP learners expressed positive feelings about peer review and research. Although they were difficult tasks to complete without the support of the instructor, EAP learners found it both enjoyable and motivating when participating in peer-review sessions and developing a 
research study. Responses also indicated that they positively perceived vocabulary and group work, which were not actively incorporated into their classrooms.

LSA surprisingly revealed that EAP learners also shared positive attitudes about the course in general and about learning academic writing. They felt satisfied being enrolled in the advanced EAP composition course; however, their behavior led them to complete the course for different reasons. According to the affective, cognitive, and behavioral aspects of attitude, learners who engage in learning tend to have positive feelings about the course. Consequently, their behavior leads them to complete their practices and assignments (Gau et al., 2003). It is reasonable to speculate that attitudes toward learning writing are related to learners' success since learners with positive attitudes about writing would be expected to put more effort into their writing tasks.

RQ4: What are the real-world writing tasks that EAP learners need to complete across disciplines, and are they aligned with those taught in the advanced EAP composition course?

In line with the conceptual framework that writing is influenced by social contexts and cultural differences and that needs analysis can construct effective writing programs that pay attention to diversity, this study incorporated the concept of needs analysis suggested by Dudley-Evans and St. John (1998) in order to examine whether the realworld writing tasks that EAP learners needed to complete across disciplines were aligned with those completed in the advanced EAP composition course.

PSA revealed that the writing tasks completed in the advanced EAP composition course were the essay followed by its structure with varied rhetorical modes and its process, as well as feedback, grammatical conventions, punctuation, vocabulary, peer 
review, and research. Regarding LSA, it could also be determined that EAP learners' instruction was based on two sets of teaching. Group 1 included EAP instructors who emphasized the use of the product-oriented writing instruction, in which model texts were first analyzed in order to better understand the structure and discourse of an essay. Feedback is also an important component of the product-based approach. EAP instructors in group 1 used feedback that focused on the use of correct grammar as a form of revising in order to clarify EAP learners' own errors rather than writing for a purpose. Group 2, on the other hand, focused more on the process-oriented approach, wherein the writing tasks were developed in a way to help foster a sense of purpose so that EAP learners could communicate with readers through written texts. Although essays were part of the instruction, EAP instructors in this group also incorporated practices that promoted critical thinking and engaged their EAP learners in planning, formulating, and revision, with the goal of revision being to foster a sense of direction in writing and clarify meaning for the reader.

Pertaining to the writing tasks completed across disciplines, Target Situation Analysis (TSA) revealed that chapter tests and quizzes, presentations, in-class and online discussions, final exams, and research projects were required of students in their disciplinary courses. While essays were the most commonly completed writing task in the advanced EAP composition course, course documents revealed that students only occasionally completed essay writings in their disciplinary courses. Research projects and discussions were implemented by a few EAP instructors; however, these practices were employed disproportionately higher across many disciplines. Tests and quizzes, as well as final exams were also completed by both EAP learners in their composition courses 
and students across different majors. However, tests and quizzes in the EAP course were based more so on rhetorical modes, grammar and punctuation, with final exams composed of a final essay with prompts leading to personal writing, whereas the content of the assessments from the disciplinary courses suggested that they were primarily related to the course content taught in that specific disciplinary course. Furthermore, findings showed that presentations were frequently assigned to students in different academic areas of study, but the use of presentations was not a task incorporated in the advanced EAP composition course. TSA subsequently showed that EAP learners would need to complete more complex assignments that could foster higher order thinking and problem solving so that they could effectively function in the target situation (necessities). Instead, they continued to develop personal essays with basic elements of writing rather than the advanced academic discourses expected of them across disciplines (lacks). EAP learners also stated that they positively perceived not only the writing tasks with fundamental elements of writing, but they also shared positive attitudes about vocabulary, group work, and research (wants).

Findings from this study revealed that the writing tasks required of EAP learners in their composition courses differed from those they were expected to complete across disciplines. These findings also support the concept that EAP learners continue to produce more personal essays with fundamental elements of writing rather than the complex assignments expected of them (Carroll \& Dunkelblau, 2011; Dudley-Evans \& St. John, 1998; Johns, 1997; Leki \& Carson, 1997). Figure 13 displays the conceptual framework along with the concept of needs analysis suggested by Dudley-Evans and St. John (1998). 


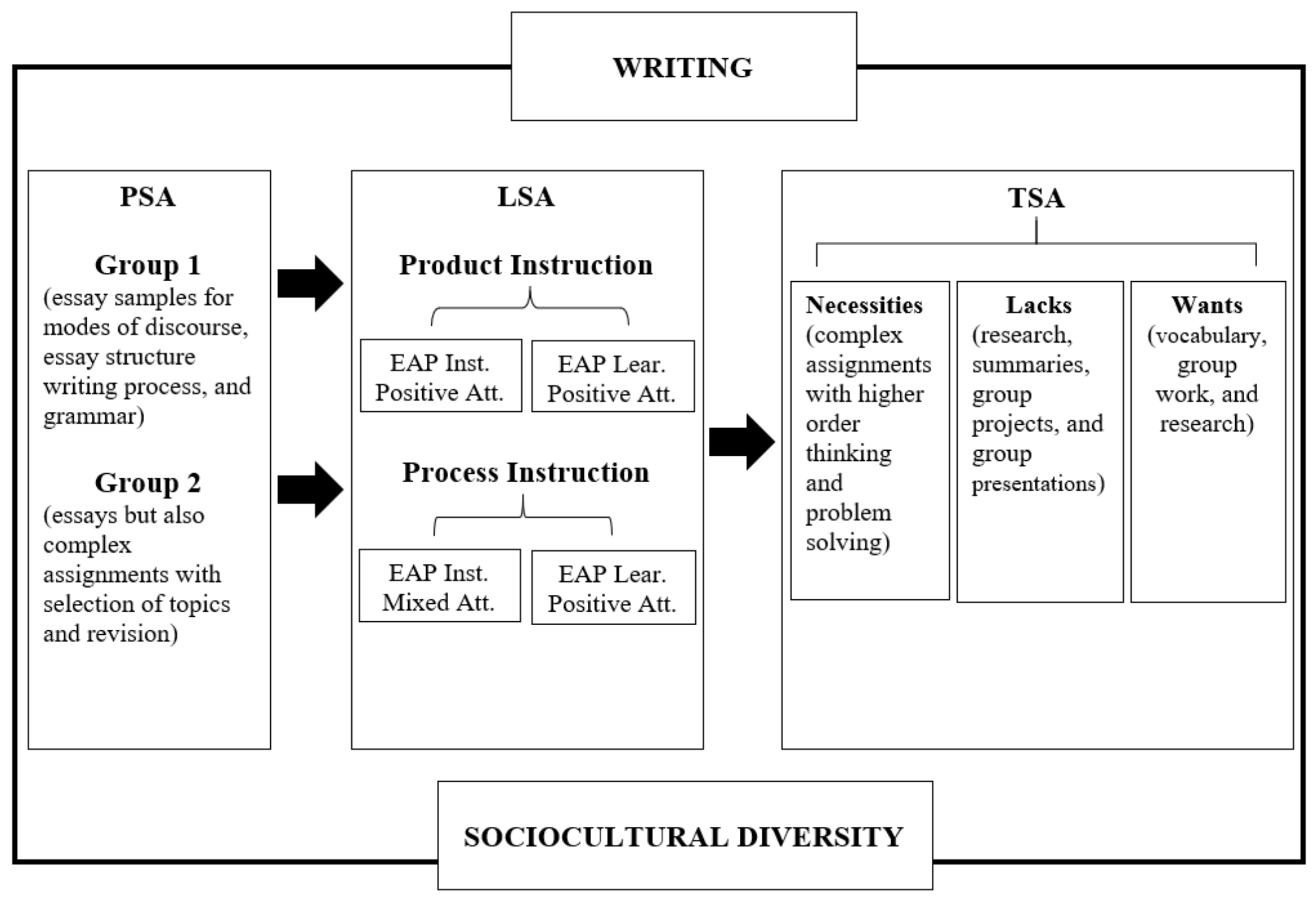

Figure 14. The Conceptual Framework Along with the Concept of Needs Analysis 
Since writing across disciplines requires extensive critical thinking and problemsolving skills, EAP instructors should better prepare their EAP learners for the types of writing assignments they will be required to complete once they leave their EAP program (Carroll \& Dunkelblau, 2011). When the writing needs of EAP learners are identified, EAP learners can improve their academic writing skills and succeed in their academic writing assignments (Long, 2005, 2015). Understanding EAP learners' writing needs can also assist in the design, implementation, and teaching of the advanced EAP composition course. Therefore, researchers and educators need to be aware of EAP learners' individual differences and need to identify specific language needs, develop writing capabilities, and create appropriate writing curriculum and syllabus. By providing insights into EAP learners' diverse backgrounds and writing needs in postsecondary education, EAP courses can be better designed so that EAP learners can be better prepared for post-secondary education.

\section{Implications of the Study}

\section{RQ1: How diverse are EAP learners across three Southeastern campuses?}

U.S. classrooms in higher education have experienced a large trend of L2 learners with culturally and linguistically diverse backgrounds. Research on diversity has shown that all students benefit from interacting with diverse L2 students by expanding the learning community and preparing these students for a multi-cultural society. Diversity also helps students understand human behavior as well as develop their ability to think, to make decisions, and to perform in diverse environments (Beyer, Gillmore, \& Fisher, 2007). In addition, diversity promotes personal growth, enriches the educational 
experience, and strengthens the learning community and workplace for economic competitiveness (Trice, 2003).

Findings from this study show that EAP programs in the three participating Southeastern state colleges hold great diversity among EAP learners. In addition, findings align with previous studies in which EAP learners with culturally and linguistically diverse backgrounds may differ in their approaches to learning and their levels of proficiency (Ball, 2006; Clark, 2012; Leki \& Carson, 1997; Matsuda, 1997, Raimes, 1998). EAP learners may also have diverse writing needs based on their cultural and linguistic backgrounds (Matsuda, 2003a; Long, 2015). Therefore, it is critical to include diversity in the study of EAP writing because diverse learners often struggle to reconcile their college experiences with their own cultural and linguistic backgrounds (Matsuda, 2003a). Moreover, it is important to consider EAP learners' rhetoric patterns since rhetorical preferences and conventions are not acquired naturally but learned in schools (Ball, 2006). It is also recommended that EAP learners' writing needs be considered when developing a course or improving writing instruction and curriculum so that their needs can reflect their real-life experiences. Recognizing their writing needs can help them better understand the content learned in the classroom, leading to their consequent success in EAP and across diverse disciplines.

RQ2: What are the real-world writing tasks currently being taught in the advanced EAP composition course?

Needs analysis was chosen as the appropriate framework to identify the writing tasks currently being taught since it can describe the content and nature of the language needs of L2 learners (Cai, 2013). Although there has been some research, only a few 
studies have been conducted on writing needs (Brown, 2009; Long, 2015; Nunan, 1999). However, these L2 writing studies have concentrated on issues related to the teaching of writing and learning strategies in general rather than on L2 learners' writing needs (Leki, 1995). Recognizing EAP learners' writing needs plays an important role in determining their target needs, which can facilitate a strong foundation for a course. Long (2015) also argued that need analysis is important due to the increased number and diversity of

\section{EAP learners.}

The findings of this study agree with the findings of studies on personality by Leki (1995) and complexity by Carroll and Dunkelblau (2011) and Keefe (2016). EAP learners complete more personal essays with fundamental elements of writing rather than complex assignments tasks (Carroll \& Dunkelblau, 2011). For EAP learners to become independent learners, they need to be assigned tasks similar to those that are expected of them in their disciplinary courses (Johns, 1997).

To improve the quality of the academic written works, EAP learners need to be able to write academic research. Studies (Cai, 2013; Keefe, 2016; Zhu, 2004) have found that research is the final project completed across disciplines. Additionally, the significance of research means that "students entering academic disciplines need a specialized literacy that consists of the ability to use discipline-specific rhetorical and linguistic conventions to serve their purposes as writers" (Berkenkotter, Huckin, \& Ackerman, 1991, p. 19). The findings from this study provide evidence that research is not a writing task commonly completed by all EAP learners in the advanced EAP composition course. It is suggested that EAP learners develop research skills in their composition courses so that they can be better prepared to complete complex projects in 
their disciplinary courses. Zhu (2004) states that EAP instructors "play a role in assisting students to acquire academic literacy through integrating authentic academic writing tasks in writing courses" (p. 31).

Language conventions are also important elements of writing. Due to common concerns about the lack of vocabulary practices as EAP learners prepare to enter disciplinary courses, the research draws attention to the importance of its instruction. Gass and Selinker (2009) argued that "The lexicon may be the most important language component for learners" (p. 449) and that limited vocabulary can affect language performance. Cai (2013) also indicates that lack of vocabulary instruction is a concern. Not being explicitly exposed to vocabulary drills can affect performance and, consequently, make their disciplinary studies more challenging (Cai, 2013).

The findings of this study revealed that vocabulary practices are not completed in the composition course under study. Therefore, EAP learners' lack of ability in vocabulary competence can pose a unique set of challenges to EAP learners with diverse backgrounds (Miller-Cochran, 2012). Vocabulary should be implemented to enhance EAP learners' repertoire of new words, which could help with the development of an accurate written text. Solutions to the lack of vocabulary instructions include the inclusion of glossaries with necessary discipline-specific vocabulary (Berman \& Cheng, 2010) and the adoption of a content-based curriculum (Baik \& Greig, 2009; Counsell, 2011, Evans \& Green, 2007; Hyland, 2002). If class time is an issue, vocabulary practices can be completed online through videos in a learning management system.

Further studies could help to understand the reasons why research and vocabulary practices are not completed by EAP instructors in composition courses and to help 
explore the perceptions of research and vocabulary from the perspectives of instructors and students. Further studies could also reveal the importance of research and vocabulary in disciplinary courses. Dooey (2010), for example, argues that research and vocabulary proficiency helps students not only improve their writing skills, but also build confidence to begin their mainstream classes.

\section{RQ3: How do both EAP learners and EAP faculty members perceive the real-world writing tasks currently taught in the advanced EAP composition course?}

EAP learners not only inject their diversity in the use of language, but they also have different attitudes that may affect their behavior in the classroom. Therefore, aspects of attitude are important factors that influence not only language learning, but also language performance, and especially writing performance. Positive attitudes about their writing ability influence the success of a writing task (Graham et al., 2007) and affect how well they perform (Clark, 2012; Nelson, 2007). Moreover, positive attitudes toward learning writing can encourage positive behavior to develop writing skills, to articulate ideas, to solve problems, to think critically, and to promote the ability to write (Gau et al., 2003; Kara, 2009).

The findings from this study are aligned with previous studies that EAP learners with positive attitudes generate high motivation and perceive value in written communication (Clark, 2012; Gau et al., 2003). Findings revealed that most EAP learners had positive attitudes overall about the writing tasks. They also indicated positive attitudes about the course and about learning how to write in academic contexts. Furthermore, the findings provide support for the aspects of attitude: affect, behavior, cognition. Regarding the cognitive component of attitude, it is pleasurable to note that in 
general, EAP learners with positive beliefs about writing expend greater effort in their written work than learners with negative beliefs. Consequently, affective and behavioral components impact their choice of writing strategy when producing a text (Graham et al., 2007). Thus, positive affect and behavior could trigger EAP learners to use more creative forms when completing their writing tasks, which could also influence their learning process (Brown, 2005; Petric, 2002).

To sum up, the findings of this study are in line with the literature that positive attitudes lead to success. One possible interpretation is that the positive attitudes that lead to success in the advanced EAP composition course continue as a result of that success in subsequent college-level content courses.

\section{RQ4: What are the real-world writing tasks that EAP learners need to complete across disciplines, and are they aligned with those taught in the advanced EAP composition course?}

Identifying the writing tasks EAP learners will need to complete in their disciplinary courses can help to better understand their writing needs and to prepare them for academic writing in their disciplines so they can succeed in post-secondary education. Some studies have reported that EAP learners have not been exposed to varied types of writing tasks during their academic endeavor (Carroll \& Dunkelblau, 2011; Grabe, 2001; Leki \& Carson, 1994, 1997). As stated by Grabe (2001), "L2 writers have less practice in the skills they need, they often are not challenged sufficiently, and they often engage in writing that is not valued in many later courses" (p. 44).

PSA revealed that the writing tasks in the EAP composition course were the essay followed by its structure with varied rhetorical modes and its process, as well as 
feedback, grammatical conventions, punctuation, vocabulary, peer review, and research. Therefore, the findings of this study are in line with the concept that EAP learners produce more personal essays with fundamental elements of writing rather than complex assignments during their time enrolled in the advanced EAP composition course (Carroll \& Dunkelblau, 2011; Leki \& Carson, 1997). Although learning how to write an essay is an important component of writing, writing across disciplines requires extensive critical thinking skills, such as analysis, reflection, and evaluation (Cai, 2013; Carroll \& Dunkelblau, 2011). TSA, on the contrary, revealed that the writing tasks that students would be required to complete in disciplinary courses were chapter tests and quizzes, presentations, in-class and online discussions, final exams, and research projects. Therefore, it is recommended that EAP learners complete more complex assignment tasks, such as summarizing, synthesizing, using quotes, and develop research skills, such as using the college library database, so that they can be better prepared for the types of writing they could encounter once they enter a full academic program (Cai, 2013; Carroll \& Dunkelblau, 2011; Leki \& Carson 1997). In addition, the findings from this study provide further support for the existing literature showing there is a difference in the type, length, and complexity of the assignments given by the instructors teaching the advanced EAP composition course and across disciplines (Carroll \& Dunkelblau, 2011; Keefe, 2016).

The findings from this study extend the research on the idea that the advanced EAP composition course may not be assisting EAP learners in their disciplinary courses because they are not exposed to different types of academic discourse (Carroll \& Dunkelblau, 2011; Grabe, 2001; Leki \& Carson 1997). EAP learners need to be able to 
learn how to supply relevant materials, learn what to include from sources, and learn how to logically support their arguments (Leki \& Carson, 1994).

When the writing needs of EAP learners are identified, EAP learners can improve their academic writing skills and succeed in their academic writing assignments while in the advanced EAP composition course and college-level content courses. It is suggested that EAP instructors help their EAP learners make connections between the EAP and disciplinary courses so they can be encouraged to make connections between the writing tasks they learn in EAP and the possible completion of these tasks in their future courses.

Furthermore, research suggests that EAP instructors should challenge their EAP learners in order to help prepare them for subsequent disciplinary studies (Leki, 1995; Dooey, 2010). EAP learners need to be exposed to more critical thinking and problemsolving tasks in order to successfully respond to different types of tasks in disciplinary courses. The progress and attainment of writing proficiency in disciplinary courses is dependent on the mastery of academic writing (Leki \& Carson, 1994). Thus, EAP learners need to be prepared to successfully respond to post-secondary writing assignments.

\section{Limitations of the Study}

The study was descriptive, so it was not designed for cause-effect conclusions. It was designed to explore the writing tasks, attitudes toward writing tasks, and their alignment with disciplinary courses. As with any descriptive study in educational institutions, there are limitations that must be acknowledged.

The first limitation was the use of the learner survey. Findings revealed that essays were the most completed task; however, more complex writing tasks were 
infrequently mentioned. A possible explanation for this response is that EAP learners did not complete complex tasks such as research term papers, or alternatively, they did not believe those tasks were relevant to be mentioned. In addition, the learner survey was completed online rather than in the EAP classrooms, which resulted in a limited response rate. Due to IRB restrictions, administering the survey online limited the ability of the researcher to get a large response rate. For this reason, a sampling issue arose, which did not allow for quantitative analysis.

Another limitation of the online survey was the use of open-ended items.

Although the open-ended questions revealed surprising responses, the researcher believed that their use further encouraged a low response rate, as well as vague responses. Participants responded to the questions using words and phrases rather than expressing themselves in explicit matters. A survey with Likert items would have overcome these issues. That type of survey probably would have revealed most of the writing tasks required of EAP learners since the items would have been clearly stated in the survey.

EAP instructor participation in encouraging online survey response was also a limitation. It was challenging to persuade EAP instructors of the importance that they encourage their EAP learners to complete the online survey. Another challenge was to motivate EAP instructors to participate in an instructor survey, which intended to gather further information on the writing tasks completed in their advanced EAP composition courses. Even though they were contacted multiple times, only one respondent completed the instructor survey. Therefore, the survey was excluded due to the low rate of respondents. Moreover, and unexpectedly, a large number of instructors from the EAP 
programs and disciplinary courses failed to respond to their emails or share their course documents.

Finally, the use of multiple research instruments to answer one research question proved to be another limitation. The researcher initially had difficulties structuring the format of the dissertation since her previous experiences focused on using one instrument to address one research question.

\section{Further Research}

The topic under study can be expanded for further study. First of all, future studies should involve more instructors as participants. Furthermore, different strategies should be explored and incorporated in regard to both approaching and engaging EAP instructors so as to increase their response rates to surveys about the writing tasks required of their EAP learners. In addition, interviews and surveys could be conducted with faculty from different departments in order to better understand the writing tasks completed across disciplines, as well as obtain their viewpoints about academic writing in their content courses. It would also be important to explore what instructors expect from their EAP learners in their disciplinary courses. Observation of disciplinary courses could also enhance the understanding of what is required of students once they leave the EAP program. Moreover, it is suggested to interview EAP learners with regards to their experiences over the course of their first term enrolled in college-level content courses in order to understand the writing tasks they are required to complete and the challenges they face in completing those tasks.

As this is a qualitatively driven study, it is also recommended that a quantitative study with a large sample of students be conducted in order to uncover other trends that 
might not have shown up in this small mixed methods study. Since few empirical studies have been conducted on writing needs and attitudes with a focus on culturally and linguistically diverse backgrounds, future research using experimental and quasiexperimental designs are needed in order to explore possible causal relationships among writing needs, attitudes, and diversity in sociocultural contexts. Furthermore, the analysis could be extended by crossing results with the demographic variables.

In addition, empirical studies are warranted to determine the casual effects of the writing needs and their attitudes on performance and achievement. Such investigations are needed because only a few research studies have linked EAP learners' writing needs and attitudes to performance (Cai, 2013; Keefe, 2016). Therefore, further research can help EAP practitioners to continue exploring EAP learners' writing needs and the support they need once they leave the EAP program.

\section{Summary}

Good communication in college with their teachers, peers, and friends is the primary goal for academic college students. As teachers, we have to take into consideration our learners' attitudes and individual needs. EAP learners need to be exposed to teaching approaches and techniques that accommodate their language needs. For EAP learners to improve writing skills, it is important that they be taught with effective teaching procedures to encourage them to participate in writing activities actively and effectively.

Due to the increase of EAP learners in U.S. higher education, it is important to continue investigating their writing needs, which play an important role in the design of EAP composition courses, and consequently, facilitates a strong foundation for the 
course. In addition, their writing needs should be addressed to better understand how to help EAP learners achieve academic writing success and improve their academic language skills.

The findings of this study are in keeping with theories and research on writing needs, attitudes, and diversity. The concept of attitudes and needs expands to sociocultural factors that represent diverse EAP learners coming from diverse backgrounds. In order to better prepare EAP learners to successfully respond to postsecondary writing assignments, researchers and educators need to be aware of EAP learners' individual differences and needs in order to identify specific language needs, develop writing capabilities, and create appropriate writing curriculum and syllabus. 


\section{REFERENCES}

Aimin, L., \& Yan, C. (2012). Development of college English teaching in China under needs analysis. Higher Education of Social Science, 2(3), 22-26.

Atkinson, D. (2003). L2 writing in the post-process era: Introduction. Journal of Second Language Writing, 12(1), 3-15.

Atkinson, D. (2004). Contrasting rhetorics/contrasting cultures: Why contrastive rhetoric needs a better conceptualization of culture. Journal of English for Academic Purposes, 3(4), 277-289.

Atkinson, D. (2010). Between theory with a big T and practice with a small p. In T. Silva \& P. K. Matsuda (Eds.), Practicing theory in second language writing (pp. 5-18). West Lafayette, IN: Parlor Press.

Atkinson, D., \& Ramanathan, V. (1995). Cultures of writing: An ethnographic comparison of L1 and L2 university writing/language programs. TESOL Quarterly, 29(3), 539-568.

Baik, C., \& Greig, J. (2009). Improving the academic outcomes of undergraduate ESL students: the case for discipline-based academic skills programs. Higher Education Research \& Development, 28(4), 401-416.

Baker, C. (1992). Attitudes and language. Clevedon: Multilingual Matters Ltd.

Ball, A. F. (2006). Multicultural strategies for education and social change: Carriers of the torch in the United States and South Africa. New York, NY: Teacher College Press.

Bandura, A. (1977). Self-efficacy: Toward a unifying theory of behavioral change. Psychological Review, 84(2), 191-215.

Bandura, A. (1986). Social foundations of thought and action: A social cognitive theory. Englewood Cliffs, NJ: Prentice-Hall. 
Bandura, A. (2000). Self-efficacy: The foundation of agency. In W. J. Perrig \& A. Grob (Eds.), Control of human behavior, mental processes, and consciousness: Essays in honor of the 60th birthday of August Flammer (pp. 17-33). Mahwah, NJ, US: Lawrence Erlbaum.

Baron, R.A., \& Byrne, D. (1984). Social psychology: Understanding human interaction. Boston: Allyn \& Bacon.

Belcher, D., \& Connor, U. (2001). Reflections on multiliterate lives. Clevedon, UK: Multilingual Matters.

Berkenkotter, C., \& Huckin, T. (1995). Genre Knowledge in disciplinary communication. Hillsdale, NJ: Lawrence Erlbaum Associates, Publishers.

Berman, R., \& Cheng, L. (2010). English academic language skills: Perceived difficulties by undergraduate and graduate students, and their academic achievement. Canadian Journal of Applied Linguistics/Revue canadienne de linguistique appliquée, 4(1), 25-40.

Bogdan, R., \& Biklen, S. K. (2007). Qualitative research for education: An introduction to theory and methods. Boston: Allyn and Bacon.

Bowen, G. A. (2009). Document analysis as a qualitative research method. Qualitative Research Journal, 9, 27-40.

Breckler, S. (1984). Empirical validation of affect, behavior, and cognition as distinct components of attitude. Journal of Personality and Social Psychology, 47(6), 1191-1205.

Brereton, J. (1995). The origins of composition studies in the American college, 1875 1925: A documentary history. London, UK: University of Pittsburgh Press.

Brindley, G. (1989). The role of needs analysis in adult ESL program design. In R. K. Johnson (Ed). The second language curriculum (pp. 63-78). Cambridge: Cambridge University Press. 
Brown, J. D. (1995). The elements of language curriculum: A systematic approach to program development. Boston, MA: Heinle \& Heinle.

Brown, J. D. (2005). Foreign and second language needs analysis. In M. H. Long, \& C. J. Doughty (Eds), The handbook of language teaching. Oxford: Blackwell Publishing.

Brown, J. D. (2009). Foreign and second language needs analysis. In M. Long \& C. Doughty (Eds.), The Handbook of language teaching (pp. 269-293). Malden, MA: Wiley-Blackwell.

Bruning, R., \& Horn, C. (2000). Developing motivation to write. Educational Psychologist, 35(1), 25-37.

Cai, G. (1999). Texts in contexts: Understanding Chinese students' English compositions. In C. R. Cooper \& L. Odell (Eds), Evaluating writing (pp. 279-297). Urbana, IL: National Council of Teachers of English.

Cai, L. J. (2013). Students' perceptions of academic writing: A needs analysis of EAP in China. Language Education in Asia, 4(1), 5-22.

Carroll, J. \& Dunkelblau, H. (2011). Preparing ESL students for "real" college writing: A glimpse of common writing tasks ESL students encounter at one community college. Teaching English in the Two Year College, 38(3), 271-281.

Charmaz, K. (2014). Constructing Grounded Theory. Thousand Oaks, CA: Sage Publications.

Chou, L. (2011). An investigation of Taiwanese doctoral students' academic writing at a U.S. University. Higher Education Studies, 1(2), 47-60.

Chuo, T. I. (2007). The effects of the WebQuest writing instruction program on EFL learners writing performance, writing apprehension and perception. TESL-EJ, 11(3), 1-27. 
Clark, I. (2012). Concepts in Composition: Theory and practice in the teaching of writing. New York, NY: Routledge.

Connor, U. (1996). Contrastive rhetoric: Cross-cultural aspects of second-language writing. Cambridge, UK: Cambridge University Press.

Corbin, J., \& Strauss, A. (2008). Basics of qualitative research: Techniques and procedures for developing grounded theory. Thousand Oaks, CA: Sage Publications.

Counsell, J. (2011). How effectively and consistently do international postgraduate students apply the writing strategies they have been taught in a generic skillsbased course to their subsequent discipline-based studies? Journal of Academic Language and Learning, 5(1), A1-A17.

Creswell, J. W. (1998). Qualitative inquiry and research design: Choosing among five traditions. Thousand Oaks, CA: Sage Publications.

Creswell, J. W. (2007). Qualitative inquiry and research design: Choosing among five approaches. Thousand Oaks, CA: Sage Publications.

Creswell, J. W. (2008). Research design: Qualitative, quantitative, and mixed methods approaches. Thousand Oaks, CA: Sage Publications.

Creswell, J. W., \& Miller, D. L. (2000). Determining validity in qualitative inquiry. Theory into Practice, 39(3), 124-130.

Creswell, J. W., \& Plano Clark, V. L. (2007). Designing and conducting mixed methods research. Thousand Oaks, CA: Sage Publications.

Creswell, J. W., \& Plano Clark, V. L. (2011). Designing and conducting mixed methods research. Thousand Oaks, CA: Sage Publications.

Cumming, A. (2001). Learning to write in a second language: Two decades of research. International Journal of English Studies, 1(2), 1-23. 
Diab, N. M. (2011). Assessing the relationship between different types of student feedback and the quality of revised writing. Assessing Writing, 16, 274-292.

Dooey, P. (2010). Students' perspectives of an EAP pathway program. Journal of English for Academic Purposes, 9(3), 184-197.

Dudley-Evans, T., \& St. John, M. J. (1998). Developments in English for specific purposes. Cambridge: Cambridge University Press.

Eagly, A. H., \& Chaiken, S. (2007). The advantages of an inclusive definition of attitude. Social Cognition, 25(5), 582-602.

Ellis, R. (2008). The study of second language acquisition. Oxford: Oxford University Press.

Etikan, I., Musa, S. A., \& Alkassim, R. S. (2016) Comparison of convenience sampling and purposive sampling. American Journal of Theoretical and Applied Statistics, $5(1), 1-4$.

Evans, S., \& Green, C. (2007). Why EAP is necessary: A survey of Hong Kong tertiary students. Journal of English for Academic Purposes, 6(1), 3-17.

Fazio, R. H., \& Olson, M. A. (2003). Attitudes: Foundations, functions, and consequences. In M.A. Hogg \& J. Cooper (Eds.), The Sage Handbook of Social Psychology (pp. 139-160). Thousand Oaks, CA: Sage Publications.

Feng, R., \& Chen, H. (2009). An analysis on the importance of motivation and strategy in postgraduates English acquisition. English Language Teaching, 2, 93-97.

Ferris, D., \& Hedgcock, J. (1998). Teaching ESL composition: Purpose, process, and practice. Mahwah, NJ: Lawrence Erlbaum.

Ferris, D., \& Hedgcock, J. S. (2014). Teaching ESL composition: Purpose, process, and practice. Mahwah: Lawrence Erlbaum. 
Flower, L., \& Hayes, J. R. (1981). A cognitive process theory of writing. College Composition and Communication, 32(4), 365-387.

Fox, J., Cheng, L., \& Zumbo, B. D. (2014). Do they make a difference? The impact of English language programs on second language students in Canadian universities. TESOL Quarterly: A Journal for Teachers of English to Speakers of Other Languages and of Standard English as a Second Dialect, 48(1), 57-85.

Friedrich, P. (2006). Assessing the needs of linguistically diverse first-year students: Bringing together and telling apart international ESL, resident ESL and monolingual basic writers. WPA Writing Program Administration: Journal of The Council Of Writing Program Administrators, 30(1-2), 15-35.

Gardner, R. (1985). Social psychology and second language learning: The role of attitudes and motivation. London: Edward Arnold.

Gardner, R. C., \& Lambert, W. E. (1972). Attitudes and Motivation in Second Language Learning. Rowley, MA: Newbury House Publishers.

Garfield, S., \& Brockman, S. (2000). Students find their voices in writing. Journal of Adolescent \& Adult Literacy, 43(5), 484-487.

Gass, S., \& Selinker, L. (2009). Second language acquisition: An introductory course. New York, NY: Routledge.

Gau, E., Hermanson, J., Logar, M., \& Smerek, C. (2003). Improving student attitudes and writing abilities through increased writing time and opportunities. East Lansing, MI: National Center for Research on Teacher Learning.

Gee, J. (1996). Social linguistics and literacies: Ideology in discourses. London: Routledge Falmer.

Giridharan, B. (2012). Identifying gaps in academic writing of ESL students. US-China Education Review, 2(6), 578-587. 
Grabe, W. (2001). Notes towards a theory of second language writing. In T. Silva \& P. K. Matsuda (Eds.), On second language writing (pp. 39-57). Mahwah, NJ: Lawrence Erlbaum.

Grabe, W., \& Kaplan, R. B. (1996). Theory and practice of writing an applied linguistic perspective. Longman, New York: Longman.

Graham, S., Berninger, V., \& Fan, W. (2007). The structural relationship between writing attitude and writing achievement in first and third grade students. Contemporary Educational Psychology, 32(3), 516-536.

Graham, S., \& Perin, D. (2007). Writing next: Effective strategies to improve writing of adolescents in middle and high schools. New York: Carnegie Corporation of New York.

Guetterman, T. C., Fetters, M. D., \& Creswell, J. W. (2015). Integrating quantitative and qualitative results in health science mixed methods research through joint displays. Annals of Family Medicine, 13(6), 554-561.

Hayes, J. R., \& Flower, L. (1980). Identifying the organization of writing processes. In L. W. Gregg, \& E. R. Steinberg (Eds.), Cognitive processes in writing: An interdisciplinary approach (pp. 3-30). Hillsdale, NJ: Lawrence Erlbaum.

Hinds, J. (1990). Inductive, deductive, quasi-inductive: Expository writing in Japanese, Korean, Chinese and Thai. In U. Connor \& A. Jones (Eds.), Coherence in writing (pp. 81-109). Alexandria, VA: TESOL.

Hinkel, E. (2002). Second language writers' text: Linguistic and rhetorical features. Mahwah: Lawrence Erlbaum.

Hinkel, E. (2011). What research on second language writing tells us and what it doesn't. In E. Hinkel (Eds.), Handbook of research in second language teaching and learning (pp 523-538). New York: Routledge. 
Hodges, T. S. (2017) Theoretically speaking: An examination of four theories and how they support writing in the classroom. The Clearing House: A Journal of Educational Strategies, 90(4), 139-146.

Hutchinson, T., and Waters, A. (1987). English for specific purposes: A learningcentered approach. Cambridge: Cambridge University Press.

Hyland, K. (2002). Specificity revisited: How far should we go now? English for Specific Purposes, 21, 385-395.

Iizuka, T. (2019). Task-based needs analysis: Identifying communicative needs for study abroad students in Japan, System 80, 134-142.

Institute of International Education (IIE). (2017). Retrieved from www.iie.org/Researchand-Publications/OPen-Doors

Ismail, N., Hussin, S., \& Darus, S. (2012). ESL students' attitude, learning problems, and needs for online writing. Gema Online Journal of Language Studies, 12(4), 1089-1107.

Iwai, T., Kondo, K., Lim, D.S.J., Ray, G., Shimizu, H., \& Brown, J.D. (1999). Japanese language needs analysis 1998-1999. Honolulu: University of Hawai`i, Second Language Teaching \& Curriculum Center. Retrieved from http://www.nflrc.hawaii.edu/NetWorks/

Johns, A. (1991). English for specific purposes: Its history and contribution. In M. CelceMurcia (Ed), Teaching English as a second or foreign language (pp. 67-77). Boston, MA: Heinle \& Heinle.

Johns, A.M. (1997). Text, role and context: Developing academic literacies. Cambridge: Cambridge University Press.

Johnson, R. B., \& Christensen, L. (2014). Research: Quantitative, qualitative, and mixed approaches. Thousand Oaks, CA: Sage Publications. 
Johnson, R. B., Onwuegbuzie, A. J., \& Turner, L. A. (2007). Toward a definition of mixed methods research. Journal of Mixed Methods Research, 1, 112-133.

Jordan, R. R. (1997). English for academic purposes: A guide and resource book for teachers. Cambridge: Cambridge University Press.

Kaplan, R. B. (1966). Cultural thought patterns in intercultural education. Language Learning, 16(1-2), 1-20.

Kara, A. (2009). The effect of a 'learning theories' unit on students' attitudes towards learning. Australian Journal of Teacher Education, 34(3), 100-113.

Keefe, K. (2016). The impact of English for Academic Purposes (EAP) programs on international students' success in university courses (Unpublished master's thesis). The University of British Columbia, Vancouver.

Kim. E. J. (2012). Providing a sounding board for second language writers. TESOL Journal, 3(1), 33-47.

Knudson, R. E. (1991). Development and use of a writing attitude survey in grades 4 to 8 . Psychological Reports, 68, 807-816.

Knudson, R. E. (1992). Development and application of a writing attitude survey for grades 1 to 3. Psychological Reports, 70, 711-720.

Knudson, R. E. (1993a). Effects of ethnicity in attitudes toward writing. Psychological Reports, 72, 39-45.

Knudson, R. E. (1993b). Development of a writing attitude survey for grades 9 to 12: Effects of gender, grade, and ethnicity. Psychological Reports, 73, 587-594.

Kotula, A. W., Tivnan, T., \& Aguilar, C. M. (2014). Students'voices: The relationship between attitudes and writing outcomes for fourth and fifth graders. Waltham, MA: Education Development Center, Inc. 
Kroll, B. (2011). Exploring the dynamics of second language writing. Cambridge, UK: Cambridge Applied Linguistics.

Lambert, C. (2010). A task-based needs analysis: Putting principles into practice. Language Teaching Research, 14(1), 99-112.

Lantolf, J. P. (2000). Sociocultural Theory and Second Language Learning. Oxford, England: Oxford University Press.

Lantolf, J., \& Thorne, S. L. (2006). Sociocultural theory and second language learning. In. B. van Patten \& J. Williams (Eds.), Theories in second language acquisition (pp. 201-224). Mahwah, NJ: Lawrence Erlbaum.

Leedy, P. D., \& Ormrod, J. E. (2005). Practical research: Planning and design. Upper Saddle River, NJ: Prentice Hall.

Leki, I. (1992). Understanding ESL writers: A guide for teachers. Portsmouth, NH: BoyntonICook, Heineman.

Leki, I. (1995). Coping strategies of ESL students in writing tasks across the curriculum. TESOL Quarterly, 29(2), 235-260.

Leki, I., \& Carson, J. (1994). Students' Perceptions of EAP Writing Instruction and Writing Needs across the Disciplines. TESOL Quarterly, 28(1), 81-101.

Leki, I., \& Carson, J. (1997). Completely different worlds: EAP and the writing experiences of ESL students in university courses. TESOL Quarterly 31(1), 39-69.

Leki, I., Cumming, A., \& Silva, T. (2008). A Synthesis of research on second language writing in English. New York, NY: Routledge.

Lingard, L., Albert, M., \& Levinson, W. (2008). Qualitative research: Grounded theory, mixed methods, and action research. British Medical Journal, 337(7667), $459-461$. 
Long, M. H. (2005). Methodological issues in learner needs analysis. In M. H. Long (Eds.), Second language needs analysis. Cambridge, England: Cambridge University Press.

Long, M. H. (2015). Second language acquisition and task-based language teaching. Oxford, UK: Wiley Blackwell.

Long, M. H. (2016). In defense of tasks and TBLT: Nonissues and real issues. Annual Review of Applied Linguistics, 36, 5-33.

Matsuda, P. K. (1997). Contrastive rhetoric in context: A dynamic model of L2 writing. Journal of Second Language Writing, 6(1), 45-60.

Matsuda, P. K. (2003a). Basic writing and second language writers: Toward an inclusive definition. Journal of Basic Writing, 22(2), 67-89.

Matsuda, P. K. (2003b). Second language writing in the twentieth century: A situated historical perspective. In B. Kroll (Eds.), Exploring the dynamics of second language writing (pp. 15-34). New York: Cambridge University Press.

Matsuda, P. K. (2003c). Process and post-process: A discursive history. Journal of Second Language Writing, 12(1), 65-83.

Matsuda, P. K. (2015). Identity in written discourse. Annual Review of Applied Linguistics, 35, 140-159.

Matsuda, P., \& Silva, T. (1999). Cross-cultural composition: Mediated integration of US and international students. Composition Studies, 27(1), 15-30.

Matsuda, P. K., Saenkhum, T., \& Accardi, S. (2013). Writing teachers' perceptions of the presence and needs of second language writers: An institutional case study. Journal of Second Language Writing, 22(1), 68-86.

Matsuda, P., \& Silva, T. (2001). On second language writing. New York, NY: Routledge. 
Matsuda, P. K., \& Tardy, C. M. (2007). Voice in academic writing: The rhetorical construction of author identity in blind manuscript review. English for Specific Purposes, 26, 235-249.

Matsumoto, K. (1995). Research paper writing strategies of professional Japanese EFL writers. TESL Canada Journal, 13(1): 17-27.

McCarthey, S. J., \& Garcia, G. E. (2005). English Language Learners' Writing Practices and Attitudes. Written Communication, 22(1), 36-75.

Merriam, S. B. A. (2002). Qualitative research in practice: Examples for discussion and analysis. San Francisco, CA: Jossey-Bass.

Miles, M. B., Huberman, A. M., \& Saldaña, J. (2014). Qualitative data analysis: A methods sourcebook. London, UK: Sage Publications.

Miller-Cochran, S. (2012). Beyond "ESL writing": Teaching cross-cultural composition at a community college. Teaching English in the Two-Year College, 40(1), 20-30.

Min, H. (2006). The effects of trained peer review on EFL students' revision types and writing quality. Journal of Second Language Writing, 15(2), 118-141.

Morse, J. M. (1994). Designing funded qualitative research. In N. K. Denizin \& Y. S. Lincoln (Eds), Handbook of qualitative research (pp. 220-235). Thousand Oaks, CA: Sage Publications.

Munby, J. (1978). Communicative syllabus design: A sociolinguistic model for defining the content of purpose-specific language programmes. London: Cambridge University Press.

Murray, D. M. (1980). Writing as process: How writing finds its own meaning. In T. R. Donovan \& B. W. McClelland (Eds.), Eight approaches to the teaching of composition (pp. 3-20). Illinois: National Council of Teachers of English. 
Myles, J. (2002). Second language writing and research: The writing process and error analysis in student texts. TESLEJ, 6(2). Retrieved from http://wwwwriting.berkeley.edu/TESL-EJ/ej22/toc.html

Nelson, N. (2007). Why write? A consideration of rhetorical purpose. In G. Rijlaarsdam (Series Ed.) and P. Boscolo \& S. Hidi (Volume Eds.), Studies in writing (pp. 1730). Oxford, England: Elsevier.

Nunan, D. (1988). Syllabus design. Oxford, UK: Oxford University Press.

Nunan, D. (1989). Designing tasks for the communicative classroom. Cambridge: Cambridge University Press.

Nunan, D. (1991). Language teaching methodology. London: Prentice-Hall.

Nunan, D. (1999). Second language teaching and learning. U.S.: Heinle \& Heinle.

Onwuegbuzie, A. J., \& Leech, N. L. (2007). Validity and qualitative research: An oxymoron? Quality \& Quantity, 41(1), 233-249.

Pajares, F. (2003). Self-efficacy beliefs, motivation, and achievement in writing: A review of the literature. Reading \& Writing Quarterly, 19, 139-158.

Pajares, F., \& Johnson, M. J. (1996). Self-efficacy beliefs in the writing of high school students: A path analysis. Psychology in the Schools, 33, 163-175.

Pajares, F., Miller, M. D., \& Johnson, M. J. (1999). Gender differences in writing selfbeliefs of elementary school students. Journal of Educational Psychology, 91(1), $50-61$.

Pajares, F., \& Valiante, G. (1997). Influence of writing self-efficacy beliefs on the writing performance of upper elementary students. Journal of Educational Research, 90, 353-360. 
Palinkas, L.A., Aarons, G. A., Horwitz, S., Chamberlain, P., Hurlburt, M., \& Landsverk, J. (2011). Mixed method designs in implementation research. Adm Policy Ment Health. 38(1), 44-53.

Palinkas, L. A., Sarah, M., Horwitz, S., Green, C. A., Wisdom, J. P., Duan, N., \& Hoagwood, K. (2015). Purposeful sampling for qualitative data collection and analysis in mixed method implementation research. Adm Policy Ment Health, 42(5), 533-544.

Park, J., \& Park, M. (2016). Qualitative versus quantitative research methods: Discovery or justification? Journal of Marketing Thought, 3(1), 1-7.

Partnership for $21^{\text {st }}$ Century Learning. (2018). Retrieved from http://www.p21.org/

Patton, M. Q. (2002). Qualitative research and evaluation methods. Thousand Oaks, CA: Sage Publications.

Patton, M. Q. (2015). Qualitative research and evaluation methods: Integrating theory and practice. Thousand Oaks, CA: Sage Publications.

Perry, K. H. (2012). What is literacy? A critical overview of sociocultural perspectives. Journal of Language and Literacy Education, 8(1), 50-71.

Petric, B. (2002). Students' attitude towards writing and the development of academic writing skills. Writing Center Journal, 22, 9-27.

Polio C., \& Williams J. (2011). Teaching and testing writing. In M. H. Long \& C. J. Doughty (Eds.), Handbook of language teaching (pp. 486-517). Malden, MA: Blackwell.

Raimes, A. (1985). What unskilled ESL students do as they write: A classroom study of composing. TESOL Quarterly, 19(2), 229-258.

Raimes, A. (1987). Language proficiency, writing ability, and composing strategies: A study of ESL college student writers. Language Learning, 37(3), 439-468. 
Raimes, A. (1991). Out of the woods: Emerging traditions in the teaching of writing. TESOL Quarterly, 25(3), 407-430.

Raimes, A. (1998). Teaching writing. Annual Review of Applied Linguistics, 18, 142-167.

Ramanathan, V., \& Kaplan, R. B. (1996). Some problematic "channels" in the teaching of critical thinking in current li composition textbooks: Implications for L2 studentwriters. Issues in Applied Linguistics, 7(2), 225-249.

Richards, J.C., \& Rodgers, T.S. (1986). Approaches and methods in language teaching. Cambridge: Cambridge University Press.

Richterich, R., \& Chancerel, J. L. (1977). Identifying the needs of adults learning a foreign language. Oxford: Pergamon Press.

Roberson, M. T., \& Sundstrom, E. (1990). Questionnaire design, return rates, and response favorableness in an employee attitude questionnaire. Journal of Applied Psychology, 75(3), 354-357.

Rosenberg, M.J., \& Hovland, C.I. (1960) Cognitive, affective and behavioral components of attitudes. In M. J. Rosenberg \& C. I. Hovland (Eds), Attitude organization and change: An analysis of consistency among attitude components. New Haven, NY: Yale University Press.

Robinson, P. (2001). Task complexity, cognitive resources, and syllabus design: A triadic framework for examining task influences on SLA. In P. Robinson (Eds.), Cognition and second language instruction (pp. 287-318). Cambridge: Cambridge University.

Rollinson, P. (2005). Using peer feedback in the ESL writing class. ELT Journal Volume, 59(1), 23-30.

Rubin, H. J., \& Rubin, I. R. (2012). Qualitative interviewing: The art of hearing data. Thousand Oaks, CA: Sage Publications. 
Sadala, M. L., \& Adorno, R. C. (2001). Phenomenology as a method to investigate the experience lived: A perspective from Husserl and Merleau Ponty's thought. Journal of Advanced Nursing, 37(3), 282-293.

Saldaña, J. (2009). The coding manual for qualitative researchers. Retrieved from http://stevescollection.weebly.com/uploads/1/3/8/6/13866629/saldana_2009_thecodingmanual-for-qualitative-researchers.pdf

Sanders-Reio, J., Alexander, P. A., Reio, T. G., \& Newman, I. (2014). Do students' beliefs about writing relate to their writing self-efficacy, apprehension, and performance? Learning and Instruction, 33, 1-11.

Schultz, K., \& Fecho, B. (2000). Society's child: Social context and writing development. Educational Psychologist, 35, 51-62.

Schunk, D. H. (2012). Learning theories, an educational perspective. Boston, MA: Pearson Education Inc.

Serafini, E. J., Lake, L. B., \& Long, M. H. (2015). Needs analysis for specialized learner populations: Essential methodological improvements. English for Specific Purposes, 40, 11-26.

Shafie, L. A., Maesin, A., Osman, N., Nayan, S., \& Mansor, M. (2010). Understanding Collaborative Academic Writing Among Beginner University Writers in Malaysia. Studies in Literature and Language, 1, 58-69.

Shen, F. (1989). The classroom and the wider culture: Identity as key to learning English composition. College Composition and Communication, 40, 456-466.

Shing, S., \& Sim, T. (2011). EAP needs analysis in higher education: Significance and future direction. English for Specific Purposes World, 33(11), 1-11.

Silva, T. (1993). Toward an understanding of the distinct nature of L2 writing: The ESL research and its implications. TESOL Quarterly, 27(4), 657-677. 
Silva, T., Leki, I., \& Carson, J. (1997). Broadening the perspective of mainstream composition studies: Some thoughts from the disciplinary margins. Written Communication, l4(3), 398-428.

Silva, T., \& Matsuda, P. K. (2001). On second language writing. Mahwah, NJ: Lawrence Erlbaum Associates.

Simeon. (2015). Scaffolding learner writing strategies in an ESL secondary class in the seychelles: A sociocultural perspective. New Zealand Studies in Applied Linguistics, 21, 21-38.

Smith, A. N. (1971). The importance of attitude in foreign language learning. Modern Language Journal, 55(2), 83-88.

Soklaridis, S. (2009). The process of conducting qualitative grounded theory research for a doctoral thesis: Experiences and reflections. The Qualitative Report, 14(4), 719-734.

Smith, Alfred.N. (1971). The importance of attitude in foreign language learning. Modern language journal, 55(2), 83-88.

Sperling, M., Appleman, D., Gilyard, K., \& Freedman, S. (2011). Voice in the context of literacy studies. Reading Research Quarterly 46(1): 70-84.

Strauss, A., \& Corbin, J. (1998). Basics of qualitative research: Techniques and procedures for developing grounded theory. Thousand Oaks, CA: Sage Publications.

Swain, M. (2001). The output hypothesis and beyond. In J. P. Lantolf (Eds.). Sociocultural theory and second language learning (pp. 97-114). Oxford: Oxford University Press.

Swain, M. (2005). The output hypothesis: Theory and research. In E. Hinkel (Eds.). Handbook of research in second language teaching and learning (pp. 471-484). Mahwah, NJ: Lawrence Erlbaum. 
The Florida College System. (2018). English for Academic Purposes. Retrieved from https://www.floridacollegesystem.com/students/programs/english_for_academic_ purposes.aspx

Trice, A. G. (2003). Faculty perceptions of graduate international students: The benefits and challenges. Journal of Studies in International Education, 7(4), 379-403

Tsui, A.B.M., \& Ng, M. (2000). Does secondary L2 writers benefit from peer comments? Journal of Second Language Writing, 9, 147-170.

Vygotsky, L. S. (1978). Mind in society: The development of higher psychological processes. Cambridge: Harvard University Press.

Vygotsky, L. S. (1986). Thought and language. Cambridge, MA: MIT Press.

Wang, Y. (2012). Differences in L1 and L2 Academic Writing. Theory and Practice in Language Studies, 2(3), 637-641.

West, R. (1994). Needs analysis in language teaching. Language Teaching, 27, 1-19.

Williams, J. D. (2003). Preparing to teach writing: Research, theory, and practice. Mahwah, NJ: Lawrence Erlbaum.

Wu, S. Y., \& Rubin, D. (2000). Evaluating the impact of collectivism and individualism on argumentative writing by Chinese and North American college students. Research in the Teaching of English, 35(2), 148-178.

Xiao, J. (2006). Web-based student-instructor interaction. Distance Education in China, 3, 33-36.

Zhang, J. (2009). Necessity of grammar teaching. International Education Studies 2(2), 184-187. 
Zhao, G. C. (2017). Voice in timed L2 argumentative essay writing. Assessing Writing $31,73-83$.

Zhu, W. (2004). Faculty views on the importance of writing, the nature of academic writing, and teaching and responding to writing in the disciplines. Journal of Second Language Writing, 13(1), 29-48. 


\section{APPENDICES}

Appendix A

\section{Interview Protocol}

\section{School:}

\section{Background Information:}

Name:

Gender:

Age:

Ethnicity:

Title:

\section{Interview Questions:}

\section{Introduction Question:}

I would like to start off by having you tell me little bit about yourself.

\section{Intermediate Questions:}

How would you describe the advanced EAP composition course as in a lesson plan/activity?

How would you describe a typical day in your composition class?

Could I ask you to describe the most important lessons/experience you learned by teaching this course?

What positive changes have occurred in your classes?

*How your views may have changed since you have started teaching?

*What didn't you learn in the advanced EAP composition course that would help you now?

What do you feel about (students') preparedness in this course? How can you help them be prepared?

*After having these experiences, what advice would you give someone who has just started teaching this particular course?

\section{Ending Questions:}

Is there anything you'd like to share that was not discussed in this interview?

How do you view your future?

Is there anything you would like to ask me? 
Follow-up Questions:

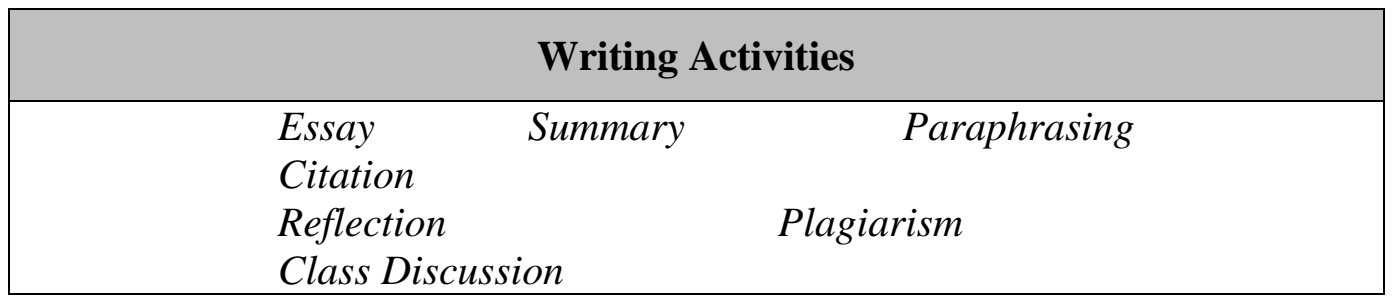

What are the activities that you use in the advanced EAP composition course?

How is the activity completed?

How long is the activity?

How often do you give this activity?

What are your expectations for this activity?

Do you provide additional assistance?

What are the benefits/challenges of learning this activity?

Could you tell me about your thoughts and feelings about $?$

How does it help you improve writing?

Do you feel confident/motivated completing the activity? Please explain.

Do you put an effort/take the time to complete the activity? Please explain.

How does that experience make you feel?

\begin{tabular}{|lll|}
\hline \multicolumn{3}{|c|}{ Writing Skills } \\
\hline Grammar & Sentence Structure & Spelling \\
Capitalization & Punctuation & Vocabulary \\
\hline
\end{tabular}

What are the skills integrated in the advanced EAP composition course?

How would you describe ?

What are the benefits/challenges of learning this skill?

Could you tell me about your thoughts and feelings about $?$

How does it help you improve writing? 
Do you feel confident/motivated completing the skill? Please explain.

Do you put an effort/take the time to complete the skill? Please explain.

How does that experience make you feel?

\begin{tabular}{|l|c|}
\hline \multicolumn{3}{|c|}{ Teaching Techniques } \\
\hline Writing Modes (narration, description, etc.) \\
Writing Process (brainstorm, first draft, revision, final draft) \\
\begin{tabular}{lcc} 
Writing Structure (introduction, body paragraphs, conclusion) \\
Instructor Feedback & Self-Editing & Peer-Editing \\
& & \\
Group Work & Reading from Samples & Individual \\
Interviews & \\
\hline
\end{tabular} \\
\hline
\end{tabular}

What are the teaching techniques that you use?

How would you describe ?

What are the benefits/challenges of using this strategy?

Could you tell me about your thoughts and feelings about ?

How does it help you improve writing?

Do you feel confident/motivated using the strategy? Please explain.

Do you put an effort/take the time to use the strategy? Please explain.

How does that experience make you feel?

\section{Probing Questions:}

You mentioned Please, tell me a little more about that?

That's interesting, could you tell me more about it?

What happened next?

You mentioned Elaborate on that a little.

Would you tell me how you define it, so I have it in your words? 
Appendix B

\section{Learner Survey}

Please, take a moment to complete the following questionnaire. Your feedback is very important and will help us to improve the quality of the course! Your answers will be kept confidential.

\section{Section I. Personal Information}

Gender: $\square$ Male $\square$ Female $\square$ Other

Date of Birth:

Age:

When did you come to US?

How many years in US:

$\begin{array}{ll}\text { Ethnicity: } & \square \text { White } \square \text { Hispanic or Latino } \square \text { Black } \\ & \square \text { Asian or Pacific Islander } \quad \square \text { Other: }\end{array}$

Country:

City/Town:

Native Language:

Other Languages:

Did you attend any English classes before coming to US? (this has to be in an educational environment, like a school or some similar institution): How long?

How many years in EAP:

Major in US:

Education: $\square$ No Schooling Completed

(In your

country)

High School, Diploma (GED)

$\square$ Some High School, No Diploma

$\square$ Associate Degree

Some College Credit, No Degree

Associate Degree

$\square$ Bachelor's Degree

Master's Degree

Doctorate Degree 


$\begin{array}{llll}\begin{array}{l}\text { Employment Status: } \\ \text { (Select all that apply) }\end{array} & \square \text { Employed } \quad \square \text { Self-employed } \quad \square \text { Not employed } \\ \text { Work } & \square \text { Student only } \quad \square \text { Retired } & \square \text { Unable to }\end{array}$

\section{Section II. Open-Ended Questions}

1. What have you learned in EAP1640? Name 3-5 specific writing activities that you have learned in class.

2. What are the steps you need to follow to complete the activities you mentioned above?

3. What would you say are the strengthens you have faced in EAP1640?

4. What would you say are the challenges you have faced in EAP1640?

5. How do you feel about the course?

6. What recommendations do you have for improving this course? 
VITA

\section{RENATA PAVANELLI PEREIRA}

B.A., English and Portuguese

Pontifícia Universidade Católica

São Paulo, Brazil

2009

M.A., Linguistics

San Diego State University

San Diego, California

2006-2009

Teaching Assistant

San Diego State University

San Diego, California

2005-present

Doctoral Candidate

Florida International University

Miami, Florida

2016-present Graduate Assistant

Florida International University

Miami, Florida

\section{PUBLICATIONS}

Análise da tradução de elementos culturais em legendagem de um episódio da série Two and a Half Men (postgraduate certificate monograph). Universidade Estácio de Sá, São Paulo, Brazil, 2013.

Authentic materials and motivation in second language instruction (master's thesis). San Diego State University Press, 2009.

Exploring the effectiveness of the flipped classroom in an EAP writing course. International Journal of Language and Linguistics, 2018.

Peer Feedback: Effects of Peer Review Training along Teacher Assistance in Freshman Composition Courses. Broward College, work in progress.

The most efficacious way to teach L2 writing: Is TBLT really more effective than PPP? Florida International University, work in progress.

Understanding L2 Learners' Writing Needs and Attitudes in EAP Writing Context (doctoral dissertation). Florida International University, work in progress. 
"Exploring the effectiveness of the flipped classroom in an EAP writing course," AFC Region V Spring Conference, Miami, FL, April 2016.

"Exploring the effectiveness of the flipped classroom in an EAP writing course," Professional Development Day, Broward College, Miami, FL, February 2017.

"The most efficacious way to teach L2 writing: is TBLT really more effective than PPP?" TESOL International Convention \& English Language Expo, Seattle, WA, March 2017.

"The most efficacious way to teach L2 writing: is TBLT really more effective than PPP?" International Conference on Task-Based Language Teaching, Barcelona, Spain, April 2017.

"Understanding L2 Learners' Attitudes and Needs in Academic Writing in EAP Contexts" Graduate Student Appreciation Week (GSAW), Miami, FL, March 2018.

"Understanding L2 Learners' Attitudes and Needs in Academic Writing in EAP Contexts" TESOL International Convention \& English Language Expo, Chicago, IL, March 2018.

"Music Delivery During Exercise" Florida Undergraduate Research Conference, Orlando, FL, February 2019.

"Understanding L2 Learners' Attitudes and Needs in Academic Writing in EAP Contexts" Sunshine State TESOL, Orlando, FL, November 2018. 